\title{
Les carences alimentaires du bétail dans leurs rapports avec la pathologie animale
}

\author{
par A. BRION \\ Professour à l'École nationale vétérinaire de Lyon \\ et J. PAGOT \\ Vétérinaire inspecteur en chef de l'Élevage de la France d'outre-mer \\ Directeur du Centre fédéral de Recherches zootechniques de Sotuba (A.O.F.)
}

\section{INTRODUCTION}

Les animaux supérieurs ont cette particularité biologique d'être très étroitement tributaires des animaux et des végétaux, sans lesquels ils ne pourraient vivre. Bien que leur organisme soit déjà un merveilleux laboratoire de synthèse, ils ont besoin de recevoir, dans leur alimentation, un grand nombre de corps ayant une individualité chimique très poussée, préfabriqués. Certains de ces corps entrent dans la constitution des tissus dont ils forment la masse principale : d'autres servent seulement au fonctionnement de l'organisme, entrent en jeu dans les réactions chimiques génératrices d'énergie; leur présence est indispensable, mais la quantité qui est nécessaire est infinitésimale. Enfin, la ration doit apporter, sous une forme quelconque cette fois, des éléments qui serviront à des synthèses, totales ou partielles.

Le milieu intérieur des organismes vivants a une certaine constance, et des rapports qualitatifs et quantitatifs précis existent entre les différents constituants des cellules et des liquides organiques. La constance de ces rapports, qui ne peuvent varier. sous peine de maladie ou de mort, que dans de très faibles limites, est assurée par un ensemble de mécanismes physiologiques faisant intervenir des organes et tissus aussi différents que le foie, les reins, le système neuro-glandulaire, le tissu réticuloendothélial, etc.

Les constances organiques seront d'autant plus facilement maintenues par les mécanismes régulateurs, dans les limites compatibles avec la vie normale, que les constituants de la ration seront plus judicieusement choisis, ne fournissant à l'organisme ni trop, ni trop peu des substances énergétiques, plastiques et catalytiques nécessaires à son activité.

Toute la science du nutritioniste est utilisée dans le but de fournir aux animaux un régime équilibré.

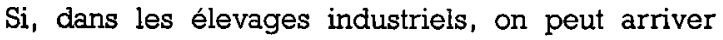
facilement à de bons résultats, chaque jour la littérature scientifique s'enrichit de descriptions de nouveaux syndromes dont les causes alimentaires sont indubitables.

Chez les animaux élevés exclusivement au pâturage, ce qui est le cas pour la majorité des élevages des zones tropicales, de nombreux syndromes ont été décrits dont l'origine alimentaire a été confirmée, et on a été amené à considérer la biocoenose formée par le sol, le végétal et l'animal; ce dernier ne pouvant subvenir à ses besoins que par l'intermédiaire végétal, ne recevra que ce que ce dernier a fabriqué grâce à la synthèse chlorophyllienne et aux minéraux qu'il a tirés du sol. Or sur ce dernier point, il faut reconnaître que physiologie végétale et physiologie animale s'écartent l'une de l'autre.

Si l'on compare les listes des éléments nécessaires aux plantes vertes et aux animaux, on note que. sans être très dissemblables, elles comportent quelques différences :

\begin{tabular}{|c|c|}
\hline \multicolumn{2}{|c|}{ ELÉMENTS RECONNUS NECESSAIRES } \\
\hline Aux plantes & Aux animaux \\
\hline $\mathrm{K}$ & $\mathrm{K}$ \\
$\mathrm{Mg}$ & $\mathrm{Mg}$ \\
$\mathrm{Ca}$ & $\mathrm{Ca}$ \\
$\mathrm{Na}$ \\
$\mathrm{N}$ & $\mathrm{N}$ \\
$\mathrm{P}$ & $\mathrm{P}$ \\
$\mathrm{S}$ & $\mathrm{S}$ \\
- & $\mathrm{Cl}$ \\
$\mathrm{Fe}$ & $\mathrm{Fe}$ \\
$\mathrm{Mn}$ & $\mathrm{Mn}$ \\
$\mathrm{Cu}$ & $\mathrm{Cu}$ \\
$\mathrm{Zn}$ & $\mathrm{Zn}$ \\
$\mathrm{B}$ & - \\
$\mathrm{Mo}$ & - \\
$\mathrm{Co}$ & $\mathrm{Co}$ \\
- & $\mathrm{I}$ \\
- & $\mathrm{Br}$ \\
- & $\mathrm{F}$ \\
&
\end{tabular}




\begin{tabular}{|c|c|}
\hline \multicolumn{2}{|c|}{ ÉLÉMENTS CONSIDERÉS COMME UTILES } \\
\hline Aux plantes & Aux animaux \\
\hline $\mathrm{Na}$ & $\mathrm{Na} \mathrm{(nécessaire)}$ \\
$\mathrm{Cl}$ & $\mathrm{Cl}$ (nécessaire) \\
$\mathrm{Mo} \mathrm{(nécessaire)}$ & Mo ? \\
$\mathrm{Si}$ & - \\
$\mathrm{Al}$ & $\mathrm{Ni} ?$ \\
$\mathrm{Ni}$ & - \\
$\mathrm{Va}$ & As ? \\
$\mathrm{Cr}$ & - \\
\hline
\end{tabular}

Un point extrêmement important, et qui est particulièrement mis en évidence par les travaux actuels de Mitchell, est celui des rapports qui existent entre la nature géologique du sol et la faculté qu'ont les végétaux d'absorber les éléments présents dans ces sols. Le manganèse des roches éruptives n'est pas absorbable par la plante; celui des roches sédimentaires' l'est; le zinc n'est absorbé que si le terrain a une réaction acide.

Maume a trouvé que les teneurs en azote total et azote protéique des graminées et des légumineuses poussant sur des sols argilo-calcaires étaient supérieures à celles des même plantes poussant sur des sols granitiques.

\begin{tabular}{|c|c|c|c|c|c|c|c|c|}
\hline \multirow{2}{*}{$\begin{array}{l}\text { PLANTES } \\
\text { au début } \\
\text { de la floraison }\end{array}$} & \multicolumn{2}{|c|}{$\begin{array}{c}\text { N TOTAL } \\
\% \text { de la matière sèche }\end{array}$} & \multicolumn{2}{|c|}{$\begin{array}{l}\text { N PROTÉIQUE, } \\
\% \text { de la matière sèche }\end{array}$} & \multicolumn{2}{|c|}{$\begin{array}{l}\text { N PROTÉIQUE } \\
\% \text { de l'azote total }\end{array}$} & \multicolumn{2}{|c|}{$\begin{array}{l}\text { MATIERES AZOTÉES } \\
\% \text { de la matière sèche }\end{array}$} \\
\hline & Moyen. & Extrême & Moyen. & Extrême & Moyen. & Extrême & Moyen. & Extrême \\
\hline \multicolumn{9}{|c|}{ 10 Sol argilo-calcaire (Azote $1,2 \%$ de terre fine) } \\
\hline Graminées ... & 1,32 & $1,24-1,50$ & 1,04 & $0,95-1,10$ & 78 & $72-87$ & 7,92 & $7,44-9$ \\
\hline Légumineuses & 2,54 & $2,08-2,80$ & 1,79 & $1,40-2,16$ & 70 & $59-77,8$ & 15,12 & $12,48-16,80$ \\
\hline \multicolumn{9}{|c|}{$2^{\circ} \mathrm{Sol}$ granitique (Azote $0,5 \%$ o de terre fine) } \\
\hline Graminees ....... & 1,02 & $0,75-1,25$ & 0,78 & $0,60-0,90$ & 76 & $72-85$ & 6,12 & $4,50-7,50$ \\
\hline Légumineuses $\ldots$ & 2,15 & $1,8-2,5$ & 1,59 & $1,35-1,90$ & 73 & $66,8-71,7$ & 12,90 & $10,8-15,0$ \\
\hline
\end{tabular}

Les variations de la composition du fourrage en fonction du stade de la végétation sont un fait connu; dans les régions tempérées, ces variations sont amorties par la répartition des pluies au cours de l'année et leur influence sur les animaux est en partie atténuée par le fait qu'en hiver, les animaux reçoivent des suppléments composés de foin, de paille et d'aliments concentrés.

Dans les zones tropicales, l'homme n'intervient pratiquement pas pour corriger les défauts des aliments que l'animal trouve en brousse; de plus,

\begin{tabular}{|c|c|c|c|c|}
\hline DÉBUT SAISON SĖCHE & $\begin{array}{c}1^{\text {re }} \\
\text { semaine }\end{array}$ & $\begin{array}{c}2^{2} \\
\text { semaine }\end{array}$ & $\begin{array}{c}3 \mathrm{e} \\
\text { semaine }\end{array}$ & $\begin{array}{c}40 \\
\text { semaine }\end{array}$ \\
\hline $\begin{array}{c}\text { Herbes (g par m²). } \\
(700 \text { à 900)... }\end{array}$ & 775 & 637 & 254 & 175 \\
$\begin{array}{c}\text { Pourcentage d'eau } \\
\text { dans ces plantes . } \\
(60 \text { à 69\%) }\end{array}$ & $40 \%$ & $40 \%$ & $10 \%$ & $0,5 \%$ \\
\hline
\end{tabular}

(D'après KACHKEROV et KOROVINE.) le cycle des plantes annuelles est très court du fait de la brièveté de la saison des pluies (mai à septembre) et de l'existence d'une saison sèche sévère (octobre à avril).

Dès la fin de la maturation, qui se produit souvent avant la fin de l'hivernage, les plantes sèchent sur pied. Ainsi au début de la saison sèche la teneur en eau passe en un mois de $40 \%$ à $0,5 \%$.

Ia maturation s'accompagne normalement d'une diminution progressive de la teneur en matières azotées brutes et digestibles; l'action néfaste de cette diminution est aggravée en zone tropicale par le fait que la température augmente la teneur en cellulose et que la structure plus fibreuse des tiges entraîne une diminution de la digestibilité.

Aussi, dans les pâturages tropicaux, la qualité des fourrages varie dans de très grandes limites: au début de la saison des pluies les fourrages: ont une composition voisine de celles des foins de printemps dans les zones tempérées; en saison sèche leur qualité est inférieure à celle des chaumes et pailles de très mauvaise qualité. 
Dans certaines zones de pâturages tropicaux, cette variation saisonnière des qualités des fourrages est atténuée par l'existence de savanes, brousse à buissons où les feuilles et les fruits des arbustes qui appartiennent en majorité aux Papilionacées, Césalpiniées, Mimosées, sont consommés par les animaux qui utilisent ainsi un pâturage aérien de bonne qualité.

En Afrique du sud, les chercheurs d'Onderstepoort ont étudié la variation saisonnière des composants chimiques de pâturages à graminées et de pâturages du type savane brousse à buissons. Ils ont trouvé que l'amplitude de variation des composants était plus grande pour les pâtırages à plantes annuelles que pour ceux de brousse à buissons. En particulier la teneur en protéines oscille au cours de l'année entre 7 et $10 \%$ pour la brousse à buissons, alors que pour les plantes annuelles la saison a une influence beaucoup plus néfaste puisqu'en hiver, saison sèche, la teneur en protéines varie entre 3 et $4 \%$ et en été entre 7 et $9 \%$, soit une variation du simple au double.

Nous avons insisté, au début de cet exposé, sur les corrélations qui existaient entre le sol, le végétal et l'animal pour préciser que les carences observées en zones tempérées seront accusées en zone tropicale par le fait que l'intervention corrective de I'homme dans cette biocoenose est pratiquement nulle. Aussi ne sera-l-il pas étonnant que des syndromes devenus historiques en zone tempérée s'extériorisent de façon spectaculaire sous les tropiques.

Il est assez difficile d'envisager le rapport qui existe entre les carences alimentaires et la pathologie. En effet, bien souvent, les carences, qu'elles soient globales (disette) ou limitées à certains corps ou éléments, ne sont pas assez importantes pour qu'il en résulte un état pathologique défini cliniquement; on assiste alors à un dérèglement de certaines fonctions et, en premier lieu, de la fonction reproductrice, à une diminution des productions zootechniques puis à un amaigrissement.

Il n'y a guère que des recherches biochimiques qui renseignent sur les carences non cliniques ou précarences. Elles sont cependant très importantes par leurs incidences économiques.

Par contre, certaines carences ont une dominante pathologique et ce sont celles que nous connaissons le mieux. Ce sont celles que nous exposerons ici, car elles appartiennent au domaine de la clinique.

\section{Nous adopterons le plan suivant :}

$1^{\circ}$ Carences en éléments chimiques indispensables à la constitution du corps et au fonctionnement de l'organisme.

a) Eléments catalytiques ou oligo-éléments ; b) Eléments à la fois plastiques et catalytiques : calcium et phosphore.

$2^{\circ}$ Carences en corps dont l'organisme ne peut faire la synthèse totale :

a) Acides aminés indispensables;

b) Vitamines.

\section{I. - CARENCES EN ÉLÉMENTS CHIMIQUES}

Ce problème a pris en ces dernières années une importance considérable, et si toute la clarté nécessaire n'est pas encore jetée sur un certain nombre de syndromes relevant d'une carence en oligoéléments, des conclusions précieuses peuvent d'ores et déjà être tirées des études qui ont été faites dans le monde entier.

Nous avons vu plus haut quels sont les éléments chimiques qui sont indispensables ou utiles aux animaux. Toutes leurs carences ne sont pas conmues dans la pratique. Certaines d'entre elles ne sont encore démontrées qu'expérimentalement. Aussi ne verrons-nous que les carences cliniques en Iode, Cuivre, Cobalt, Manganèse, Magnésium, et les carences complexes.

\section{a) ÉLÉMENTS CATALYTIQUES}

\section{L'iode}

En 1882, Coindet estime que les vertus thérapeutiques des cendres d'éponges dans le goître sont dues à l'iode qu'elles contiennent, mais son emploi immodéré devait le faire déconsidérer jusqu'à ce que Baumann mette en évidence la grande richesse de la thyroïde en iode : environ $10 \mathrm{mg}$, soit à peu près la moitié de la teneur totale du corps d'un homme adulte, la teneur du sang étant en moyenne de 15 y p. $100 \mathrm{~cm}^{3}$. L'iode est un des constituants de la thyroxine.

\section{Carence.}

La carence en iode se manifeste essentiellement, dans toutes les espèces, par une hypertrophie de la thyroïde, ou goitre, et des manifestations générales, signes du dysfonctionnement endocrinien.

L'iode intervient par l'intermédiaire de la thyroïde dans la vie sexuelle. Sa carence entraîne un ralentissement de la croissance, avec réduction de taille des organes génitaux. On observe de la bradycardie et une tendance à l'hypothermie et à l'obésité. Chez l'adulte, les troubles sont plus discrets car ils ne portent pas sur la morphogénèse; la frigidité est de règle chez les femelles, elle est causée par 
des troubles du cycle œstral qui s'accompagnent de baisse de la production laitière.

L'action sur le métabolisme général a été mise en évidence par Kelly qui a montré que, chez le porc, les sujets qui reçoivent $25 \mathrm{mg}$ d'iode pour $100 \mathrm{~g}$ d'aliments utilisent mieux l'azote, le phosphore et le calcium. De très faibles doses restent sans effet $(0,38 \mathrm{mg})$.

La thyroïde intervenant dans la transformation du carotène en vitamine $A$, une carence en iode se répercutera sur l'anabolisme de cette vitamine et pourra entraîner une carence secondaire.

Welch, en 1917, et Steenbock, en 1918, imputent l'absence de soies chez les porcelets à une carence en iode chez les truies. En effet toutes les mères de porcelets sans soies présentent, à des degrés divers, des hypertrophies thyroïdicnncs. Lo dernier auteur pense que l'iode est indispensable à l'obtention de portées normales.

In 1920, Kalkus confirme les conclusions précédentes en observant que le goître sévit dan's de nombreuses régions des Etats-Unis, qu'il est sans conséquences pour les adultes, mais qu'il entraîne des troubles très graves chez les jeunes. Des dosages devaient montrer que les eaux de source des contrées où sévissait la maladie ne contenaient que 0,014 à 1,330 partie d'iode par milliard.

En France, on a observé des symptômes analogues dans les hautes vallées des Alpes, dans le Massif Central, dans l'Orne, c'est-à-dire dans les régions où on observe des goîtres chez l'homme.

En Afrique occidentale française, les recherches d'Autret ont permis de dresser une carte du goître humain, qu'il serait peut-être intéressant de comparer avec les éventuelles observations de lésions thyroïdiennes chez les animaux.

\section{Besoins en iode.}

Les besoins exacts en iode des animaux sont difficiles à dèterminer; on se base, pour les évaluer, sur les résultats des travaux de Mitchell et Mc Clure ainsi que sur les teneurs en iode des rations des espèces vivant dans des zones où ne sévit pas le goître.

Pratiquement, on distingue les régions proches de la mer et celles qui en sont éloignées; dans les premières on n'observe jamais de goîtres, l'air renfermant, comme l'a démontré Gauthier dès 1889, suffisamment d'iode: dans les secondes, on veillera à distribuer des suppléments iodés, particulièrement aux femelles en gestation et en lactation, aux jeunes, aux animaux de travail et aux poules pondeuses.

On se souviendra également que les besoins en iode sont déterminés par les besoins en hormone thyroidienne et que tout facteur qui augmente l'utilisation de cette hormone entraînera un besoin accru en iode : excès de protéines, de calcium dans la ration, certains états infectieux, températures froides, etc.

Teneur en iode de la ration de quelques espèces vivant dans des régions où on ne constate pas de goître clinique :

\begin{tabular}{|c|c|c|c|}
\hline \multirow{2}{*}{ ESPECES } & \multirow{2}{*}{$\begin{array}{c}\text { POIDS } \\
\text { du } \\
\text { corps }\end{array}$} & \multicolumn{2}{|c|}{$\begin{array}{c}\text { IODE DANS LA RATION } \\
\text { (en } \% \text { ) }\end{array}$} \\
\hline & & par jour & $\begin{array}{c}\text { par kg } \\
\text { de poids } \\
\text { vif }\end{array}$ \\
\hline Volailles & $2 \mathrm{~kg}$ & 5 & 2,5 \\
\hline Mouton & $55 \mathrm{~kg}$ & 120 à 2.000 & 2 à 40 \\
\hline Porc au sevrage. & $25 \mathrm{~kg}$ & 40 à 80 & 1,5 à 3 \\
\hline Truie & $200 \mathrm{~kg}$ & 200 & 1 \\
\hline Vache & $550 \mathrm{~kg}$ & 3.000 à 30.000 & 6 à 60 \\
\hline
\end{tabular}

Besoins des animaux en iode d'après leur métabolisme :

\begin{tabular}{|c|c|c|c|c|}
\hline \multirow[b]{2}{*}{ ESPËCES, } & \multirow[b]{2}{*}{$\begin{array}{l}\text { POIDS } \\
\text { du } \\
\text { corps } \\
\text { en kg }\end{array}$} & \multirow{2}{*}{$\begin{array}{c}\text { PRO- } \\
\text { DUCTION } \\
\text { de } \\
\text { chaleur } \\
\text { (Cal.) }\end{array}$} & \multicolumn{2}{|c|}{ IODE (en $\gamma$ ) } \\
\hline & & & par jour & $\begin{array}{l}\text { par kg } \\
\text { de poids } \\
\text { vif et } \\
\text { par. jour }\end{array}$ \\
\hline Poulet & 2,5 & 225 & 4,5 à 9 & 1,2 \\
\hline Mouton & 55 & 2.500 & 50 à 100 & $0,5-1$ \\
\hline Porc. & 75 & 4.000 & 80 à 160 & $0,5-1$ \\
\hline Vache laitière. & 500 & 20.000 & 400 à 800 & 1 \\
\hline
\end{tabular}

\section{Le cuivre}

Le cuivre est un constituant universel et essentiel des tissus animaux. Il est régulièrement trouvé dans le cerveau, I'intestin, le cceur, le foie, le sang, le lait, les plumes et l'œuf.

Le sang du cheval en contient environ $0,5 \mathrm{mg}$ par litre. Selon Elvehjem et Hart, le taux de cuivre dans le lait de vache et de chèvre est de 0,12 à $0,20 \mathrm{mg}$ par litre. Cunningham constate l'existence d'une réserve cuprique hépatique à la naissance chez le rat, le cobaye, le lapin et signale que cette réserve n'existe pas chez le mouton et le chien: Le foie de veau contient dix fois plus de cuivre que celui du bœeuf.

Son importance hématopoiétique a été montrée par Hart, Steenbock, Waddell, Elvehjem, Mc Hargue, Healy et Hill qui, en 1938 , on prouvé que le cuivre était nécessaire aux mammifères pour la synthèse de l'hémoglobine; on pense qu'il agit en favorisant 
la multiplication des hématies et en mobilisant le fer hépatique.

Une certaine quantité de fer est nécessaire pour que le cuivre ait une action maxima, mais le rapport de ces deux éléments ne semble pas très fixe, puisque, suivant les auteurs, le rapport fercuivre optimum varie de 8 pour un à 25 pour un.

Le cuivre, outre ses propriétés hématopoiétiques, joue un rôle certain dans les oxydo-réductions. Un grand nombre d'oxydases, telles que la polyphénoloxydase, l'indophénoloxydase, sont des composés cupro-protéidiques. Kubowitz considère que l'ion $\mathrm{Cu}++$ est un constituant de leur groupe prosthétique, fixé de façon irréversible. Agner a préparé à partir du foie de cheval une catalase très pure qui contient du fer et du cuivre:

Chez les animaux adultes, les besoins alimentaires de cuivre sont, par jour, selon Lenkeit :

$\begin{array}{lll}\text { Bovins } \ldots \ldots \ldots \ldots \ldots & 50-70 \mathrm{mg} \\ \text { Equidés } \ldots \ldots \ldots \ldots \ldots & 50-60 \mathrm{mg} \\ \text { Ovins } \ldots \ldots \ldots \ldots \ldots & 10-15 \mathrm{mg} \\ \text { Porcs } \ldots \ldots \ldots \ldots \ldots & 10-20 \mathrm{mg}\end{array}$

Pour les animaux en croissance, Mitchell estime que les quantités suivantes de cuivre, par $\mathrm{kg}$ de matière sèche de la ration, sont nécessaires :

Veaux $\ldots \ldots \ldots \ldots \ldots \ldots, \quad 9 \mathrm{mg}$
Porcelets $\ldots \ldots \ldots \ldots \ldots \ldots, 8 \mathrm{mg}$
Agneaux $\ldots \ldots \ldots \ldots \ldots, 5 \mathrm{mg}$

\section{Carence.}

Sous des noms différents, les auteurs ont décrit des anémies survenant chez les animaux au pâturage : marasme enzootique ou " coast disease" en Australie, "bush sickness» ou "Morton Mains disease » en Nouvelle-Zélande, "pine», "pining», " border pine » en Ecosse, "nakuruitis» au Kenya, "salt sickness» en Floride, "neck-ail» dans le Massachussets, "Lechsucht" en Hollande et en Allemagne. Ces maladies, bien que désignées sous des vocables différents, ont des symptomatologies identiques : elles sont caractérisées par une débilité progressive s'accompagnant d'anémie et d'amaigrissement. Le début de l'affection est insidieux. Les animaux sont tristes, nonchalants, la peau est sèche, le poil long et grossier. Chez les jeunes, la croissance est retardée. A mesure que la maladie progresse, les muqueuses pâlissent, la fréquence des pulsations cardiaques, qui est normale au repos, s'accélère rapidement à l'exercice. L'appétit, qui est diminué chez les bovins, est supprimé chez les veaux. On observe du pica. La diarrhée, fréquente chez le veau, est plus rare chez les adultes. Chez la vache, la sécrétion lactée est diminuée et les saillies rarement efficaces. J.es mâles sont frigides. "

La durée de l'évolution est variable. Sous l'in- fluence de l'anémie, les animaux meurent dans le marasme 6 semaines à 2 mois après l'apparition des premiers symptômes.

L'autopsie révèle une émaciation extrême du cadavre. Le foie présente des lésions de dégénérescence graisseuse accompagnée d'hémorragies punctiformes.

L'examen hématologique montre une diminution considérable des hématies : 2.800 .000 chez les bovins contre 5,5 à 6,5 millions normalement et 3.700 .000 chez les ovins contre 14 millions normalement. L'anisocytose est constante chez le veau; de nombreuses hématies ont des dimensions inférieures à la normale. Le taux de l'hémoglobine est faible: il peut atteindre $6,5 \%$ chez le veau, $4,5 \%$ chez l'agneau, contre 11-14 normalement.

Sjollema signale que la matière sèche du sang passe de $18-20 \%$ à 13-14 \%. La teneur en cuivre du sang est de $0,09 \mathrm{mg}$ pour 100 grammes chez les malades contre $0,27 \mathrm{mg}$ chez les animaux sains.

L'affection n'est observée que chez les bovins et les ovins, le cheval n'est jamais atteint.

Chez la vache, les troubles survionnent souvent aussitôt après le vêlage. Les moutons de tous âges sont atteints, mais chez les agneaux la maladie évolue plus rapidement.

La maladie est observée en toutes saisons, avec plus de sévérité au printemps et au début de l'été, au moment où l'herbe est en pleine cruissance.

La guérison rapide, obtenue par le transport des malades dans les pâturages de régions indemnes, permet d'éliminer l'hypothèse d'une maladie infectieuse.

En étudiant le phénomène de plus près, les chercheurs ont remarqué que la maladie frappait les animaux dans les zones où une carence en cuivre était décelable chez les plantes qui présentaient des symptômes de chlorose et dont la fécondité était faible.

La nature géologique du sol intervient, les sols tourbeux et sablonneux sont plus fréquemment carencés du fait du lessivage. La preuve du rôle du sol a été apportée par les auteurs américains qui ont montré que l'épandage de sulfate de cuivre sur les pâturages avait le même résultat favorable sur la santé des animaux que la distribution de solution ou l'injection de sulfate de cuivre aux malades.

Une autre maladie où les symptômes gastrointestinaux dominent le tableau clinique a été décrite par Sjollema et par Brouwers et ses collaborateurs. Elle sévit chez les bovins et les chèvres; elle n'affecte pas nécessairement tous les animaux du troupeau, elle est caractérisée par une diarrhée dont l'intensité va croissant jusqu'à la consistance entièrement liquide; les animaux même fortement atteints n'ont pas toujours un mauvais aspect; cependant, leur 
production laitière diminue et ils s'amaigrissent lentement.

Les examens de laboratoire montrent une diminution très nette du taux de l'hémoglobine du sang.

De nombreux sujets présentent un grisonnement des poils noirs; Hundley a observé ce symptôme chez les rats carencés en cuivre et le considère comme pathognomonique. Gorter en a déduit qu'il fallait plus de cuivre pour empêcher l'achromotrichie que l'anémie.

Sarata et Yoshikama ont montré que la teneur en cuivre des cheveux augmentait avec leur pigmentation. Ce rôle doit tenir à la présence de cuivre dans la tyrosinase qui intervient dans l'oxydation de la tyrosine en dihydroxyphénylalanine puis dans la transformation de ce corps en précurseur des pigments.

Bien que les auteurs n'aient pas trouvé de grandes différences entre les teneurs en cuivre des fourrages provenant des prairies incriminées et celles des fourrages provenant des prairies saines, l'étiologie est précisée par le traitement : la distribution de cuivre à la dose de 1 à $2 \mathrm{~g}$ par jour fait disparaitre tous les symptômes décrits ci-dessus.

Enfin, une autre affection a été rattachée aux carences en cuivre: l'ataxie enzootique des agneaux ou "swayback », "swingback》, "swingleback》 qu'on observe en Grande-Bretagne (Cheviot, Derbyshire, Yorkshire, Gloucestershire, Somerset), en Australie, en Italie, en Suède, aux Indes, au Pérou. Stewart l'identifie, en 1932, en Angleterre, Bennetts, en 1937, en Australie. Dunlop en donne la description suivante :

"Dans la plupart des cas, les symptômes s'observent chez l'agneau qui. vient de naître. Certains demeurent couchés, tendent leur tête et font des efforts spasmodiques pour essayer de se lever afin de pouvoir téter. Ces vaines tentatives les font tomber sur le côté, où ils demeurent, agitant vigoureusement leurs pattes de derrière dans un mouvement de pédalage. D'autres peuvent se tenir debout mais souvent leur arrière-train vacille et les fait chuter. Quand la démarche est possible, elle est toujours incoordonnée, raide et chancelante. On peut parfois observer de la cécité. Dans certains cas les symptômes peuvent être très légers au moment de la naissance et n'apparaître avec toute leur gravité que quelques semaines plus tard. »

La mortalité est, d'après Dunlop, de $100 \%$. Si les adultes ne présentent pas de symptômes nerveux, on note que leur laine est sèche. La distribution de cuivre fait disparaître ce défaut.

A l'autopsie, on trouve des lésions de démyélinisation cérébrale avec destruction consécutive des cylindraxes, formation de cavités et dégénérescence secondaire des faisceaux moteurs. On ne constate jamais d'infiltrations périvasculaires. Il s'agit donc bien d'une dégénérescence pure et non d'un phénomène inflammatoire. La démyélinisation se produit dans les dernières semaines de la gestation, c'est-à-dire après la formation de la myéline. On constate dans certains cas des lésions dégéneratives de la substance grise et de certains nerfs périphériques : sciatique, tibial, fémoral. L'existence de lésions dégénératives du cerveau chez des agneaux n'ayant vécu que quelques minutes indique que ce processus est prénatal.

L'origine exacte de la maladie est encore discutée, un seul fait est signalé par tous les chercheurs : la distribution de cuivre aux brebis gestantes évite la maladie chez les agneaux.

On est en droit.de se demander si, dans ces affections, il ne s'agirait pas d'une carence conditionnée. On sait en effet, par exemple, que la proportion trop forte de molybdène dans une plante empêche l'assimilation du cuivre. Dans le Comté de Somerset, en Angleterre, existent des pâturages luxuriants sur lesquels les bovins surtout, et moins gravement les moutons, sont atteints d'un syndrome diarrhéique (maladie des teart-pastures) mortel pour les jeunes. L'analyse spectrographique des fourrages a révéló une sculc différenco notable entre les plantes des régions saines et celles des pâturages où sévit la maladie :' les secondes ont une teneur en molybdène de 33 pour 1 million, tandis que dans les herbes saines, elle n'est que de 5 pour 1 million. On a d'ailleurs pu reproduire la maladie en ajoutant du molybdène à la ration des animaux ou en répandant $25 \mathrm{~kg}$ de molybdate de sodium par hectare sur les pâturages. Or, ces animaux guérissent par administration de 1 ou $2 \mathrm{~g}$ de sulfate de cuivre à la ration journalière et, moyennant cette administration préventive, on peut laisser pâturer les prairies nocives.

Ayant répandu du sel de cobalt sur un pâturage, Mitchell et ses collaborateurs constatent que l'herbe s'enrichit non seulement en cobalt, mais aussi en molybdène et que les animaux contractent alors l'entérite signalée ci-dessus, qui guérit parfaitement par l'adjonction de cuivre à leur ration.

Des faits semblables montrent qu'il y a également un antagonisme entre le plomb et le cuivre et que tout excès de plomb peut entraîner une carence en cuivre, ou, tout au moins, une affection curable par les sels de cuivre.

Ceci expliquerait peut-être des faits d'apparence contradictoire, et notamment la teneur normale en cuivre de certains fourrages prélevés dans des zones où sévissent les syndromes de carence cuprique chez les végétaux. Il en est ainsi en Hollande pour le "lecksucht》, en Angleterre pour le " marasme enzootique». De même, pour l'ataxie 
enzootique, Innes et Shearer trouvent à peu près la même quantité de cuivre dans le sang des mères d'agneaux sains $(0,045 \mathrm{mg} \%)$ et des meres d'agneaux malades $(0,058 \mathrm{mg} \%)$.

La question reste donc à l'ordre du jour, en ce qui concerne l'étiologie et la pathogénie de la carence en cuivre.

Pour le vétérinaire, il demeure une conclusion valable : la curabilité par les sels de cuivre de syndromes engendrés soit par une carence des plantes et du sol en cet élément, soit par une carence d'utilisation, elle-même conditionnée par un excès de molybdène ou de plomb.

Pour terminer, nous exposerons les résultats obtenus par Teague et Carpentier dans l'étude de la carence expérimentale en cuivre chez les porcelets.

Les symptômes principaux sont la baisse du taux de l'hémoglobine, la faiblesse des membres, des déformations des rayons osseux qui rappellent celles du rachitisme.

Le plus souvent, au bout d'un certain temps, sans qu'il $y$ ait paralysie, les animaux sont incapables de se tenir debout.

L'examen radiologique précise qu'il n'y a pas de lésions assimilables au rachitisme. Le cuivre ajouté à la ration fait disparaître les symptômes.

Les accidents de la morphogénèse apparaissent quand le taux de l'hémoglobine tombe au-dessous de $6 \%$.

La teneur en cuivre du sang tombe entre $24 \mathrm{mg}$ à $34 \mathrm{mg}$ pour $100 \mathrm{~g}$ alors que chez les témoins elle est de 121 à $175 \mathrm{mg}$.

A l'examen histologique des muscles des membres, on trouve une dégénérescence des fibres musculaires et de l'œdème interstitiel abondant.

\section{Le cobalt}

Le rôle physiologique et pathologique du cobalt est étroitement lié à celui du cuivre : les carences sont, en effet, fréquemment mixtes. Toutefois, la découverte du rôle joué par le cobalt dans la constitution de la vitamine $B_{12}$ impose d'examiner séparément son action sur les organismes.

\section{Rôle du cobalt.}

La teneur des tissus animaux en cobalt est toujours faible. 11 y est généralement présent en même temps que le nickel. Bertrand et Machebœuf l'ont trouvé en 1926 dans le thymus des veaux et, associé au nickel, dans les pancréas du veau, du cheval, du mouton et du porc. On a constaté que l'addition de nickel et de cobalt améliorait l'action des préparations insuliniennes.

Le cobait est un catalyseur d'oxydation, on le trouve dans de nombreux enzymes, tels que les peptidases qui transforment les peptides en acides amines, l'arginase qui transforme l'arginine en ornithine et urée, la diamino-oxydase '(histaminase) qui, dans la muqueuse intestinale, oxyde les diamines telles que l'histamine. Par là, il intervient dans la synthèse et la destruction des éléments cellulaires et dans les phénomènes de détoxication.

Dès 1899, on avait montré que le cobalt, administré sous forme de chlorure, déterminait une augmentation de la teneur en hémoglobine du' sang (Pettini et Messina).

Les principales observations qui ont permis de préciser le rôle du cobalt dans le métabolisme sont les suivantes :

Ditroit et Zbinden décèlent le cobalt dans les tissus normaux des animaux par l'examen spectroscopique. Bertrand et Nakamura montrent que des souris recevant un supplément de nickel et de cobalt dans leur ration vivent plus longtemps que les sujets soumis à un régime carencé en cobalt.

Store et Elvehjem prouvent que l'administration d'une dose journalière de 0,02 à $0,05 \mathrm{mg}$ de cobalt était suffisante pour déterminer de la polyglobulie et que les quantités minima qui peuvent être decelées par les méthodes spectrographiques sont suffisantes pour les besoins physiologiques et pour provoquer de la polyglobulie.

$\mathrm{K}$. et K. Waltner, en 1929 , Masharpe, en 1930 , observent sur le rat et le chien, respectivement, que l'addition de fortes doses de cobalt à la ration fait augmenter le nombre et le volume des hématies, ainsi que leur teneur en hémoglobine.

Myers et coll., ajoutant 0,05 $\mathrm{mg}$ de cobalt par jour à la ration de rats soumis à un régime lacté contenant du fer et du cuivre, observent une forte polyglobulie et une augmentation du volume du sang.

Barron constate que la polyglobulie est due à une inhibition par le cobalt de la fonction respiratoire des hématies. Quand celles-ci ont perdu leur pouvoir respiratoire, elles sont remplacées par d'autres. Mais les observations les plus probantes sur le rôle du cobalt devaient être fournies par l'étude d'affections relevant de sa carence.

\section{Carence en cobalt.}

Historique. - Les premières observations écrites relatives à des maladies qui se révélèrent ultérieurement être dûes à des carences en cobalt sont celles de Robert Frazer en 1794 et celles de James Hogg en 1807. Ce dernier consacre un chapitre de son Manuel du berger au "pining» ou "daising $»$. Ces deux auteurs conseillent de déplacer les troupeaux malades vers les vallées et Frazer indique que les fermiers du Devon, anticipant en 
cela sur les travaux des auteurs modernes qui rattachèrent cette affection à une carence du sol, utilisaient comme médicament curatif des breuvages composés d'eau mélangée à de la terre des zones saines.

Ce sont surtout les chercheurs néo-zélandais et australiens qui élucidèrent l'étiologie de ces maladies.

En 1893, un premier rapport de Clifton signale l'existence de la «Tauranga disease» chez les moutons; cette maladie est caractérisée par une croissance médiocre et une faible fécondité des brebis.

En 1898, Park mentionne la «bush sickness 》 chez les bovins d'une zone recouverte de cendres volcaniques dans le centre de l'île nord de la NouvelleZélande. La maladie était caractérisée par une anémie qui devenait fatale si les animaux ne transhumaient pas dans des pâturages éloignés. Le fait était connu des fermiers qui ne laissaient pas les ruminants plus de 6 mois sur les pâturages incriminés. Park indique que «cette forme d'anémie est due à quelque déficience du sol des localités " et il conseille de distribuer du carbonate de fer pour améliorer les animaux qui ne transhument pas.

Des recherches ayant prouvé qu'aucun élément toxique n'était présent dans le sol des zones incriminées, et ces zones couvrant de très grandes surfaces en Nouvelle-Zélande, une ferme expérimentale de 400.000 hećtares fut créée en 1912 dans la région couverte de cendres volcaniques.

Les premiers essais furent faits sur des prairies améliorées par des engrais composés de superphosphates mélangés avec du sulfate de fer commercial; ce dernier produit avait été ajouté, car des analyses avaient montré que la teneur en fer des tissus des malades était très faible. Des animaux entretenus pendant 18 mois sur les pâturages améliorés ne furent pas malades. Des expériences faites, de 1912 à 1924, par Reakes et par Reakes et Aston, on peut retenir que de nombreuses préparations à base de fer furent utilisées : sulfate de fer, sirop de phosphate ferreux, citrate ferro-ammoniacal. Tous les produits étaient de la qualité commerciale, distribués en blocs à lécher; ils furent tous efficaces.

Aston pensait à une déficience du sol en fer et il conseillait aux fermiers de distribuer aux animaux malades du citrate ferro-ammoniacal. Ayant trouvé que la limonite provenant de certaines régions était efficace, cette roche facilement concassée et très bon marché remplaça le citrate ferro-ammoniacal. Or la limonite, outre le fer, renferme aussi du zinc, du nickel, du manganèse, et du cobalt.

Certains lots de limonite s'étant révélés inefficaces, les chercheurs australiens pensèrent que la maladie était due à une carence en oligo-éléments et que la limonite et toutes les préparations « commerciales » étaient actives contre la maladie grâce à la partie "impuretés » tolérée dans les produits commerciaux.

Filmer et Underwood étudiant une maladie connue dans l'ouest de l'Australie sous le nom de «maladie du Danemark» ou «marasme enzootique» analogue en apparence à la "bush sickness 》 de la NouvelleZélande montrèrent, en utilisant des extraits de limonite exempts de fer, que la carence en fer n'était pas la cause de la maladie et que l'élément était soit le nickel, soit le cobalt, soit le manganèse, soit le zinc.

Ils utilisèrent le nickel et eurent des succès mais plus tard ils trouvèrent que le nickel avait été " contaminé » par le cobalt. Les chercheurs sudafricains qui, à la même époque, étudiaient la " coast disease » utilisèrent le cobalt en premier et eurent des résultats heureux, mais plus tard trouvèrent que le cuivre était également utile pour obtenir une guérison complète de la «coast disease $\%$.

Les travaux des deux équipes ont été résumés par Russell : une dose journalière de 0,3 à $1,0 \mathrm{mg}$ de cobalt chez les vaches et de $0,1 \mathrm{mg}$ chez les moutons est suffisante pour maintenir les animaux en bonne santé:

Les recherches faites en Grande-Bretagne, par Russel Greig, Dryerre, Mc Gowan et Smith, Corner, suivirent les mêmes cheminements et en 1938 le role prépondérant du cobalt dans les anémies géographiquement localisées était admis.

\section{Symptomatologie.}

Les premiers symptômes commencent à se manifester, insidieusement, après 3 à 4 mois de séjour dans les régions incriminées. Les sujets sont tristes. Le poil des bovins, la laine des moutons perdent leur lustre; les muqueuses, la conjonctive en particulier, deviennent pâles, les yeux sont larmoyants. Chez les jeunes, la croissance se ralentit puis s'arrête. L'anorexie est précoce et constante. La production laitière des vaches diminue. Les animaux maigrissent, présentent parfois une démarche hésitante; ils deviennent cachectiques et meurent.

L'évolution de la maladie est variable, elle peut durer de quelques semaines, à 1 ou même 2 ans.

Souvent les animaux sont infestés de parasites à tel point qu'au début des recherches on avait pensé à une anémie parasitaire.

A l'autopsie on ne trouve aucune lésion spécifique.

Seuls les ruminants sont sensibles à la carence en cobalt; le cheval, le porc, les volailles semblent ne pas en être incommodés. On a cependant montré récemment que du cobalt distribué quotidiennement 
à la dose de $2-3 \mathrm{mg}$ à des porcelets accélérait leur croissance.

\section{Mécanisme d'action du cobalt.}

Russell, résumant les recherches faites par les différentes équipes de chercheurs, écrit :

«Bien qu'il ait été établi indubitablement que le cobalt soit nécessaire aux ruminants, le rôle qu'i! joue dans la nutrition n'est pas encore connu; en effet, pourquoi les chevaux peuvent-ils vivre normalement en bonne santé avec peu ou, peut-être même, pas du tout de cobalt ?»

On a d'abord supposé que le cobalt jouait un rôle analogue à celui que l'on avait observé chez le rat où la distribution de fortes doses de cet élément entraîne de la polycythémie et où les animaux malades ont une apparence anémique.

Dans ces maladies, le diagnostic d'anémie est basé sur la pâleur des muqueuses; mais des recherches ont montré qu'il n'y avait pas toujours d'anémie dans la "bush sickness»; que dans la "Morton Mains disease " la sévérité de l'affection n'était pas fonction du degré d'anémie; que, dans la « coast disease 》l'anémie mesurée par le taux d'hémoglobine et le nombre d'hématies n'était marquée que lorsque l'animal était sur le point de succomber; qu'enfin dans la "salt sickness 》 de Floride certains malades avaient une quantité normale d'hémoglobine.

De plus, un symptôme constant a été trouvé, mais qui est moins facilement appréciable que la pâleur des muqueuses : une diminution marquée du volume sanguin. Il est probable que les variations du volume du plasma font que la détermination du taux de l'hémoglobine est une mauvaise mesure de l'inaptitude des animaux à la synthétiser. On en a une preuve par la chute rapide du taux d'hémoglobine qui suit l'administration de cobalt à des animaux carencés; le taux normal ne revient que lentement et graduellement. Il semble que le système hématopoiétique ne peut suivre le même rythme que celui de l'augmentation du volume du plasma consécutive au retour de l'appétit.

Compte tenu des remarques précédentes, quel est le mécanisme intime de l'action du cobalt? Des rats nourris avec des rations riches en cobalt présentent de la polycythémie et Josland a trouvé chez les moutons carencés qu'un sur six de ceux qui reçoivent du cobalt présente une augmentation du nombre des hématies et du taux de l'hémoglobine.

Becker et Smith ont montré que le cobalt augmentait la digestibilité de l'extractif non azoté de la ration de moutons carencés. Ils affirmèrent que la flore qui, dans le rumen, attaque la cellulose n'était pas modifiée par la carence en cobalt, mais que la quantité de nourriture ingérée était très faible. Des preuves de la corrélation existant entre la carence en cobalt et la diminution de l'appétit et de la consommation d'aliments ont été données par Das et Stewart.

La découverte de l'existence du cobalt dans la molécule de la vitamine $B_{12}$ devait bientôt orienter les recherches sur de nouvelles bases. Fn effet, la vitamine $B_{12}$ est un médicament héroïque d'une très grave affection humaine, l'anémie pernicieuse de Biermer, et un syndrome anémique semble tout de même exister chez les moutons et bovins carencés en cobalt. Comme les autres vitamines du groupe B, la vitamine $B_{12}$ est un produit de synthèse bactérienne qui se forme dans les réservoirs digestifs des polygastriques. La déficience en cobalt de la ration ôte aux bactéries un aliment primordial de la synthèse, d'où une carence en vitamine $B_{12}$.

Ces considérations devaient amener à des tentatives de traitement des syndromes cobaltiprives par cette vitamine.

Hale et coll. montrèrent en 1950 que l'injection parentérale de vitamine $B_{12}$ ne guérissait pas la carence en cobalt non plus que la distribution journalière de cette vitamine per os pendant quatre semaines. Dans cette observation il semble que les doses données per os étaient trop faibles car Marston et coll. ont obtenu des résultats favorables en distribuant un complexe vitaminique B pendant sept semaines. Ils en déduisirent que le cobalt chez les ruminants intervenait dans la synthèse de plusieurs corps du groupe vitaminique B. Smith, Kock et Turk montrèrent ultérieurement que la vitamine $B_{12}$; donnée à la dose minimum de $150 \gamma_{\text {}}$ était efficace contre la carence en cobalt (augmentation de l'appétit, du poids, du nombre des globules rouges). Selon Sedwick et coll., la vitamine $B_{12}$ serait efficace par la voie parentérale et non par voie buccale.

Marston attira l'attention sur le fait que le cobalt était indispensable à certains micro-organismes qui pouvaient peut-être en opérer la concentration et que de ce fait il devait être un facteur sélectif de croissance bactérienne déterminant la nature et l'activité de la flore du rumen.

Ford, Kon et Porter, étudiant l'activité vitaminique du contenu du rumen et des fèces de veaux, ont montré que certains composés contenaient du cobalt et que ces composés avaient une activité différente de celle de la vitamine $B_{12}$. Ils suggèrent que le cobalt agit de deux façons : d'abord dans la synthèse des composés différents de la vitamine $B_{12}$ qui seraient essentiels pour le maintien de la flore gastrique mais pas pour l'animal, ensuite dans la synthèse de la vitamine $B_{1:}$ elle-même qui est peut-être nécessaire dans le rumen et qui est indispensable à l'animal. 
En utilisant du cobalt radioactif, Tosic et Mitchell ont montré que le cobalt injecté par voie intraveineuse était éliminé dans les urines et que, donné per os, il était retrouvé en majeure partie dans les fèces. Une très faible partie apparaît dans le sang, la salive, le lait.

Utilisant de la vitamine $B_{12}$ marquée par du cobalt 60, Rosemblum, Chow, Condon et Yamamoto ont confirmé ces résultats.

Tosic et coll., comme Ford et coll., supposent que la très faible quantité de cobalt présente dans les aliments doit être suffisante pour l'hôte et la flore du rumen.

Les rcchorchos' récentes montront que le rôle joué par le cobalt dans la nutrition des ruminants est en majeure partie dû à la vitamine $B_{12}$ synthétisée par les micro-organismes de la panse. Marston et Lee ont observé que l'injection parentérale de $100 \gamma$ de vitamine $B_{12}$ trois fois par semaine produisait une amélioration immédiate. chez des moutons nourris depuis un an sur des pâturages déficients en cobalt et présentant des symptômes nets de carence : des résultats identiques ont été oljtenus avec des animaux soumis à des régimes synthétiques carencés.

En résumé, les symptômes observés dans les carences en cobalt seraient ceux d'une carence conditionnée en vitamine $B_{12}$.

Cependant, certains faits expérimentaux semblent prouver qu'en outre, le cobalt doit intervenir plus directement dans le métabolisme.

Quand on eut précisé l'origine tellurique des carences on a été amené à considérer quelles étaient les teneurs minima en cobalt du sol qui pouvaient être considérées comme dangereuses.

En général, des sols contenant moins de 2 millionièmes de cobalt sont considérés comme dangereux. Certains chercheurs ont trouvé que, sur dés sols contenant 3 à 4 millionièmes, les moutons sont atteints de carence.

Se référant au cobalt soluble dans l'acide acétique à $2,5 \%$, Stewart et Paterson indiquent qu'en GrandeBretagne, tout sol contenant moins de 2,5 millionièmes de cobalt est dangereux.

Pour les plantes, on considère qu'une teneur en cobalt inférieure à 5 pour 100 millions est insuffisante; au delà de 8 pour 100 millions les animaux ne sont pas incommodés. L'épandage de $2 \mathrm{~kg}$ de chlorure de cobalt à l'hectare suffit à amener le taux de l'herbe à un niveau convenable.

Quelques dosages ont été faits sur des terres d'A.O.F.

D'après les résultats il semble que certains terrains de l'A.O.F. sont déficients en cobalt, ce qui n'est pas surprenant étant donné la structure sablonneuse de nombreux sols de pâturages et le lessi- vage auquel ils sont soumis pendant la saison des pluies.

Dès 1950, l'un de nous avait associé certains symptômes observés chez les moutons de la région de Nioro à une carence probable en cobalt.

\section{POLYCARENCES}

Nous avons étudié jusqu'à présent les cas où un seul oligo-élément était absent dans le régime; il peut se faire que le régime soit carencé en plusieurs éléments. Deux syndromes ont été décrits qui sont imputables' à des polycarences : l'anémie des porcelets à la mamelle et l'anémie des poussins.

\section{Anémie des porcelets a la mamelle.}

On observe cette anémie sur les porcelets âgés de 3 à 6 semairies, nés el entretenus à l'abri du soleil dans des porcheries à sol cimenté et ne recevant comme alimentation que le lait maternel, La maladie sevit plus fréquemment pendant la saison froide et sur les portées dont les mères sont nourries avec des sous-produits industriels.

Cette affection fut signalée pour la premiere fois en 1923 par Mc Goway et Grighton, en Angleterre.

Les porcelets nés à terme et normaux montrent, vers l'âge de 3 semaines, de l'indolence, de l'apathie, de la faiblesse, des signes d'entérite plus ou moins marqués, un amaigrissement rapide, un aspect misérable. La peau devient pâle, les soies sont abondantes, ternes et bourrues, les formes épaissies, l'aspect général est lourd. L'appétit est très diminué, La respiration est accélérée, le pouls est petit et filant. Le nombre des hématies tombe de 7.500 .000 à 3.000 .000 et le taux d'hémoglobine descend quelquefois à $3 \%$.

L'amélioration spontanée n'est pas exceptionnelle. Elle survient vers l'âge de 5 à 6 semaines, quand on commence à distribuer des grains aux porcelets. Mais le plus souvent, la mort survient en quelques. jours. Doyle a constaté que le taux de la mortalité chez les sujets anémiques entre la $I^{\mathrm{re}}$ et la $8^{\mathrm{e}}$ semaine était au moins 20 fois plus élevé que chez les sujets normaux.

A l'autopsie on trouve les lésions caractéristiques d'une anémie intense : dilatation générale du coeur, dégénérescence du myocarde, infiltration cedémateuse de différents organes, transsudat pleural, péricardique et péritonéal, dégénérescence hépatique.

La maladie est observée sur des portées provenant de truies entretenues normalement au pâturage, puis rentrées quelques semaines avant l'accouchement dans des loges cimentées où elles sont nourries de sous-produits industriels, de farine de poisson, 
de farine de maïs. Elle est plus fréquente dans les portées de février et de mars.

Si les porcelets ont dans les boxes de la verdure et de la terre à leur disposition, le taux d'hémoglobine est beaucoup plus élevé que chez les sujets qui en sont privés : $10,8 \%$ à 4 semaines au lieu de $5,1 \%$ chez les témoins (Doyle). L'ingestion de seigle vert ou de luzerne par les mères et les jeunes n'amène aucune amélioration. Il semble donc que c'est la terre elle-même qui joue un rôle thérapeutique. Par la suite, Moe, Craft, Thompson (1935) ont constaté que l'addition à l'alimentation de sulfate de fer et de sulfate de cuivre produisait une élévation plus considérable du taux de l'hémoglobine que la terre ou l'oxyde de fer seuls. De plus, le cuivre favorise l'augmentation du poids. Hamilton pense que les heureux résultats obtenus avec l'oxyde de fer sont dus aux traces de cuivre présentes dans les préparations employées.

Les auteurs sont d'accord pour considérer l'anémie des porcelets à la mamelle comme une manifestation d'une polycarence en fer, cuivre et peut-être cobalt.

Cette anémie serait l'exagération, provoquee par une hygiène alimentaire défectueuse, de l'anémie physiologique qui, chez le porcelet, s'observe du $1^{\text {er }}$ au $10^{\text {e }}$ jour de la vie.

D'après Radeff le taux de l'hémoglobine chez les porcelets normaux passe de $11,1 \%$ à la naissance à $7,98 \% 10$ jours après, puis se relève pour atteindre $9,23 \%$ le $15 \mathrm{e}$ jour et redevenir normal vers le 20 a d $11 \%$.

Andersen a noté que chez les porcelets élevés dès les premiers jours au pâturage le taux de l'hémoglobine se relevait plus rapidement que ne l'indique Radeff.

Ainsi, dans les conditions naturelles, l'apport de sels minéraux compense les déficiences du lait maternel, diminue l'intensité de l'anémie physiologique, et évite l'apparition des signes de maladie. L'administration de fer et de cuivre à la truie est sans effet, ces éléments ne passant pas dans le lait.

Le fer donné à la dose de $5 \mathrm{mg}$ et le cuivre à la dose de $\mathrm{l} \mathrm{mg}$ par kilo de poids vif et par jour evitent l'appanition de la maladie; et si, au début du traitement, les animaux n'étaient pas au stade ultime, la guérison est de règle.

Le taux de l'hémoglobine redevient normal en 3 semaines.

\section{Anémies carentielles des volailles.}

Elvehjem et Hart ont déterminé une anémie expérimentale des poussins en les élevant sur des grillages et en leur distribuant comme nourriture du lait, un extrait alcoolique de riz et du phosphate de chaux. Le fer ne guérit cette anémie que s'il est donné en même temps que le riz. L'adjonction de traces de cuivre est nécessaire à l'action thérapeutique du fer si la ration ne contient pas de riz.

Chez les poussins élevés dans des conditions artificielles, on a observé une anémie qui est quérie par l'administration de foie, de fer ou de laitue hachée.

Une anémie intéressant les embryons de poulets se traduit par une forte mortalité en coquille pendant les premiers jours de l'incubation. Elle serait en relation avec une déficience complexe en fer, cuivre, cobalt.

\section{Le manganèse}

\section{Rôle du manganèse chez les animaux.}

La présence du manganèse dans le sang des animaux a été mise en évidence par G. Bertrand et Medigreceanu en 1913.

Le sang en contient $0,02 \mathrm{mg}$ par litre, le rein $1,57 \mathrm{mg}$, le foie $3,7 \mathrm{mg}$ et le cœur $4 \mathrm{mg}$ en moyenne par kilo de tissu frais.

Les organes génitaux sont pauvres en manganèse. Le lait de vache en contient très peu.

Le colostrum est cinq fois plus riche en manganèse que le lait.

Le manganèse, soluble dans le suc gastrique, serait absorbé au niveau de l'intestin; l'excédent de métal scrait éliminé par la bile : l'ingestion de manganèse entraîne une augmentation de la teneur de la bile en ce métal.

Gruzewska et Roussel étudiant la teneur des foies des embryons et fotus de veaux trouvent les valeurs suivantes :

Embryon de 4 mois :

$3,7 \mathrm{mg}$ pour $100 \mathrm{~g}$ d'organe frais;

Embryon de 5 mois :

$2,6 \mathrm{mg}$ pour $100 \mathrm{~g}$ d'organe frais;

Embryon de 6 mois :

$7,4 \mathrm{mg}$ pour $100 \mathrm{~g}$ d'organe frais;

Embryon de 7 mois :

$6,4 \mathrm{mg}$ pour $100 \mathrm{~g}$ d'organe frais;

Embryon de 8 mois :

$6,8 \mathrm{mg}$ pour $100 \mathrm{~g}$ d'organe frais.

Naissance $8,3 \mathrm{mg}$. Puis le taux décroît rapidement après la naissance.

On voit que ces teneurs sont considérables par rapport à celles des organes adultes. On peut expliquer ce fait par la place tenue par le manganèse dans un très grand nombre d'enzymes dont l'activité est intense au cours du développement embryonnaire.

\section{On trouve du manganèse :}

- Dans les enzymes qui assurent la synthèse et la destruction des éléments cellulaires; 
- Dans les peptidases que l'on trouve dans le sérum sanguin et la plupart des organes qui transforment les peptides en acides aminés;

- Dans l'arginase du foie et du muscle, qui dégrade l'arginine en ornithine et urée:

- Dans les enzymes d'oxydo-réduction qui interviennent en accélérant les processus énergétiques :

Les cytochromes et les peroxydases, où le manganèse est associé au fer;

Les transphosphatases qui contrôlent la réaction suivante :

acide 1,3 diphosphoglycérique + A.D.P. $\leftrightarrow$ A.T.P. + acide 3 - phosphoglycérique:

L'énolase qui transforme l'acide 2 - phosphoglycérique en acide phosphopyruvique:

La déshydrogénase de l'acide pyruvique.

Enfin le manganèse intervient dans les réactions de détoxication du type de celle de la cholinestérase qui par hydrolyse transforme l'acétylcholine en choline et acide acétique.

La présence du manganèse dans tous ces enzymes nous laisse entrevoir les désordre graves qu'entraînera sa carence.

\section{Carences en manganèse.}

Les carences en manganèse ont été étudiées expérimentalement sur les rats et sur les oiseaux.

Les expériences faites de 1924 à 1928 avec des rats et des souris en vue de démontrer le rôle du manganèse dans l'économie donnent des résultats suggestifs mais non concluarts. En 1932, Orent et Mc Collum montrent qu'un régime purifié privé de manganèse détermine une dégénérescence testiculaire chez les rats mâles et une diminution notable de la lactation chez les rates mais ne trouble pas le cycle cestral.

Kemmerer, en 1931, soumettant des souris femelles à un régime lacté additionné de fer et de cuivre, montre que l'addition de traces de manganèse à ce régime favorise la croissance et régularise l'ovulation. Kell précise que des rats soumis au régime lacté ferro-cuprique ne se reproduisent pas à la seconde génération si on n'ajoute pas de manganèse à leur alimentation. Daniels et Everson ont montré que la' mortalité des rats issus de mères carencées était causée par des lésions se développant chez le fœetus. Les cendres des sujets qui composent ces portées ont une teneur en manganèse de $65 \%$ inférieure à la normale.

En résumé, chez les animaux de laboratoire, la carence en manganèse entraîne surtout des troubles génitaux chez les adultes et des troubles de la croissance des jeunes.

Les observations faites sur les animaux domestiques portent sur les bovins et les volailles.

\section{Troubles de la reproduction.}

Bentley et Phillips pensent que, dans certaines régions des Etats-Unis, $10 \%$ des cas de stérilité sont dus à une carence en manganèse. Ils estiment que des rations contenant moins de 10 millionièmes de manganèse n'entravent pas la croissance des génisses mais retardent l'apparition des premières chaleurs; les différences avec les témoins sont significatives. La teneur des ovaires en manganèse est très faible : 0,85 y par gramme de matière sèche au lieu de $2 \cdot \gamma$ chez les sujets non carencés.

Les fourrages provenant des zones incriminées contenant moins de 10 millionièmes de mangasène. les auteurs conseillent de distribuer du manganèse chaque fois que les fourrages en contiennent moins de 20 millionièmes.

Les troubles de la reproduction que l'on observe sont les suivants :

Chez la femelle, un retard de la puberté, une altération du rythme ou de la forme du cycle cestral, des avortements par troubles trophiques du foetus, enfin une diminution de la sécrétion lactée.

Cher les mâles, un retard de la puberté, une diminution de l'appétit sexuel et une diminution notable de la spermatogénèse.

Orent et Mc Collum avaient pensé que le manganèse pouvait intervenir dans l'élaboration des hormones anté-hypophysaires et que les troubles observés dans le comportement sexuel des animaux provenaient directement de la carence en cet élément. Puis Barker et Sir Gowland Hopkins considérèrent le manganèse commo un biocatalyseur favorable à, l'élaboration de certaines sécréfions internes.

Les recherches des physiologistes de l'Université de Calcutta mirent en évidence le rôle du manganèse dans la synthèse de la vitamine $C$, dont la carence est, selon Phillips, génératrice de stérilité.

Le foie vivant de rat plongé dans un liquide physiologique additionné de mannose synthétise de l'acide ascorbique.

Or, la transformation de la molécule de sucre en acide ascorbique est une déshydrogénation qui est activée par une déshydrogénase dans laquelle le manganèse joue le rôle de co-enzyme. L'action de la diastase permettant cette transformation ne se produit qu'à partir du moment où les ions manganèse sont introduits dans le milieu.

Les troubles génitaux observés seraient donc dus à une modification du métabolisme de la vitamine $C$.

Chez les oiseaux, la carence en manganèse retentit sur la production des œufs, leur fécondation, et le taux des éclosions (Noriss et Gallup, Chubb). Ceci est démontré par les observations suivantes effectuees sur trois groupes de poules.

Dans le premier groupe, la ration est très pauvre 
en manganèse; dans le second, la ration est composée du mélange du groupe I auquel on a djouté du manganèse en quantité suffisante pour obtenir une teneur égale à la moitié de celle du mélange standard health trust breeder dont est compose le régime du groupe 3.

\begin{tabular}{|c|c|c|c|}
\hline $\begin{array}{c}\text { NOMERE TOTAL } \\
\text { d'cufs récoltés }\end{array}$ & GROUPE 1 & GROUPE 2 & GROUPE 3 \\
\cline { 1 - 2 } Infertiles ........... & 30,5 & 28,8 & 29,2 \\
Morts en coquille... & 20 & 8,3 & 7,2 \\
Eclosions .......... & 49,5 & 75,0 & 79,1 \\
Eclosions parmi les & & & \\
cufs fertiles ...... & 71,2 & 90,0 & 91,7 \\
\hline
\end{tabular}

Mortalité exprimee en pourcentage des ceufs féconds :

\begin{tabular}{|c|c:c|c|}
\hline GROUPES & \multicolumn{3}{|c|}{ MORTALITE } \\
\hline Groupe $1 \ldots \ldots \ldots$ & 2,6 & 3,9 & 22,2 \\
Groupe $2 \ldots \ldots \ldots$ & 1,3 & 0,4 & 5,8 \\
Groupe $3 \ldots \ldots \ldots$ & 1,6 & 0,0 & 6,5 \\
\hline
\end{tabular}

\section{Pérose des oiseaux.}

A côté des troubles génitaux, la carence en manganèse entraîne des troubles de l'ossification qui, chez les oiseaux, déterminent une maladie bien caractérisée : la pérose, connue aussi sous les noms de «perosis», «slipped tendon», «leg-weakness », « hock disease ».

Cette maladie s'observe chez les jeunes oiseaux éclos en incubateur et élevés artificiellement et en captivité. Elle est beaucoup plus rare chez les animaux jouissant d'une certaine liberté dans des parquets.

Wilgus, Norris et Heuser signalent les premiers que la pérose est due à une carence en manganèse.

Les signes cliniques evoluent en trois phases, bien décrites par Lesbouynes.

Dans la première, on observe une légère boiterie en meme temps que le jarret prend une teirte bleuatre facile à constater quand les tarses ne sont pas pigmentés. L'articulation se tuméfie ensuite, cependant que les poulets restent accroupis.

Au cours de la deuxième phase, il y a déviation des tarses. Les os longs des membres se raccourcissent, le tibia, le métatarse s'incurvent en dehors amenant les jarrets à se toucher tandis que les extrênités sont rejetées vers l'extérieur; les muscles sont atones et les deplacements impossibles.
Dans la troisième période, le tendon du muscle gastrocnémien glisse hors des condyles, tantôt vers l'extérieur, tantôt vers l'intérieur. Cette luxation se produit sur une ou sur les deux pattes.

La mort survient en quelques jours ou en 2 à 3 semaines à la suite d'inanition ou de complications infectieuses, elle peut frapper 50 a $70 \%$ des malades.

A l'autopsie on note de l'anémie, une atrophie des muscles, de la thyroide, des parathyroïdes et de la rate.

Les lésions osseuses sont pathognomoniques, elles consistent en un raccourcissement avec épaissement el courbure des os longs des pattes. L'examen histologique révèle un arrêt de l'ossification enchondrale du cartilage épiphysaire.

Chez les sujets carencés, la teneur des os en manganèse est très faible : $4 \mathrm{mg}$ au lieu de $7,5 \mathrm{mg}$ chez les individus normaux.

Dans lo foie, los tencurs rospectives sont de 0,17 et $1,46 \mathrm{mg} / \mathrm{g}$.

\section{Etiologie et pathogénie.}

Serfontein et Payne ont montré la possibilité de la transmission héréditaire de la pérose, ce qui explique l'origine d'un certain nombre de déformations observées chez les poussins âgés de 2 à 4 semaines. Ces dernières conclusions sont confirmées par les recherches de Lyons et Insko qui. montrent que les embryons des œufs de poules soumises à un régime pérosigène meurent en coquille ou donnent fréquemment des poussins à bec de perroquet ou à pattes raccourcies. Caskey et Norris (1938) ont constaté également que les poules soumises à un régime pauvre en manganèse produisent des poussins qui, à la naissance, présentent des troubles spasmodiques, de la rétraction de la tête, des temblements et une extrême nervosité.

Henderson, prenant le terme rachitisme au sens large, estime que, dans la pérose comme dans le rachitisme vrai, il y a déséquilibre entre les substances minérales et organiques de la ration. Les achondroplasiques sont des sujets alourdis par une alimentation trop riche en protides.

Les travaux de Gallup et Norris ont précisé les corrélations existant entre la teneur en manganèse de la ration et l'apparition des cas de pérose (Voir tableau page suivante).

Les races lourdes sont atteintes plus sévèrement que les autres.

Jukes, en 1940, a montré que le manganèse n'était pas l'unique agent préventif de' la pérose, il doit être associé à d'autres corps tels que la choline et la biotine pour avoir une action maxima.

On a remarqué également que l'excès de sels de calcium dans la ration favorise l'apparition de la pérose. Les sels de chaux solubilisés dans la partie 
antérieure de l'intestin ont tendance à se reprécipiter dans la partie distale, entraînant avec eux le manganèse et déterminent ainsi une carence conditionnée.

\begin{tabular}{|c|c|c|c|}
\hline \multirow{3}{*}{$\begin{array}{c}\text { TENEUR } \\
\text { en manganèse } \\
\text { (millionièmes) }\end{array}$} & \multicolumn{3}{|c|}{ CAS DE PÉROSE POUR 100 POULETS } \\
\hline & \multirow{2}{*}{ Leghorn } & \multicolumn{2}{|c|}{ New-Hampshire } \\
\hline & & Souche B & Souche C \\
\hline $10 \ldots \ldots$ & 46 & 70 & 87 \\
\hline 20 & 21 & 60 & 一 \\
\hline $30 \ldots \ldots \ldots$ & 0 & 16 & 35 \\
\hline 40 & - & 6 & - \\
\hline 50 . & 0 & 7 & 18 \\
\hline $100 \ldots \ldots \ldots \ldots$ & - & 4 & - \\
\hline
\end{tabular}

C'est à ce phénomène qu'on attribue la diminution du taux du manganèse diffusible dans l'intestin des poussins ayant consommé de grandes quantités de poudre d'os.

\section{Traitement et prophylaxie de la pérose.}

La diminution de la quantité de matière protéique dans la ration entraîne une amélioration de l'état des malades.

La distribution de son de riz, de foie de porc, de luzerne, de-germes ou tiges vertes de blé ou d'avoine riches en manganèse ont un effet préventif et quelquefois curatif.

La réduction du taux du phosphore a une action favorable, de même que la mise au grand air en parcours ouvert.

On admet qu'une ration contenant 5 milligrammes de manganèse par kilo d'aliment est équilibrée pour ce métal.

\section{Troubles osseux chez les mammifères.}

Orent et Mc Collum ont suggéré, nous l'avons vu, une action possible du manganèse dans la fonction hypophysaire.

Wachtel, Elvehjem, Hart ont établi que si le manganèse jouait un rôle dans ce domaine, c'était soit dans la production des hormones, soit dans l'utilisation des hormones après leur élaboration par la glande. Ils injectèrent à des rats carencés des extraits aqueux de pituitaire de moutons. La croissance de ces animaux qui était irrégulière ou même arrêtée reprend un rythme normal après le traitement, ce qui prouve que le manganèse était indispensable à l'élaboration de l'homone somatotrope hypophysaire.

Chez le veau, la carence en manganèse entraine une incurvation des membres antérieurs.
Chez le porc, Miller et ses coll. ont décrit des accidents osseux dus à des carences expérimentales en manganèse.

Sandstedt et Carlquist, dans un cas de rachitisme du porc par carence en manganèse, ont trouvé que la principale manifestation clinique était la présence de bosselures au niveau du contour postéro-externe du jarret.

Le traitement consiste, chez cet animal, à donner des doses journalières de $0,5 \mathrm{mg}$ de manganèse.

En résumé, le manganèse intervient dans les phénomènes de la croissance et de la reproduction soit directement comme co-enzyme, soit peut-être par l'intermédiaire de la vitamine $\mathrm{C}$.

Dans les carences observées, son rôle est primordial, mais l'influence des autres composants de la ration peut être déterminante dans l'apparition des phénomènes morbides.

\section{Magnésium}

Le magnésium est incontestablement un élément nécessaire aux animaux, comme. le montrent les expériences de Lœb, d'Osborne et Mendel, de J. Leroy, de Lavollay, etc. Les rats carencés présentent des phénomènes congestifs, de l'hyperexcitabilité, puis des crises convulsives, généralement mortelles.

Mais la carence en magnésium est extrêmement difficile à étudier en raison des nombreuses et étroites interférences entre cet élément et les autres métaux alcalins ou alcalino-terreux, ainsi que le. phosphore.

On sait que, après P. Delbet, de nombreux auteurs ont consacré des travaux aux relations qui existent entre le cancer et le déficit magnésien des rations: alimentaires. Quels que soient les résultats apportés par les partisans et les détracteurs de la théorie, aucune conclusion ne s'impose encore à l'heure actuelle.

On ne peut pas plus retenir comme démonstratives les multiples affirmations (par exemple celles de P.-J. Favier dans, son livre : Equilibre minéral et santé) selon lesquelles la plupart des maladies des animaux sont guéries soit par des amendements magnésiens des terres, soit par l'ingestion de magnésie ou de chlorure de magnésium, si bien que l'on ne sait plus si ces traitements sont purement pharmacodynamiques où s'ils ivisent à corriger une carence : depuis la fièvre aphteuse, les brucelloses, la rage même, jusqu'aux "affections indéterminées », toute la pathologie animale serait justiciable du magnésium.

Les seuls travaux sérieux en la matière sont ceux qui ont été faits dans les tétanies et nous les étudierons à propos des carences phospho-calciques. 


\section{B) ÉLÉMENTS PLASTIQUES ET CATALYTIQUES}

\section{Phosphore et calcium}

\section{Généralités.}

Le phosphore et le calcium sont présents en quantités appréciables dans l'organisme animal et il ne fait aucun doute que les besoins en ces éléments sont considérables.

On ne peut séparer les études sur le calcium de celles qui ont trait au phosphore, tant sont étroites les relations qui existent entre les métabolismes de ces deux éléments.

Leur rôle dans l'économie est de deux ordres :

Catalytique par les fonctions multiples remplies au cours du métabolisme et de l'activité organique.

Plastique par la place statique qu'ils tiennent dans la composition du squelette et de nombre de constituants cellulaires.

\section{Rôle catalytique du phosphore.}

Harden et Young, étudiant la fermentation du glucose par la levure, trouvèrent que le jus de macération additionné de glucose fermentait immédiatement mais que la vitesse de dégagement de $\mathrm{CO}$. s'atténuait rapidement; l'addition au mélange d'un phosphate minéral faisait reprendre à la réaction son rythme initial. lls déterminèrent que le phosphore intervenait dans la réaction, sous forme d'un hexose-diphosphate (ester de Harden et Young). Robinson identifia ultérieurement un ester monophosphorique ayant les mêmes propriétés.

Les composés organiques phosphorés doivent leur activité au groupement $-\mathrm{PO}_{3} \mathrm{H}_{2}$ qui sert de transporteur d'énergie.

Les principaux composés phosphorés qui interviennent dans le métabolisme sont les suivants :

\section{$1^{\circ}$ L'acide adénosine-triphosphorique (A.T.P.).}

Par perte d'une liaison phosphorique, il donne de l'acide adénosine-diphosphorique (A.D.P.) qui, luimême, perdant une liaison phosphorique, donne l'acide adénylique; ce dernier, terme ultime de la dégradation, ne comporte qu'une seule liaison, est pauvre en énergie et ne peut rien céder.

\section{$2^{\circ}$ Les acylphosphates.}

T.e type en est l'acide 1-3 diphosphorique, terme intermédiaire de la contraction musculaire.

$3^{\circ}$ Les amidines phosphates, auxquelles appartiennent la phosphocréatine et la phosphoguanidine qui entrent dans la composition des acides nucléiques.

\section{Les énolphosphates.}

Tels que l'acide phospho-énol-pyruvique qui entre dans les réactions chimiques de la contraction musculaire.

Le phosphore intervient dans le métabolisme suivant un cycle comportant une série de réactions exothermiques et endothermiques.

$1^{\circ} \mathrm{L}^{\prime}$ incorporation du phosphate minéral dans une molécule organique se fait à la faveur d'une oxydation; le composé possede alors une forte énergie potentielle.

$2^{\circ}$ Le composé subit une transphosphorylation grâce à l'A.T.P.

$3^{\circ}$ Il y a formation d'esters phosphoriques avec perte d'une liaison phosphore.

$4^{\circ}$ Une hydrolyse des esters phosphoriques formés par les phosphatases libère le phosphate minéral qui peut être utilisé dans un nouveau cycle.

Meyerhoff et Lundegaard ont montré qu'en l'absence d'énergie de la glycolyse ou de la respiration, la scission de la phosphocréatine ou phosphagène fournissait l'énergie nécessaire au travail musculaire. La respiration et la glycolyse interviennent ultérjeurement dans la resynthèse de la phosphocréatine.

Le phosphore entre dans la composition des nucléoprotéides des noyaux cellulaires et joue ainsi un rôle essentiel dans la cinétique de la division cellulaire.

Il entre également dans la composition des lipides phosphorés qui règlent la perméabilité cellulaire, dans celle des glucides phosphorés qui constituent une des sources de l'énergie musculaire, enfin dans les esters phosphorés.

Il stimule l'activité de certaines hormones, voire de certaines vitamines.

\section{Rôle catalytique du calcium.}

Le calcium intervient comme élément catalytique dans nombre de processus biologiques essentiels tels que :

- le métabolisme de l'eau où il est l'antagoniste du sodium:

- la coagulation du sang;

- la précipitation de la caséine par le lab-ferment;

- l'activation du trypsinogène et de l'amylase:

- la régulation de l'excitabilité neuro-musculaire; ce dernier rôle sera étudié en détail dans l'étiologie des névroses animales.

\section{Rôle plastique du phosphore et du calcium.}

Pour donner une idée du rôle plastique du phosphore et du calcium, il suffit de rappeler que, chez les bovins, le taux du calcium est, dans le corps entier, de $1,35 \%$ et que celui du phosphore est de $0,74 \%$.

La majeure partie de ces deux éléments se trouve dans le squelette sous forme de phosphate et de 
carbonate de calcium. Dans les cendres d'os, on trouve $36 \%$ de calciurn et $17,6 \%$ de phosphore.

Le jeune se nourrissant du lait de sa mère reçoit par cet intermédiaire de grandes quantités de calcium et de phosphore.

Le lait contient en effet $0,12 \%$ de calcium et $0,1 \%$ de phosphore.

Dans le sang, le phosphore et le calcium sont répartis entre les hématies, les leucocytes et le plasma.

Les éléments figurés sont pauvres en calcium, le dosage de la calcémie se fait sur le sérum, elle est exprimée en milligrammes pour $100 \mathrm{~cm}_{\mathrm{a}}$ de sérum. Chez les bovidés, elle varie entre 10 et 12 .

Dans le sang, le calcium existe sous deux formes: une forme non diffusible (proteinate de calcium, calcium colloïdal), évaluée à $50 \mathrm{mg}$ par litre, et une partie diffusible dans laquelle on trouve du calcium non ionisé et du calcium ionisé. Ce dernier varie de 40 à $45 \mathrm{mg}$ par litre, il est la forme biologiquement active.

Le phosphore existe dans l'organisme principalement sous forme de sels (phosphates) et d'esters phosphoriques qui contiennent du phosphore à l'état complètement oxydé.

On doit distinguer du point de vue de l'activité biologique le phosphore minéral (ions phosphoriques, phosphates) du phosphore organique constitué dans sa presque totalité d'esters phosphoriques:

Parmi les sels minéraux, le phosphate de chaux joue un rôle statique en assurant la rigidité du squelette et un rôle dynamique en servant de réserve facilement mobilisable. Les phosphates solubles alcalins et alcalino-terreux jouent le rôle de tampons dans le maintien du $\mathrm{pH}$ organique.

Dans le sang, les éléments figurés sont riches en phosphore, en particulier les globules blancs qui contiennent une forte proportion de nuclésprotéides dans leurs noyaux.

Le sérum contient surtout du phosphate minéral (pyro et orthophosphates). La phosphatémie est appréciée par le dosage du phosphore minéral; elle s'exprime en mg pour $100 \mathrm{~cm}_{3}$ de sérum. Elle est plus variable que la calcémie, elle varie de 3 à $8 \mathrm{mg}$ chez les ruminants, de 2,5 à $4 \mathrm{mg}$ chez le cheval.

La phosphatémie et la calcémie varient au cours de la vie, en fonction de l'âge, de la production, de la gestation, de la lactation, etc.

Pour couvrir les besoins en phosphore et calcium, il faut que l'alimentation apporte chaque jour des quantités considérables de ces éléments, en particulier chez les jeunes, qui édifient leur squelette, et chez les femelles en gestation et lactation, qui ont à faire face à de gros besoins.
Le tableau suivant donne les chiffres très généralement admis pour les besoins journaliers.

\section{Bovidés.}

Besoins moyens pour des : animaux atteignant $700 \mathrm{~kg}$ à l'âge adulte, en grammes par jour (compte non tenu de la gestation).

10 Calcium :

\begin{tabular}{|c|c|c|}
\hline AGE & RACES LAITIËRES & RACES A VIANDE \\
\hline 2 mois $\ldots \ldots$ & 30 & 37 \\
4 mois $\ldots \ldots$ & 40 & 43 \\
6 mois $\ldots \ldots$ & 43 & 44 \\
8 mois $\ldots \ldots \ldots$ & 43 & 43 \\
10 mois $\ldots \ldots$ & 41 & 41 \\
12 mois $\ldots \ldots$ & 39 & 40 \\
16 mois $\ldots \ldots$ & 36 & 37 \\
\hline
\end{tabular}

$2^{\circ}$ Phosphore :

\begin{tabular}{|c|c|c|}
\hline AGE & RACES LAITLERES & RACES A VIANDE \\
\hline 2 mois & 18 & 24 \\
\hline 4 mois & 25 & 29 \\
\hline 6 mois & 31 & 33 \\
\hline 8 mois. & 33 & 33,5 \\
\hline 10 mois. & 33 & 33,5 \\
\hline 12 mois & 34 & 34 \\
\hline 16 mois & 32 & 33 \\
\hline
\end{tabular}

Ensuite, on compte environ, par $100 \mathrm{~kg}$ de poids vif, $5 \mathrm{~g}$ par jour de calcium et $5 \mathrm{~g}$ de phosphore. de telle sorte que le rapport $\mathrm{Ca} / \mathrm{P}$ soit voisin de 1 et ne dépasse pas 1,2 .

Pour les Iaitieres, ajouter, à partir du $6 \mathrm{e}$ mois de Ia gestation, progressivement, 5 à 30 grammes par jour et, pendant la lactation, 4 a $5 \mathrm{~g}$ de calcium et 3 à $4 \mathrm{~g}$ de phosphore par litre de lait produit.

\section{Ovins.}

Les besoins sont les mêmes, proportionnellement au poids, que pour les bovidés. Mais comme les brebis allaitantes foumissent un lait contenant par $\mathrm{kg} 2 \mathrm{~g}$ de Ca et $\mathrm{l}, 35 \mathrm{~g}$ de $\mathrm{P}$, elles doivent recevoir un supplément journalier de $6 \mathrm{~g}$ de $\mathrm{Ca}$ et de $4 \mathrm{~g}$ de $\mathrm{P}$ par kiló de lait produit.

\section{Porcs.}

10 Porcelet. - Le jeune porcelet pesant de 15 
à $50 \mathrm{~kg}$ a besoin de 0,7 à $0,8 \%$ de sa ration en $\mathrm{Ca}$ et de 0,4 a $0,5 \%$ en P. Entre 50 et $100 \mathrm{~kg}$, on diminuera cette quantité jusqu'à $0,5 \%$ de $\mathrm{Ca}$ et $0,3 \%$ de P.

Pratiquement, on sera dans ces limites en donnant, par jour :

\begin{tabular}{|c|c|c|c|c|c|c|}
\hline & & & $\mathrm{de} \mathrm{Ca}$ & & $g$ de $P$ & \\
\hline dans le & ler & mois & $7-8$ & et & 5 & \\
\hline- & $2^{e}$ & - & $8-9$ & et & 6 & \\
\hline- & $3^{e}$ & 一 & $10-15$ & et & $6-10$ & progressivement. \\
\hline - & $4 e$ & $一$ & $15-20$ & et & $10-14$ & - \\
\hline- & $5^{\mathrm{e}}$ & 一 & $20-25$ & et & $14-15$ & - \\
\hline - & $6^{e}$ & 一 & 25 & et & 13 & - \\
\hline 一 & $7^{e}$ & 一 & 22 & et & 12 & 一 \\
\hline
\end{tabular}

$2^{\circ}$ Truie. - La déperdition journalière de Ca et de $\mathrm{P}$ par le lait étant de 16 à $20 \mathrm{~g}$ pour le $\mathrm{Ca}$ et de 8 à $11 \mathrm{~g}$ pour le $\mathrm{P}$, la truie doit recevoir, en plus de sa ration minérale d'entretien, pour compenser ces pertos, 2,5 à 3 fois plus, c'est-à-dire 40 à $60 \mathrm{~g}$ de $\mathrm{Ca}$ et 23 à $33 \mathrm{~g}$ de $\mathrm{P}$, avec un rapport $\mathrm{Ca} / \mathrm{P}$ compris entre 1,5 et 1,9 . Ceci correspond environ à $8 \mathrm{~g}$ de Ca et $5 \mathrm{~g}$ de $\mathrm{P}$ par kilo de la ration totale.

\section{Cheval.}

Le cheval est beaucoup plus exigeant en $\mathrm{Ca}$ que les ruminants et beaucoup moins en $P$. On compte en moyenne que le cheval dont la croissance est terminée a besoin de $60 \mathrm{~g}$ de Ca par jour et $30 \mathrm{~g}$ de $P$, avec un rapport $\mathrm{Ca} / \mathrm{P}$ voisin de 1,8 .

\section{Volailles.}

10 En croissance : 1,1 à $1,5 \%$ de la ration en $\mathrm{Ca}$, et 0,55 en $\mathrm{P}$. Rapport $\mathrm{Ca} / \mathrm{P}$ compris entre 1,6 et 2,6 .

$2^{\circ}$ Pondeuses : $\mathrm{Ca} 2 \%$ et $\mathrm{P} 0.9 \%$ de la ration.

\section{Absorption du phosphore et du calcium.}

Les phosphates et les sels de valcium sont solubilisés dans l'estomac par l'acide chlorhydrique. Les composés calciques ne contenant qu'un atome de calcium sont solubilisés sous forme de chlorure de calcium. Les composés bi et tricalciques sont solubilisés sous forme de sels acides : sulfate acide de calcium, phosphate monocalcique.

Puis, dans le duodénum, où le milieu est très alcalin, le chlorure de calcium est transformé en carbonate insoluble. Les phosphates monométalliques passent à l'état bimétallique insoluble. Les acides gras libérés donnent également des savons calciques insolubles. Seuls quelques phosphates provenant de la digestion des nucléines et des lécithines sunt absorbés directement.

L'absorption des composés phospho-calciques se fait grâce aux phosphatases présentes dans la bile et sécrétées par les cellules et glandes intestinales. Ces diastases libèrent l'acide ortho-phosphorique qui transforme les sels de calcium insolubles en phosphate monocalcique soluble. Cette action des phosphatases est réversible; elles peuvent refaire la synthèse des esters phosphoriques quand l'apport calcique est trop important.

L'absorption so fait sous formo do phosphate monocalcique, seul phosphate de calcium soluble. Suivant les rapports des quantités de calcium et de phosphore en présence, la formation du phosphate monocalcique sera favorisée ou inhibée. Les conditions optima seront remplies dans l'intestin lorsqu'à un atome de phosphore correspondra un atome de calcium, c'est-à-dire quand le rapport $\mathrm{Ca} / \mathrm{P}$ sera égal à 1,3 .

Malgré l'apport inconstant de phosphore et de calcium par les aliments, la phosphatémie et la calcémie restent constantes ou varient entre de très faibles limites. C'est un mécanisme complexe (dans lequel interviennent : les parathyroïdes, l'antéhypophyse, les vitamines $D$ et $A$ et les reins) qui règle cet équilibre, assez caractéristique dans chaque espece animale.

Le seuil d'excrétion rénale serait contrôlé par la parathormone. D'après Greenwald et Gross, l'hormone parathyroïdienne maintiendrait en solution le phosphate de calcium qui se trouve dans le sang à l'état de sursaturation. La sécrétion de cette hormone est activée par la parathyroïdostimuline antéhypophysairc.

Comme nous le verrons plus loin, les vitamines D et $\AA$ permettent à la muqueuse intestinale d'absorber le calcium et le phosphore dans un rapport convenable. Elles favorisent la fixation de ces deux substances minérales sur l'os en voie d'ossification en augmentant la perméabilité des membranes cellulaires lipoïdiques. La vitamine $A$ intervient dans l'élimination normale, par le rein, de la chaux et des phosphates.

De l'exposé rapide des rôles joués par le phosphore et le calcium, on peut déduire que les carences en ces éléments entraineront des troubles graves.

Les syndromes correspondront, soit au trouble des mécanismes catalytiques, soit au trouble de l'ostéogénèse; dans le premier cas, on observera des névroses, dans le second, des ostéopathies.

\section{CaRENCES PHOSPHO-CALCIQUES}

\section{I. - Névroses.}

\section{Étiologie.}

Dans certaines névroses animales, en l'absence de lésions spécifiques des centres nerveux, on a été amené à considérer les troubles humoraux constatés au cours de ces affections comme la cause de la maladie. Liégeois les a désignés sous le terme général de névroses humorales. 
On a trouvé dans ces névroses qu'il y avait un trouble profond de l'excitabilité neuro-musculaire, influencée par l'équilibre ionique des milieux intérieurs, et, d'après Loeb, elle est fonction du rapport:

$$
\text { E.N.M. }=f\left(\frac{\mathrm{K}^{+}, \mathrm{Na}^{+}}{\mathrm{Ca}^{++}, \mathrm{Mg}^{++}}\right)
$$

Les ions $\mathrm{K}^{+}$et $\mathrm{Na}^{+}$étant des excitants, $\mathrm{Ca}^{++}$ et $\mathrm{Mg}++$ étant des dépresseurs.

Le mécanisme intime de l'action de ces cations a été en partie élucidé expérimentalement; la clinique et la thérapeutique ont permis généralement de confirmer les conclusions des expérimentateurs.

Le potassium est un excitant du tissu nerveux et du tissu musculaire; la teneur en potassium des muscles est proportionnelle à leur activité fonctionnelle. Le potassium intervient dans la transmission de l'influx nerveux, il a d'etroites relations avec le médiateur chimique de la transmission de l'influx neuro-musculaire, en particulier l'acétylcholine. Il augmente la perméabilité des membranes cellulaires. Il favorise la transformation du glycogène en glucose et, par là, il est un hyperglycémiant.

Le sodium est nécessaire à la contractilité du muscle strié. Il augmente la perméabilité des membranes cellulaires mais son rôle est moindre que celui du potassium.

Le magnésium est un modérateur de l'E.N.M. Son excès amène non seulement une paralysie périphérique mais aussi une paralysie des centres nerveux.

Le calcium est l'élément modérateur essentiel de l'E.N.M. Il serait quatre fois plus actif que le magnésium.

Expérimentalement, on déclenche de l'hyperexcitabilité en déterminant de l'hypocalcémie par des injections d'oxalates alcalins.

Cliniquement, l'hypocalcémie se rencontre dans les tétanies qui guérissent par calcithérapie.

Le mécanisme intime de l'action des ions calcium est encore discuté. Pour les uns, dans l'hypocalcémie, les ions calcium ne jouant plus leur rôle déshydratant, les membranes cellulaires s'imbiberaient, deviendraient plus perméables et laisseraient passer des poisons convulsivants provenant du métabolisme normal ou pathologique (guanidine).

Pour les autres, l'hypocalcémie entrainnerait une diminution de l'activité de la cholinesterase qui détruit le médiateur chimique libéré au niveau de la liaison myo-neurale; la tétanie serait la conséquence du déséquilibre fonctionnel neuro-musculaire entraîné par l'excès d'acétylcholine (Massart, Dufait, Vincent).

L'action modératrice du magnésium se ferait de même au niveau de la liaison myo-neurale, par l'intermédiaire de la cholinesterase. Le magnésium entrant dans ce système enzymatique, son excès entrainerait une hyperactivité de l'enzyme et la destruction très rapide de l'acétylcholine qui déterminerait des paralysies.

D'après Bacq, les tétanies s'observent lorsque l'action convulsivante des ions potassium l'emporte sur l'action modératrice des ions calcium, ceux-ci étant en trop faible quantité du fait de l'hypocalcémie qui trouble l'équilibre $\mathrm{K}^{+} / \mathrm{Ca}{ }^{++}$.

Quelle que soit la theorie retenue, il est admis que c'est sous forme de cations que les excitants et modérateurs nerveux interviennent; aussi tous les facteurs susceptibles de modifier l'équilibre ionique auront un retentissement sur l'E.N.M.

Si la calcémie est le facteur principal qui contrôle le degré de l'ionisation calcique du sang, il a été prouvé que ce dernier était influencé par l'équilibre acide-base et la richesse du sang en phosphates inorganiques et en protéines; tous ces facteurs dépendent eux-mêmes de facteurs exogènes (alimentation, milieu, climat) et endogènes (activité des glandes endocrines).

On admet que les phénomènes tétaniques apparaissent quand la calcémie totale est inférieure à 6-7 $\mathrm{mg} \%$.

Les mécanismes qui entrainent l'hypocalcémie sont nombreux. Elle peut être déterminée en premier lieu par une insuffisance du taux du Ca dans la ration ou par l'anormalité du rapport Ca/P, c'est l'hypocalcicose alimentaire. Elle peut être due à une absorption insuffisante déterminée soit par des troubles intestinaux, soit, plus généralement, par une avitaminose D ou A. Elle est souvent causée par une élimination trop intense pouvant survenir au niveau soit de l'intestin, lors de diarrhées, soit de l'utérus pendant la gestation, soit de la mamelle au cours de la lactation.

L'hypocalcémie peut s'installer lorsque, par suite d'un dysfonctionnement glandulaire, le calcium osseux n'est pas mobilisé en quantité suffisante, ce qui est de règle dans l'hypothyroïdisme.

Dans tous les' cas d'hypocalcémie, il y a baisse du degré d'ionisation calcique et tendance à des phénomènes tétaniques.

Un autre facteur de l'ionisation calcique est l'équilibre acide-base du sang. D'après Roma et Takahashi:

$$
\mathrm{Ca}^{++}=\mathrm{f}\left(\frac{\mathrm{H}^{+}}{\mathrm{BHCO}_{3}}\right)
$$

l'ionisation du calcium se faisant aux dépens du calcium lié aux protéines et qui existe sous forme colloïdale.

L'acidose s'accompagne d'une augmentation du calcium ionisé. Elle est cliniquement caractérisée par une tendance comateuse alors que, dans les 
alcaloses, en raison d'une diminution des ions calciques, l'E.N.M. augmente et on observe une tendance aux contractures et aux convulsions.

Gyorgy a montré que l'augmentation de la phosphatémie entraînait une diminution de l'ionisation calcique et Hasting a trouvé que l'augmentation de la protéinémie avait le même résultat.

En résumé, l'alcalose, l'hyperphosphatémie, l'hyperprotéinémie comme I'hypocalcémie déterminent une baisse de l'ionisation calcique et peuvent, par là, être à l'origine de tétanies.

Pour traduire ces conclusions par une formule. Liégeois propose d'inclure dans la formule de Loeb tous les facteurs modifiants l'E.N.M.

E.N.M. $=\mathrm{f}\left(\frac{\mathrm{K}^{+}, \mathrm{Na}^{+}, \mathrm{BHCO}_{3}, \mathrm{HPO}_{3}^{-}, \text {protides }}{\mathrm{Ca}++, \mathrm{Mg}++, \mathrm{H}+}\right)$

En considérant isolément le rôle de chacun des termes de la formule initiale de Loeb, on n'a pas trouvé d'explication fournissant des solutions valables à tous les problèmes posés par les névroses. En la conplétant comme ci-dessus, on serre peut-être la vérité de près, mais il faudra considérer, non pas les valeurs absolues de chacun des facteurs, mais leurs valeurs relatives, certains déséquilibres provenant de la rupture des antagonismes existant à l'état physiologique. Récemment Bacq a montré que l'équilibre $\mathrm{K}+/ \mathrm{Ca}++$ pouvait être rompu par la présence de substances chimiques sensibilisant le muscle strié à l'action convulsive du potassium. Ces substances sont des produits normaux du catabolisme des nucléo-protéides et des protéides tels que les dérivés puriques, la guanine, la xanthine, l'uracyle, l'acide urique, la guanidine. Leur action sensibilisatrice interviendrait soit quand leur taux dans le sang atteint un certain seuil, soit quand, par hypocalcémie, le rapport $\mathrm{K}+/ \mathrm{Ca}+t$ augmente.

Parmi les tétanies on a classé la fièvre vitulaire. la tétanie d'herbage, la tétanie des jeunes, de voyage, de repos. Si on rencontre quelquefois des cas de fièvre vitulaire sous les tropiques, c'est la tétanie d'herbage qui est la plus fréquente, et c'est la seule que nous étudierons.

\section{La tétanie d'herbage}

La tétanie d'herbage est une maladie qui atteinł presque exclusivement les bovins, se manifeste peu de temps après la mise au pâturage et se caractérise par des signes nerveux variés où les états convulsifs et tétaniques sont les plus fréquents. Elle est due à un déséquilibre humoral complexe où prédominent l'hypocalcémie et l'hypomagnésiémie.

Elle est connue aussi sous les noms de " tétanie de pâturage », "vertige d'herbe », "maladie du printemps », " grass-tetany ».
Elle a été surtout étudièe aux Pays-Bas, et en Belgique.

Longtemps elle fut confondue avec les autres tétanies, vitulaires ou non, et avec des affections nerveuses. L'apparition de la tétanie au moment de la mise au pâturage a été signalée en 1924 par Mason. Les études de Sjollema, Seeckles ont élucidé en partie son étiologie et sa pathogénie. En Frarice, Detrez, en 1932, a fait une étude détaillée de sa pathogénie.

Sous les tropiques, l'affection est signalee dans les rapports d'activité des Centres 'd'élevage et des circonscriptions.

Le « tiéoudé » de la zone du Delta Central Nigérièn est à rattacher aux tétanies d'herbage.

$\mathrm{Si}$, en Europe, la maladie atteint plus particulièrement les vaches laitières, on l'observe cependant aussi chez les taureaux, les bœufs, les génisses et les veaux. On a décrit des troubles semblables chez les moutons.

En région tropicale, l'affection sévit surtout chez les jeunes bovins qui vont subir pour la première fois la saison des pluies et qui, ayant été sevrés depuis plusieurs mois, ont reçu un régime composé presque exclusivement de paille de brousse très sèche et de faible pouvoir nutritif.

\section{Symptômes.}

La forme aiguë est la plus fréquente; elle est caractérisée par une hyperexcitabilité croissante.

Au début l'animal reste isolé; immobile, anxieux, ne mange pas, ne rumine pas. Quand il marche, il le fait lentement et avec hésitation; puis les signes d'excitation se font plus nets; on observe de la sialorrhée, des frissons, des tremblements des masses musculaires (anconés, croupe).

La maladie atteint alors sa période d'état. I'hyperexcitabilité devient maxima : elle consiste en convulsions, d'abord cloniques, puis toniques, ces dernières étant suivies de périodes de dépression. L'animal essaie de se relever mais vacille, tombe et se remet en décubitus latéral; les membres sont agités dans tous les sens.

Le faciès est crispé en trismus, les oreilles sont droites, la salive s'écoule de la bouche.

Puis l'animal se met en opisthotonos, fait des mouvements impulsifs, présente de l'automatisme ambulatoire, des mouvements de léchage, des accès de fureur, il pousse au mur, etc.

A ce stade, la polypnée est constante. L'animal répond violemment à toute excitation par des convulsions et des contractures.

Le coma s'installe, entrecoupé de longs frissons quand l'animal est tétanisé.

A côté des symptômes nerveux quị dominent le 
tableau clinique, on note que la température augmente et dépasse rapidement $40^{\circ}$ à la phase d'excitation et que la phase comateuse s'accompagne d'hypothermie.

Les signes digestifs sont l'arrêt de la rumination, la constipation.

La dyspnée, intense et plaintive, est due à un emphysème mixte, alvéolaire et interstitiel.

Dans la forme suraiguë, les symptômes précédents se succèdent très rapidement et l'animal meurt en quelques heures.

Dans la forme subaiguë, les symptômes se manifestent brusquement mais les signes nerveux sont moins accusés. On observe des tremblements, de l'hyperesthésie, une démarche trébuchante mais jamais de contractures cloniques.

Dans la forme aiguë, l'évolution peut durer quelques jours; quand, en cas de guérison, la convalescence est longue, l'appétit ne revient que très lentement.

\section{Étiologie.}

On incrimine généralement le brusque passage d'un rationnement riche en cellulose à une alimentation au pâturage trop riche en proteines, trop pauvre en minéraux et cellulose. La forte production laitière qui épuise les réserves minérales des vaches est un facteur prédisposant.

Sous les tropiques, le même déséquilibre existe. Les animaux n'ont reçu, pendant la saison sèche et en particulier à la fin de celle-ci, que des aliments grossiers, cellulosiques, très pauvres en calcium et phosphore.

Ils ont épuisé leurs réserves à tel point qu'à la fin de la saison sèche la plupart des veaux maigrissent de 5 à 6 kilos, quelquefois plus.

On a noté, comme cause favorisant l'éclosion de la maladie, les facteurs atmosphériques. En Europe, la maladie s'observe après une nuit froide, par un temps frais et humide, par temps orageux, lourd, par les fortes chaleurs.

Au début de l'hivernage, les variations des caractéristiques météorologiques qui accompagnent en zone tropicale chaque tornade sont encore plus accusées que celles qu'on peut observer en zone tempérée et le rôle favorisant de ces conditions est certain.

La tétanie apparaît 1 à 5 semaines après la mise au pâturage. Sjollema a trouvé que $46 \%$ des cas de tétanie apparaissent une semaine après la mise au pâturage, $28 \%$ au cours de la deuxième semaine et $26 \%$ aú-delà du $15^{\mathrm{e}}$ jour.

Cherchant à déterminer la cause de l'action néfaste de l'herbe, les auteurs sont arrivés à la conclusion que c'était surtout sur les pâturages améliorés oì on répandait des engrais azotés que l'on observait le plus de cas de tétanies.

Sjollema, effectuant 400 analyses d'herbe de pâturages suspects, trouva que la première herbe était très riche en protéines et en potassium et déficiente en calcium et magnésium.

Les dosages opérés sur le sérum des animaux malades ont montré que la calcémie était toujours diminuée ( $6,6 \mathrm{mg}$ au lieu de $11 \mathrm{mg}$ ); elle est cependant supérieure à celle des vaches atteintes de fièvre vitulaire.

Le taux de la phosphatémie est subnormal.

L'hypomagnésiémie semble être le signe dominant, elle serait pour Sjollema le critere le plus important.

L'hyperguanidinémie, constatée semble due à l'excès des déchets azotés de l'alimentation intensive hivernale, augmentée encore lors de la mise au pré par la forte teneur de l'herbe nouvelle en protéines.

Si on se reporte à l'étude des facteurs de régulation de l'E.N.M., il est facile d'expliquer le mécanisme du déclenchement des tétanies.

Les animaux, au sortir de l'hiver, ont un équilibre humoral métastable, certains sont même des subcarencés en calcium et magnésium. L'herbe nouvelle, consommée en grande quantité, accuse le déséquilibre par sa pauvreté en calcium et magnésium, par sa forte teneur en protéines qui, comme nous l'avons indiqué précédemment, diminue l'ionisation calcique.

Tous les animaux d'un troupeau étant soumis aux mêmes facteurs exogènes, certains auteurs pensent que seuls les hypoparathyroidiens incapables de rétablir la calcémie normale sont atteints de tétanie. Expérimentalement, l'hypoparathyroidie s'accompagne, en effet, d'hypocalcémie et d'hyperguanidinémie.

D'autres incriminent, pour expliquer la prédisposition individuelle, un hyperfonctionnement hypophysaire.

La pathogenie de la télanie d'herbage est certainement complexe mais on doit retenir qu'un déséquilibre minéral d'origine alimentaire est certainement à son origine, que ce déséquilibre se manifeste par une hypocalcémie et une hypomagnésiémie et que la thérapeutique magnésio-calcique est efficace.

Pour les zones tropicales, le déséquilibre est dû a une carence véritable provenant de la faible teneur en élements minéraux de l'herbe de brousse on fin de saison sèche et dont le rôle pathogène est peut-être également aggravé par une carence en vitamine $A$. 


\section{II. - Ostéopathies carentielles}

Lorsque les animaux sont soumis à un régime nettement carencé en phosphore et en calcium, des troubles trophiques sont observés dont les manifestations cliniques les plus spectaculaires portent sur le squelette.

Les ostéopathies d'origine carentielle sont classées par Liégeois sous la désignation d'ostéopathies chimio-dystrophiques par déficit d'ossification; elles sont caractérisées essentiellement par un ramollissement de l'os et une diminution de la substance osseuse.

Initialement, on faisait des ostéopathies malaciques les manifestations différentes d'une seule maladie : rachitisme ou ostéomalacie suivant l'âge des animaux.

Les études anatomo-pathologiques et étiologiques ont permis de séparer plusieurs maladies ayant chacune ses caractères propres.

Dans l'ostéoporose, dystrophie aplasique, l'os disparu est remplacé par de vastes cavités médullaires.

Dans le rachitisme et l'ostéomalacie, dystrophies hyperplasiques, l'os est remplacé par du tissu ostéoïde non calcifié qui, sous l'action des tiraillements et pressions qui s'exercent au niveau des articulations et des insertions ligamenteuses, s'hyperplasie par hyperactivité des ostéoblastes.

Dans l'ostéofibrose, dystrophie métaplasique, la destruction de l'os par les ostéoclastes s'accompagne d'une réaction mésenchymateuse qui remplace l'os détruit par du tissu fibreux.

Selon Theiler, les caractéristiques anatomo-pathologiques des dystrophies osseuses dépendent de caractères spécifiques. Les bovins ont surtout du rachitisme et de l'ostéomalacie, les chevaux et les chèvres de l'ostéofibrose, le chien et les porcins les uns ou les autres.

\section{Étiologie.}

\section{L'Ostéoporose}

L'ostéoporose est considérée par certains comme le premier stade de l'ostéomalacie. Cependant Liégeois et ses collaborateurs en font une maladie bien individualisée dans laquelle l'ossification ne se produit pas, l'ébauche protéique étant insuffisante en quantité ou qualité pour permettre le dépôt de sels mineraux.

Cette insuffisance peut provenir soit d'un ralentissement de l'activité des ostéoblastes, ce qui est le cas le plus fréquent, soit d'une exagération des phénomenes de protéolyse.

Les études portant sur les modifications humorales survenant au cours de l'ostéoporose donnent, quant aux modifications de la calcémie et de la phosphatémie, des résultats discordants et les modifications, quand elles existent, sont de faible amplitude.

Par contre, les variations de la protéinémie sont plus nettes. L'ostéoporose s'accompagne d'une diminution sensible de la protéinémie totale. Liégeois et ses collaborateurs ont montré, au moins chez le jeune chien, que l'hypo-albuminemie etait constante et pouvait être considérée comme le trouble humoral caractéristique de l'ostéoporose.

Celle-ci proviendrait ainsi d'un trouble du métabolisme des protéines dont l'hypo-albuminémie serait le témoin.

Si maintenant on considère l'origine de ce trouble, on trouve en premier lieu la carence protidique de la ration. Les ostéoblastes manquent de matière première pour synthétiser l'osséine.

En second lieu, il faut placer les états dans lesquels l'organisme animal doit faire face à des déperditions de protéines : parasitisme, maladies cachectisantes. La gestation et la lactation agissent de façon identique.

Cependant, Theiler et ses élèves imputent l'ostéor porose à une carence en phosphore et la considèrent comme un premier stade de l'ostéomalacie.

Ils basent leurs conclusions sur les expériences faites, en Afrique du sud, sur des animaux entretenus sur des sols pauvres en phosphore. Dans leurs comptes rendus il y a peu de renseignements sur les bilans protidiques des rations.

De plus, si l'on veut bien considerer que la teneur en protéines des graminées et légumineuses est proportionnelle à la teneur en phosphore du sol, on est amené à conclure que les troubles observés étaient le résultat d'une carence multiple : protéique et phosphorique, ce qui expliquerait la possibilité de la coexistence de l'ostéoporose et de l'ostéomalacie.

Cependant, l'ostéoporose peut être déterminée par des troubles de l'activité propre des ostéoblastes. Ainsi, certains cas sont imputés à une carence en manganèse. Cette carence entraine une diminution de la synthèse de la vitamine $C$ qui détermine un ralentissement de l'activité du mésenchyme et de l'osséinogénèse.

L'activité des ostéoblastes est également ralentie au cours de la sénilité et de certains troubles endocriniens. L'hypothyroidie, qui ralentit le métabolisme protidique, serait à l'origine de certains cas d'ostéoporose observés chez des poulains présentant des stigmates de dysfonctionnement thyroidien.

\section{Symptomatologie.}

L'ostéoporose se manifeste par des symptômes généraux : maigreur, asthénie, apathie, anémie, 
et des symptômes particuliers : déformation des os longs qui sont tordus, coudés, ce qui entraîne le raccourcissement des membres, la défectuosité des aplombs. On observe souvent des tuméfactions juxta-articulaires qui sont très nettes chez le veau. Des fractures spontanées peuvent, du fait de là fragilité des os, se produire à la faveur d'un faux mouvement ou survenir au cours de manceuvres de contention. Ces fractures sont compliquées, multiples, et les traits de fractures sont irréguliers, «en bois vert».

Les zones œdématiées sont douloureuses à la pression, les déplacements sont pénibles, le décubitus est fróquont.

L'examen radiologique confirme la déformation des os et permet de voir que leur tissu est transparent, poreux, que la corticale est mince, le canal médullaire très large.

Microscopiquement; on remarque l'épaississement du périoste, une extrênne raréfaction du tissu osseux et du tissu ostéoïde. La corticale est spongieuse par suite de l'élargissement des canaux de Havers.

\section{Le rachitisme et l'ostéómalacie}

En traitant des carences phospho-calciques, il est difficile, pour l'anatomo-pathologiste, de séparer le rachitisme de l'ostéomalacie. En effet, on dófinit le rachitisme comme « une ostéopathie chimiodystrophique malacique caractérisée par une insuffisance de ininér alisation de la substance pré-osseuse au cours de la croissance » et l'ostéomalacie comme « une ostéopathie chimio-dystrophique malacique caractérisée par un déficit de minéralisation des us à l'âge adulte, c'est-à-dire après la disparition des cartilages de conjugaison. »

Il n'y a donc entre les deux maladies qu'une question d'âge des malades et Liégeois propose de désigner l'ostéomalacie sous le vocable de "rachitisme des adultes $\gg$.

Ces deux ostéopathies se rencontrent sous toutes les latitudes. La fréquence des cas et leur gravité dépendent des conditions d'entretien des animaux. On n'observe habituellement que des cas sporadiques; cependant, quand de grands effectifs sont soumis aux conditions défavorables que nous étudierons plus loin, on peut rencontrer des cas en série qui en imposent comme une épizootie.

\section{Étiologie.}

Ces deux affections ont été étudiées cliniquement et expérimentalement. Elles sont dues à un trouble du métabolisme phospho-calcique affectant l'apport, l'absorption ou la fixation de ces éléments sur la substance pré-osseuse. a) L'insuffisance d'apport peut porter sur le calcium ou le phosphore (rapport $\mathrm{Ca} / \mathrm{P}$ alimentaire modifié) ou sur les deux éléments à la fois.

L'hypocalcicose est rare chez les bovidés. L'apport alimentaire est généralement suffisant.

Par contre, l'hypophosphorose est très fréquente. Papenheim a montré expérimentalement son rôle rachitigène chez le rat blanc, Theiler et ses collaborateurs en ont fait la cause essentielle des ostéopathies observées sur les bovins en Afrique du sud; l'addition de calcium aux rations carencées en phosphore aggravait les symptômes et, dans tous les cas, l'hypophosphorémie précédait l'apparition des symptômes cliniques de rachitisme ct d'ostćomalacio.

Chez les équidés, les rations sont généralement riches en phosphore (grains) et pauvres en calcium alors que le cheval est particulièrement sensible à ce déficit calcique.

Dans certains cas, on peut avoir une carence mixle phospho-calcique. Marek el Wellnımır en ont $\mathrm{vu}$, chez le porc et le chien, le rôle possible.

b) L'insuffisance d'absorption peut provenir, comme nous l'avons indiqué plus haut, des modifications du rapport phospho-calcique de la ration. Examinons les différents cas qui peuven! se présenter.

$1^{0}$ Régime trop riche en chaux, normal en phosphates. Le rapport Ca/P est augmenté. L'acide phosphorique libéré dans l'intestin attaque tous les sels de chaux insolubles et il se produit successivement du phosphate tricalcique, du phosphate bicalcique, tous deux inassimilables, et du phosphate monocalcique. Comme il y a trop de chaux, l'acide phosphorique est insuffisant pour parfaire toutes ces réactions ef à amencr tous los phosphatcr au stade monocalcique. Seuls ces derniers sont assimilés, les autres sont rejetés, d'où une perte, à la fois, de calcium et de phosphore. Le sang est donc pauvre en chaux (hypocalcémie ou acalcicose) et en phosphore (aphosphorose). Cet état est favorable à l'éclosion du rachitisine chez les jeunes et de l'ostéomalacie chez les adultes.

$2^{\circ}$ Régime insuffisant en phosphore. Le rapport $\mathrm{Ca} / \mathrm{P}$ est trop élevé du fait de la diminution du dénominateur de cette fraction. Comme dans le cas précédent, l'assimilation du calcium intestinal ne peut se faire en totalité et tout ce qui n'a pas été amené à l'état de' phosphate monocalcique est rejeté. Le sang s'appauvrit à la fois en calcium et en phosphore, d'où rachitisme et ostéomalacie.

Un cas particulier doit être envisagé ici : celui du phosphore phytique. Le phosphore des grains de céréales est en grande partie sous forme d'acide phytique qui est particulièrement inassimilable. $\mathrm{Ce}$ corps doit être hydrolysé par une diastase, la phytase, qui est peu abondante dans les grains mais 
qui peut se trouver dans l'intestin du fait du métabolisme microbien. Si la phytase est insuffisante, une ration riche en phosphore phytique devient rachitigène.

30 Régime trop riche en phosphore. Le rapport $\mathrm{Ca} / \mathrm{P}$ est diminué par augmentation du dénominateur. Tout le calcium de la ration peut être amené à I'état de phosphate monocalcique et se trouve absorbé mais, en même temps, d'autres phosphates sont absorbés et il en résulte un excès de phosphore sanguin; le milieu sanguin n'est pas favorable à une correcte ossification, laquelle exige un rapport phospho-calcique normal. La réaction se traduit en ce cas par de l'ostéofibrose.

40 Régime insuffisant en calcium. Le rapport $\mathrm{Ca} / \mathrm{P}$ est diminué. La conséquence en est la même que ci-dessus. Tout le calcium est bien absorbé, mais avec un excès de phosphore. Le déséquilibre phospho-calcique sanguin est encore augmenté par le fait qu'il n'y a pas assez de calcium, d'où une intrication d'ostéofibrose et d'ostéomalacie ou rachitisme.

Par un mécanisme qui n'est pas encore bien élucidé, la vitamine $D$ semble intervenir au niveau de l'intestin pour améliorer l'absorption phosphocalcique lorsque le rapport $\mathrm{Ca} / \mathrm{P}$ s'écarte de la valeur optimale.

L'absorption du calcium et du phosphore peut être troublée également par des affections modifiant en particulier le $\mathrm{pH}$ intestinal : entérites, diarrhées, parasitisme intestinal.

c) Le calcium et le phosphore, étant.absorbés normalement, peuvent ne pas se fixer sur les ébauches osseuses. Si le rôle des facteurs nerveux et vasculaires n'est pas élucidé, il est certain que les facteurs endocriniens interviennent : l'ovariotomie améliore l'état des vaches atteintes d'ostéomalacie, l'hyperthyroïdisme l'aggrave.

Roche et Simonnet ont moritré que, dans le rachitisme expérimental, les zones d'ossification voyaient diminuer leur aptitude à fixer le calcium et le phosphore, et ils imputent ce défaut à un trouble des complexes enzymatiques.

L'acidose et l'alcalose modifiant l'ionisation calcique, il est vraisemblable qu'elles ont une influence sur l'ossification des ébauches protéiques osseuses du fait du caractère amphotère de ces dernières.

En résumé, si le rachitisme et l'ostéomalacie sont quelquefois la complication de certains troubles digestifs ou de maladies organiques, la cause principale est le déséquilibre minéral alimentaire.

Le rachitisme des très jeunes est rare. En effet, dans les premiers jours de son existence, le jeune animal, alimenté au lait maternel, reçoit habituellement une ration suffisamment riche en phosphore et calcium. La teneur du lait en ces éléments est maintenue normale par épuisement des réserves maternelles. Cependant, on a signalé du rachitisme chez des veaux nourris par des mères atteintes d'ostéomalacie.

L'allaitement artificiel est souvent la cause du rachitisme les barbotages distribués n'étant pas equilibrés. Le sevrage, qui est une période critique, est souvent le point de départ de l'action des facteurs rachitigènes, surtout s'il a été précoce et si les animaux ne reçoivent pas une alimentation convenable à cette époque.

Sous les tropiques, la cause principale du rachitisme des veaux est la pratique qui consiste à ne leur laisser qu'une traite sur deux, l'autre étant utilisée par le berger, soit pour son alimentation personnelle, soit pour la vente. Comme la production laitière est faible, les veaux sont sous-alimentés et carencés; surtout en éléments minéraux, phosphore et calcium, qu'ils ne peuvent trouver dans les fourrages grossiers qu'ils broutent autour des campements où ils sont relenus pendant que les vaches vont dans les pâturages.

La. sous-alimentation, rachitigène par elle-même, a son action renforcée par les dyspepsies consécutives à l'ingestion des fourrages grossiers qui diminuent encore l'absorption normale des éléments utiles de la ration.

Après le sevrage et chez les adultes, la cause déterminante des dystrophies osseuses est l'alimentation. Les autres causes, facteurs climatiques et milieu, gestation, lactation, n'interviennent que pour aggraver des troubles provenant du déséquilibre alimentaire.

Certains aliments sont, par eux-mêmes, pauvres en phosphore et calcium : les racines, les tubercules; d'autres riches en calcium eti pauvres en phosphore : les foins, surtout les légumineuses, les feuilles de betteraves; d'autres sont riches en phosphore mais pauvres en calcium : tourteaux, grains, son...

Une ration devra être composée d'un mélange de ces différents aliments pour être équilibrée et, de plus, ne contenir aucun corps susceptible de troubler l'absorption des éléments minéraux, en particulier des acides (acide salicylique des foins de prairie, de marécages, acide oxalique des feuilles de betteraves).

La distribution d'une ration équilibrée suppose une alimentation artificicllo; or ccrtains animaux, et en premier lieu les bovins, doivent se contenter de ce qu'ils trouvent sur le pâturage. Ceci est particulièrement vrai en zone-tropicale el dans les élevages extensifs.

Un facteur essentiel intervient : la nature des sols, 
qui détermine, dans une certaine mesure, la flore des pâturages et, entièrement, la composition chimique des plantes.

Dans les zones à ostéomalacie, on a toujours trouvé de I'hypophosphorose des sols, ce défaut étant souvent accusé par de l'hypercalciose, ce qui est le cas de la Champagne crayeuse, de la Nièvre, du nord de la France et d'une partie de l'Afrique du sud.

Le rôle du phosphore a été confirmé par les observations faites pendant la querre 1939-1945 lorsque, la diminution du disponible en engrais phosphoriques ayant entraîné la suppression presque complète de l'épandage des engrais sur les prairies, on a vu l'ostéomalacie, qui ne se rencontrait que dans quelques régions bien délimitées, gagner toute la France puis diminuer dès que la fumure phosphorique des prairies fut reprise.

Les facteurs climatiques interviennent pour aggravor los caroncos phospho-calciquos.

Par la sécheresse, la végétation donne des tiges dures et des feuilles rugueuses qui diminuent la digestibilité des fourrages et, par là, l'absorption des substances minérales. Ce fait a été confirmé par Fingerling et Hart qui ont montré que les fourrages verts permettaient une meilleure absorption du phosphore que le foin de même composition.

Theiler a constaté que la jeune herbe contient, au moment des premières pluies de printemps, le maximum d'acide phosphorique ou plutôt le taux optimum de ses sels. Tant que les conditions atmosphériques sont favorables, les plantes, en se développant, accumulent des réserves dans leurs feuilles; lorsqu'elles deviennent défavorables, les sels en excédent decendent dans les racines et même retournent au sol (Mme Henrici).

Lewite a montré que la sécheresse faisait perdre 7 à $49 \%$ du phosphore à la plante et l'enrichissait en calcium.

Les animaux, sous los tropiquos, n'ont à leur dis' position en saison sèche que de la paille : le taux du phosphore de la ration est très faible, de l'ordre de $0,1 \%$

Parmi les causes favorisant le rachitisme et l'ostéomalacie on cite des prédispositions d'espèces; nous pensons qu'il laul plus y voir la conséquence du mode d'entretien qu'un caractère spécifique. Parmi les espèces prédisposées, on classe le chien et les bovins ; le premier est victime des erreurs de rationnement, les seconds des défauts du sol et des erreurs des propriétaires. Mais le porc, élevé à l'abri de la lumière, avec des rations mal équilibrées, paie lui aussi un lourd tribut au rachitisme.

Les femelles sont plus souvent victimes de la carence phospho-calcique. Chez la vache qui a son premier veau avant la fin de la croissance, le.rachitisme s'accompagne souvent d'ostéoporose, la gestation ef la lactation détournant, suivant les circonstances, les protéines ou les minéraux de la ration, et déterminant ainsi soit du rachitisme, soit de l'ostéoporose suivant que l'ébauche protéique osseuse se forme ou non.

Chez les adultes, gestation et lactation sont les causes prédisposantes essentielles de l'ostéomalacie, à tel point que souvent, dans les troupeaux, seules les femelles sont malades, les mâles restant indemnes.

On doit citer encore, comme cause prédisposante, la précocité qui, accélérant le rythme de l'édification du squelette, augmente les besoins journaliers en phosphore et calcium.

La consanguinité révélant qualités et défauts du génotype, peut être responsable de certains cas familiaux de rachitisme et d'ostémalacie du fait que los dosccndants d'une même famille auront des rythmes de croissance identiques et auront plus de chances d'être soumis aux mêmes conditions de milieu.

On signale souvent des cas de rachitisme et d'ostéomalacie à la suite du déplacement d'animaux dans un nouveau milieu, en particulier lors d'importations sous de nouveaux climats.

Le cas classique est celui des étalons transportés des climats tempérés sous les tropiques. Aux modifications du régime alimentaire s'ajoutent toutes les modifications physiologiques dues aux facteurs météorologiques et aux troubles endocriniens qu'ils entraînent, en particulier les troubles hypophysaires.

\section{Lésions.}

Les lésions du rachitisme et de l'ostéomalacie diffèront seulemont par l'existence de modifications pathologiques au niveau des cartilages de conjugaison dans le rachitisme, ces lésions étant absentes dans l'ostéomalacie car l'ossification des cartilages a eu lieu avant l'action des facteurs morbifiques.

Macroscopiquement, les os sont légers, poreux, facilement entamés au couteau. Les os longs sont déformés, coudés, présentent fréquemment des exostoses; les cartilages épiphysaires adhèrent lâchement à l'os; le perioste est infiltré, surtout près des articulations; le tissu compact est aminci, et s'il y a eu des fractures, les cals sont mous.

Le canal médullaire est élargi et rempli d'une moelle rouge.

Les os courts sont épaissis, boursoufflés et friables. Chez les volailles, le bréchet est en S.

Dans le rachitisme, les cartilages de conjugaison sont épaissis, très vascularisés et irréguliers.

Microscopiquement, on observe une ostéolyse 
abondante, compensée par une régénération ostéoìde sans calcification.

Le tissu ostéoide non calcifié s'hyperplasie sous l'influence des sollicitations mécaniques, surtout près des articulations et des insertions tendineuses.

On note une augmentation du diamètre des systèmes de Havers ( 140 à 600 microns au lieu de 100 a 140) et des canaux de Havers (20 à 70 microns, au lieu de 20 à 30 ).

Cette haversomégalie s'accompagne d'une raréfaction du nombre des systëmes de Havers : 8 à 15 par $\mathrm{mm}^{2}$ au lieu de 20 à 30 .

L'examen chimique montre que le rapport : $\frac{\text { matière minérale }}{\text { matière organique }}$ passe de $\frac{70}{30}$ pour l'os normal, à $\frac{20}{80}$ pour l'os rachitique. La diminution porte surtout sur le phosphate tricalcique.

La perméabilité de l'os aux rayons $\mathrm{X}$ est augmentée.

Le sang n'offre qu'assez tardivement des modifications du taux du calcium et du phosphore : l'évaIuation de la calcémie et de la phosphorémie est donc un mauvais test du rachitisme et de l'ostéomalacie. Par contre, les études que l'un de nous a faites sur le chien et qu'il poursuit actuellement sur les autres espèces montrent qu'un signe précoce du rachitisme, sensible avant même que n'apparaissent les premiers symptômes cliniques, est l'augmentation de l'activité phosphatasique alcaline du plasma sanguin. Le taux normal de phosphatase (phosphomonoestérase I), exprimée en Unités Bodansky, varie à l'état physiologique, chez le jeune chien, entre 0,6 et 3,25 .

Chez des chiens soumis à une diète défectueuse

\begin{tabular}{|c|c|c|c|}
\hline SUJETS & $\begin{array}{c}\text { CALCIUM } \\
\text { (mg/litre) }\end{array}$ & $\begin{array}{c}\text { PHOSPHORE } \\
\text { (mg/litre) }\end{array}$ & $\begin{array}{c}\text { PHOSPHAT ASE } \\
\text { (U.B.) }\end{array}$ \\
\cline { 1 - 2 } & & & \\
$1 \ldots \ldots$ & 153 & 105 & 5,7 \\
$2 \ldots \ldots$ & 168 & 88 & 4,4 \\
$3 \ldots \ldots$ & 133 & 84 & $?$ \\
$4 \ldots \ldots$ & 170 & 57 & 14,9 \\
$5 \ldots \ldots$ & 138 & 80 & 13,7 \\
$6 \ldots \ldots$ & 128 & 75 & 7,5 \\
$7 \ldots \ldots$ & 130 & 56 & 8,2 \\
$8 \ldots \ldots$ & 133 & 92 & 4,8 \\
$9 \ldots \ldots$ & 110 & 74 & 4,9 \\
$10 \ldots \ldots$ & 121 & 72 & 18 \\
$11 \ldots \ldots$ & 88 & 30 & 9 \\
$12 \ldots \ldots$ & 116 & 92 & 5,2 \\
$13 \ldots \ldots$ & 128 & 80 & 21,5 \\
$14 \ldots \ldots$ & 143 & 63 & 5,8 \\
\hline
\end{tabular}

et qui se révèleront plus tard cliniquement rachitiques, nous avons trouvé les chiffres du tableau ci-contre pour le $\mathrm{Ca}$, le $\mathrm{P}$ et la phosphatase.

\section{Symptômes}

\section{a) Rachitisme.}

Veau. - Le début est insidieux et l'on ne peut en fixer l'époque avec certitude. Les premiers symptômes perceptibles sont de la difficulté de la marche et de la gène dans le relever. Aussi ces veaux restent couchés la plupart du temps, ils se nourrissent mal, dépérissent, s'amaigrissent, ont le poil terne et piqué

Puis vient alors la seconde période, celle des déformations osseuses. Les articulations sont grosses. les us s'infléchissent, se courbent. Certains rayons osseux ne poussent plus en longueur et les membres deviennent difformes, ils se courbent en dedans, en avant, et en dehors, en arrière. Quand la colonne vertebrale est atteinte, elle s'incurve elle aussi donnant soit une bosse (cyphose), soit une ensellure (lordose). La déformation latérale (scoliose), si fréquente chez les enfants, est rare. La taille n'est pas suffisante, comparée à la longueur et à la grosseur du corps : ces veaux sont nains.

Les animaux non traités, ou traités trop tardivement, deviennent incapables de rester debout : ils succombent dans le marasme.

Poulain, - Le rachitisme du poulain est bien plus rare, en France tout au moins, que celui des autres animaux, et surtout ses signes sont plus discrets. Le poulain rachitique a des déformations osseuses peu apparentes, des formes, eparvins, jardes, jardons, sore-shins. Ses aplombs sont dévies. Ses boulets sont gros. Ces animaux ressentent des douleurs osseuses et articulaires qui les font boiter sans que l'on puisse, à la palpation, déceler nettement les points douloureux. Les os perdent leur résistance et l'on, voit se produire des fractures, dites spontanées, sous l'influence de chocs ou d'efforts minimes, surtout aux points de soudure des noyaux d'ossification. Les exemples en sont nombreux chez les chevaux de course à qui l'on demande, à un âge où ils sont encore en croissance, des efforts très rudes alors qu'on leur administre une ration qui, très énergétique, est en même temps très déséquilibrée.

Porcelet. - Les porcelets rachitiques souffrent de leurs articulations et ils ne se déplacent qu'en grognant. Incapables de se relever entièrement, ils marchent avec une attitude caractéristique : les membres antérieurs pliés sous la poitrine et l'appui pris sur le sol par les genoux. Ces animaux ont aussi des crampes, dues à l'insuffisance de calcium 
de leur sang (tétanie), et des spasmes, comme celui de la glotte, qui provoque des crises d'asphyxie. Ces crampes et spasmes sont parfois tellement importants et fréquents qu'ils constituent les symptômes les plus marquants du rachitisme chez lć porcelet.

Chien. - Le chien est très souvent rachitique, dans les villes surtout, et quand il provient d'une forte portée dont la mère n'a pas été suralimentée et traitée par des suppléments minéraux. Certaines races paraissent prédisposées, comme les bergers allemands, les danois, etc. Le chiot rachitique grandit peu et ses articulations "se nouent 》, c'est-à-dire que les épiphyses se tuméfient et font saillie. Tout le long de la poitrine, en arrière des coudes, on sent une série de petites nodosités siégeant sur chaque côte : c'est le " chapelet costal ». L'extrémité de la tête, les os des mâchoires sont gonflés, les yencives sont arrondies, les dents sont jaunes, perdent leur émail, et le remplacement des dents de lait par les dents d'adulte est en retard. Les membres se raccourcissent et se courbent en arcde-cercle. Les tendons s'allongent et le chien devient plantigrade : il prend appui sur le sol par toute la face palmaire jusqu'au poignet et plantaire jusqu'au jarret. La colonne vertébrale peut être déviée en cyphose, lordose et scoliose.

Oiseaux. - Au début, l'appétit est capricieux, irrégulier et dépravé : les sujets recherchent tout ce qui est minéral, graviers, cailloux, débris de plâtre et de ciment, résidus de toutes sortes. La digestion est lente. Le jabot est tendu et dur. De la diarrhée alterne avec de la constipation. L'abdomen est distendu par des fermentations. La peau est sèche et le duvet ne fait place aux plumes que lentement. Les animaux sont indolents, apathiques, se tiennent à l'écart, couchés, le dos rond et l'œil mi-clos.

Bientôt, les lésions osseuses deviennent patentes. Le bréchet est dévié et tordu; lès articulations sont tuméfiées; les os longs s'incurvent et manquent de rigidité. La colonne vertébrale se met en cyphose, lordose ou scoliose. Les poulets hésitent à se déplacer; leurs jarrets, enflarnmés, se blessent par les contacts fréquents et prolongés avec le sol; il en résulte des plaies et des abcès.

Lo rachitisme du poulet peut aussi se traduire par des phénomènes de vertige, des paralysies, des mouvements anormaux de la tête et du cou, des convulsions, de l'essouflement.

On voit encore souvent des déformations du bec (bec croisé); les mâchoires sont molles, déformables, à tel point que ces sujets ne peuvent plus prendre de nourriture.

L'évolution du rachitisme est assez rapide, elle amène la mort s'il n'y est point porté remède a temps.

\section{b) Ostéomalacie.}

La promière phase de l'ostéomalacie se traduit par du pica, c'est-à-dire par la tendance qu'ont les animaux à ingérer, de préférence à leur alimentation normale, des subslances non alimentaires : chiffons, papiers, terre, excréments... Ils lèchent avidement les murs; herbivores, ils mangent des cadavres de petits animaux trouvés dans le fourrage ou dans les pâturages (souris, rats, lapins, oiseaux, etc.), ou même ceux de leurs congénères morts, ou les os restés dans les pâturages après disparition des chairs. Les beaux travaux de Theiler sur l'ostéophagie des bovins d'Afrique du sud et son rôle'dans l'étiologie du botulisme sont trop connus pour que nous insistions sur ce point. Les femelles ont des ovulations sans chaleurs (fausse frigidité), ou de la frigidité temporaire ou permanente:

Dans la seconde période apparaissent des boiteries. L'animal reste longtemps couché et, quand on le fait relever, il marque un temps d'arrêt sur les genioux pliés. Le dos est vouté, la tête est portée basse; la marche est pénible et se fait à petits pas. Les os sont sensibles à la pression.

La dernière période est celle des fractures et du ramollissement osseux, surtout sensible aux mâchoires qui se laissent tordre à la main et perdent leurs dents.

L'ostéomalacie, maladie chronique, a une évolution lente qui peut durer des années avec des alternatives d'amélioration et d'aggravation des symptômes; ce que nous connaissons de son étiologie l'explique.

\section{Prophylaxie et traitement.}

La prophylaxie du rachitisme et de l'ostéomalacie tient toute entière dans l'établissement de rations correctes et, pour les herbivores au pâturage, dans l'amendement des sols. La distribution de vitamine $D$ est une nécessité dans tous les cas où les animaux sont insuffisamment insolés et où l'on n'est pas sûr de la normalité du rapport phospho-calcique de la ration.

\section{L'ostéofibrose}

L'ostéofibrose est une dystrophie osseuse caractérisée par le fait que la place de l'os disparu sous l'action anarchique des ostéoclastes est comblée par du tissu fibreux incapable de fixer les sels de calcium et qui provient d'une transformation de la moelle osseuse. Elle semble surtout résulter d'une hyperphosphatémie.

Chez le cheval, l'ostéofibrose est fréquente; elle 
est d'ailleurs associće au rachitisme. Mais, dans des conditions étiologiques spéciales, on peut remarquer certains symptômes qui sont le fait plus précisément de l'ostéofibrose : il s'agit d'un gonflement, d'une tuméfaction des os de la tête, de la difficulté de la respiration, du déchaussement des dents, des arrachements tendineux à leurs points d'insertion, aux membres.

Les symptômes ont été fort bien décrits et rapportés à leur cause par Carougeau, à Madagascar. En raison de son étiologie, les Italiens appellent encore cette maladie " maladie du son " ou " pytirosis $"$.

Chez le porc, l'ostéofibrose est essentiellement la "maladie du reniflement » : en quelques semaines, la face prend un aspect bouffi et boursouffé, elle semble gonfler de jour en jour; l'animal en arrive à ne plus pouvoir fermer sa bouche ni mastiquer ses aliments; l'os envahit et obture les cavités nasales; la respiration devient ronflante, puis ne peut plus se faire que par la bouche maintenue ouverte. L'amaigrissement et l'anémie surviennent, et l'animal meurt.

La chèvre manifeste l'ostéofibrose par le ramollissement de ses maxillaires inférieurs qui gonflent et se. laissent facilement tordre à la main.

Chez la poule, les os longs, surtout ceux des pattes, deviennent énormes, en fuseau; la croissance se ralentit et les sujets atteints sont nettement plus petits que leurs congénères normaux du même âge. Les pattes se couvrent de grosses écailles dont le développement semble suivre l'hypertrophie des os.

\section{Lésions osseuses de la fluorose}

La fluorose est une intoxication chronique provoquée par l'absorption continue de petites doses de composés fluorés souillant les aliments et les boissons et caractérisée principalement par des lésions osseuses et dentaires, et de la cachexie.

Elle est connue en de nombreux pays. Velu a eu le mérite de reconnaître son rôle dans l'étiologie d'une maladie appelée en Afrique du Nord le "darmous ».

Il a vu notamment que cette maladie était provoquée par l'usage, comme boisson, de l'eau ayant circulé dans des terrains riches en phosphates chargés, comme impureté, de fluor. Ruminants, équidés, et hommes en sont atteints.

Cette maladie ne nous intéresserait pas ici, puisqu'il s'agit d'une intoxication, si, dans sa pathogénie, n'intervenait une carence conditionnée. Bien que ce chapitre soit encore obscur, Hugues Bouley pense que le fluor agit de plusieurs façons :

- par son action toxique propre sur les parenchymes:
- par son action sur le métabolisme général;

- par son action sur le métabolisme calcique.

Dans ce dernier cas, il semble que les fluorures alcalins empruntent du calcium à l'organisme pour se transformer en fluorure de calcium, qui, stable, et inéliminable, se fixe sur les os pour leur donner un aspect marmoréen caractéristique. Ce calcium immobilisé est ainsi soustrait à la réserve calcique à laquelle l'organisme peut faire appel en cas de besoin.

\section{Pica}

Le pica, manifestation d'un appétit dépravé qui pousse les animaux à ingérer des substances non alimentaires ave: une sorte de prédilection, est regardé par tous les auteurs actuellement comme la manifestation d'une carence. Mais il semble bien que cette carence ne soit pas univoque et que les animaux réagissent par du pica à des carences diverses ou multiples.

Il est possible que son origine réside dans des troubles fonctionnels nerveux et, pour notre part, nous on ferions volonticrs unc psychosc, ou plutôt nous verrions le pica survenir et évoluer à l'occasion d'une carence unique ou de polycarence sur des animaux dont le psychisme est primitivement altéré.

Les causes alimentaires se trouvent assez facilement.

Chez les bovins, le pica apparait lors de la disette de fourrages, surtout sur les sujets dont les besoins sont importants, comme les vaches gestantes ou laitières; on le voit aussi au moment du sevrage des veaux, chez les agneaux dont les mères sont mal nourries et qui ont un lait insuffisant. La régularisation du régime le fait alors disparaître sans grande difficulté.

Dans les cas rebelles, l'attention a été portée sur les divers composants de la ration.

Tantôt il s'agit d'une carence protidique (Krupski et coll., Sherman). Le fait est alors fréquent chez les oiseaux, qui guérissent dès que l'on complète la ration en protéines et surtout en protéines d'origien animale (Malke, Krause, Ward et Gallacher, Hart).

Tantôt il s'agit d'une carence minérale. L'hypophosphorose est, nous le savons, un facteur très important de pica, lequel précède ou accompagne le rachitisme et l'ostéomalacie. Lemke. Hess le voient apparaitre sur des animaux qui manquent de calcium. Wilcke, puis Miller et Bearse se sont aperçus que la distribution d'avoine entière à des volailles atteintes de pica et de cannibalisme faisait regresser le vice alors qu'il persiste dans les lots nourris de maïs, de blé, et d'orge. On pouvait penser alors soit à une carence en cellulose, dont le grain 
d'avoine est relativement riche par rapport aux autres, soit à une carence en manganèse, nettement moins abondant dans le mais et l'orge que dans l'avoine. Cependant, la correction de la ration du lot témoin avec du manganèse et de la cellulose montre que ces corps ne sont pas en cause.

On a aussi incriminé l'insuffisance de chlorure de sodium, ou, d'une façon générale, de sels sodiques (Nessler). Zuntz croit à une carence en sodium conditionnée par l'excès de potassium des aliments.

L'étude dés anémies de nutrition au pâturage, dont le pica est un signe important, a attiré l'attention sur les carences en fer (Aston), en cuivre (Sjollema), en cobalt (Askew et Dixon, Underwood).

Les succès thérapeutiques obtenus avec diverses vitamines ont orienté vers l'idée d'une avitaminose multiple, B et D (Zaborowski), $A$ et D (Schultz).

A l'époque de la mue, les phénomènes de picage, de mallophagie sont améliorés par l'administration de soufre, les acides aminés soufrés étant abondants dans les phanères.

I.a seule conclusion d'ensemble qui puisse être tirée de toutes ces études est que le pica ne peut pas être regardé comme la manifestation d'une carence déterminée mais comme un syndrome commun à de multiples carences.

\section{***}

\section{II. - CARENCES EN CORPS DONT L'ORGANISME NE PEUT FAIRE IA SYNTHÈSE}

Parmi les principes alimentaires que reçoivent les animaux, il faut faire une place de choix aux protides. En pathologie tropicale humaine, la carence protidique s'extériorise cliniquement par une grave maladie appelée «kwashiorkor », rencontrée principalement en Afrique noire, aux Indes, en Amérique centrale. On en connaît divers aspects : arrêt de la croissance, apathie, œdèmes, dermatoses, dépigmentation des cheveux et de la peau chez les noirs, lésions du pancréas, cirrhose, etc. La plupart des auteurs sont d'accord pour reconnaitre que cette maladie est le fait d'une insuffisance de la ration protéique et qu'elle guérit dès que l'on rétablit une diète normale, notamment à l'aide de lait écrémé. OrI peut l'éviter en laissant très longtemps. l'enfant au sein de sa mère.

Nous ne connaissons rien d'aussi grave en pathologie vétérinaire. Peut-être la ration des animaux est-elle suffisamment variée pour qu'un minimum de protides y soit présent. L'insuffisance globale de la ration protéique aboutit surtout à une diminution des productions. Mais il convient d'autre part de porter l'attention sur la composition des protides alimentaires, notamment sur leur teneur en acides. aminés essentiels, et nous voulons en traiter rapidement avant d'aborder le grand chapitre des avitaminoses.

\section{a) Acides aminés essentiels}

$80 \%$ des matières sèches des cellules actives des animaux sont des matières azotées qui subissent une dégradation continuelle que signale l'azote urinaire.

A côté des besoins d'entretien, l'organisme doit faire face aux besoins de production : lait, œufs, croissance, laine, etc.

Mitchell, en 1942, a montré qu'on pouvait évaluer les besoins en azote à 2 milligrammes par calorie du métabolisme basal.

Ainsi, pour une vache de $600 \mathrm{~kg}$ dont le métabolisme basal est évalué à $7.600 \mathrm{cal}$., le besoin d'entretien en azote est de $15,2 \mathrm{~g}_{*}$ soit, exprimé en matières albuminoïdes contenant $16 \%$ d'azote, $95 \mathrm{~g}$.

Terroine a donné les chiffres suivants :

En gramme par jour et par kilo de poids vif :

\begin{tabular}{|c|c|}
\hline apin & 0,70 \\
\hline Tolailles & 0,81 \\
\hline hien,$\ldots \ldots \ldots$ & 0,58 \\
\hline n de moins de $40 \mathrm{k} \ldots$ & 0,15 \\
\hline $40 \mathrm{k}$. & 0,1 \\
\hline & 0,2 \\
\hline$(500 \mathrm{k})$ & \\
\hline
\end{tabular}

La mesure des besoins de production est faite en évaluant les quantités de matières albumino:̈des fixées lors de la croissance ou de l'engraissement, éliminées par le lait ou les ceufs, ou nécessaires pour la croissance du foetus et de ses annexes.

Pour couvrir ces besoins, il faudra apporter des quantités suffisantes de protéines et pas trop, l'excès étant aussi préjudiciable que la carence.

Les recherches faites sur l'alimentation proteique ont permis de voir que tous les acides aminés n'avaient pas la même valeur et que certains devaient' être nécessairement fournis aux animaux qui se' montraient incapables d'en faire la synthèse. $\mathrm{Ce}$ sont les acides aminés indispensables.

Les recherches de Osborn et Mitchell, de Mitchell et Block ont montré que la valeur nutritive d'un protide était fonction de l'équilibre des aminoacides qu'il renferme. L'absence, dans un protide considéré, d'un seul amino-acide "indispensable » entraine l'inaptitude du protide à couvrir le besoin azoté. Un protide sera d'autant plus efficace que sa 
composition se rapprochera de celle des protides tissulaires. Inversement, il sera d'autant moins efficace que son équilibre en amino-acides differera de celui de l'organisme.

Milchell el Block ont introduit la notion de «facteur limitant $\%$, qui est l'amino-acide indispensable dont la déficience entraîne l'inaptitude partielle de l'aliment considéré.

Pour comparer l'efficacité des différents protides, Mitchell et Block se servent des protides de l'œuf entier comme standard de référence. Connaissant la teneur en amino-acides des protides de ce dernier et celle d'autres aliments, ils calculent les différences et les expriment en pourcentage.

Ainsi, les protides de l'œuf renferment $7,2 \%$ de lysine, les protides de l'arachide $3 \%$. In différence est de $-4,2$, le pourcentage de déficit sera de $-4,2: 7,2=-58 \%$.

Plus lo déficit du facteur limitant sera élevé plus médiocre sera l'efficacité in vivo.

Jacquot résume ainsi quelques résultats :

\begin{tabular}{|c|c|c|c|}
\hline PROTIDES & $\begin{array}{c}\text { FACTEUR } \\
\text { limitant }\end{array}$ & \begin{tabular}{|} 
POUR- \\
CENTAGE \\
de \\
déf́cit
\end{tabular} & $\begin{array}{c}\text { EFFICA- } \\
\text { CITÉ } \\
\text { protéique } \\
\text { in vivo (*) }\end{array}$ \\
\hline Euf entier.. & Standaid & 0 & 3,8 \\
\hline \multicolumn{4}{|l|}{ Tourteaux de : } \\
\hline Tournesol. & Lysine & -47 & 2,5 \\
\hline Soja cuit. . & Méthionine & -51 & 2,3 \\
\hline Sésame. & Lysine & -61 & ? \\
\hline Coton cru & Lysine & -63 & 2 \\
\hline Coprah.... & Valine & -63 & 2 . \\
\hline Palmiste ... & Méthionine & -63 & 2 \\
\hline $\operatorname{Lin} \ldots \ldots \ldots$ & Lysine & -65 & 1,9 \\
\hline Arachide & Am. ac. soufrés & -69 & 1,9 \\
\hline Viandes & Méthionine & -29 & 3,2 \\
\hline Lait sec ... & Méthionine & -32 & 2,9 \\
\hline Blé........ & Lysine & -63 & 1,5 \\
\hline Maïs. . . . . . & Lysine & -72 & 1,2 \\
\hline rotides inge & ids, en g., & rat, & ar g de \\
\hline
\end{tabular}

Mitchell a émis l'idée que tous les acides aminés pouvaient être synthétisés par les organismes animaux et que la différence entre acides amirnés banaux et essentiels dépendait du rythme de la synthèse. Pour les acides banaux, le rythme de la demande est inférieur à celui de la synthèse alors que, pour les acides indispensables, le rythme de la demande dépasse celui de la synthèse.
Rose a confirmé cette conclusion en montrant que si l'arginine ćtait indispensablo à la croissance du rat, ce dernier pouvait satisfaire à ses besoins si cette croissance n'était pas trop rapide.

Pratiquement, les animaux à croissance rapide (volailles) ont besoin d'un plus grand nombre d'acides aminés essentiels que ceux à croissance lente (bovins), d'où la complexité des formules alimentaires pour les oiseaux.

Certains états pathologiques peuvent augmenter la demande en acides aminés, en particulier en acide glutamique.

De plus, il existe des interactions entre différents acides aminés : si la tyrosine est contenue dans la ration à une dose inférieure à $1 \%$, la phénylalanine est indispensable; si elle est contenue à une dose supérieure à $3 \%$, la phénylalanine n'est plus indispensable.

La tyrosine est transformée en phénylalanine et couvre ainsi les besoins en cet acide aminé.

Quand, dans la ration, le taux de cystéine baisse, les besoins en méthionine augmentenl', mais l'inverse ne s'observe pas. On ne peut couvrir les besoins en méthionine par apport de cystéine; l'organisme ne peut faire la synthèse de la méthionine à partir de la cystéine, donc la méthionine a un caractère plus indispensable que la cystéine.

Terroine a donné des listes d'acides aminés banaux et indispensables :

\section{Acides aminés insuffisamment étudiés :}

Alanine,

Valine,

Sérine,

Leucine.

Acides aminés inutiles pour la croissance et l'entretien:

Clycocolle (indispensable au poulet),

Ac. aspartique,

Ac. glutamique,

Ac. hydroxyglutannique.

Acides aminés probablement inutiles pour la croissance et l'entretien :

Proline,

Arginine (indispensable à la croissance du rat).

Acides aminés douteux pour l'entretien :

Cystine,

Tyrosine,

Phénylalanine.

Acide aminé tress vraisemblablement necessaire pour l'entretien :

Histidine. 
Acides aminés de nécessité certaine: pour l'entretien : pour la croissance : Tryptophane

$$
\begin{gathered}
\text { Cystine, } \\
\text { Histidine, } \\
\text { Lysine, } \\
\text { Méthionine. }
\end{gathered}
$$

\section{Carence protidique.}

Les déficiences en protéines ou en acides aminés essentiels, de la ration déterminent des signes cliniques qui ne sont pas spécifiques, ils ressemblent à ceux que l'on observe dans la sous-alimentation :

Chez tous les mammifères un régime carencé en protéines entraîne le repos sexuel.

L'existence de périodes d'inactivité sexuelle chez les ruminants sous les tropiques pourrait s'expliquer par la subcarence protéinique à laquelle les animaux sont soumis à la fin de la saison sèche.

Le jeûne protidique favorise l'éclosion des maladies infectieuses et parasitaires.

Ainsi les moutons recevant des tourteaux sont plus résistants aux trichostrongyloses que les témoins, de même les volailles soumises à un régime pauvre en protides sont plus abondamment infestées par Ascaridia lineata.

Les infections à protozoaires sont, comme les helrninthiases, influencées par la carence protidique : aggravation des leishmanioses (Ritterson, Kirk, Corkill), aggravation du parasitisme expérimental des poussins (Seeler et Ott).

Dans certains cas, les déficiences protidiques peuvent inhiber ou, tout au moins, ralentir l'établissement d'un état d'immunité ou de prémunition.

Dans la lutte anti-infectieuse et antiparasitaire, les protides interviennent (Euzéby) :

10 par leur action eutrophique générale;

$2^{\circ}$ par leur action compensatrice des spoliations causées par les parasites;

$3^{\circ}$ en favorisant l'élaboration de $1^{\prime}$ hémoglobine et en s'opposant à l'action anémigène de certains parasites;

$4^{\circ}$ en favorisant la synthèse des globulinesanticorps.

Ainsi s'expliquent, sans aucun doute, les effets nocifs de la carence sur la réceptivité aux protozooses et les défaillances de l'immunité.

Choz les volailles, les accidents portent sur la croissance et la fécondité.

\section{B) AVITAMINOSES}

\section{AVITAMINOSE $\AA$.}

La vitamine $\AA_{\text {, liposoluble, est encore désignée }}$ sous son nom chimique d'axérophtol et, d'après ses fonctions, sous les noms de vitamine antixérophtalmique, vitamine de protection épithéliale, vitamine de croissance.

Elle provient du dédoublement hydrolytique d'un pigment tres répandu dans les végétaux, le carotène, qui est par conséquent sa provitamine et qui est doué de la même action physiologique que la vitamine elle-mëme du fait que cette transformation est aisément réalisée par les animaux, notamment dans le foie.

On peut donc dire que le carotène et l'axérophtol ont des propriétés semblables en tant qu'activité vitaminique $A$.

D'ailleurs l'Unité Internationale de Vitamine A est définie par l'activité de $0,6 \gamma$ de carotène $\beta$ étalon. Ce carotène $\beta$ se dédouble pour donner 2 molécules d'axérophtol tandis que son isomère, carotène $\alpha$, n'en fournit qu'une molécule et est, par conséquent, deux fois moins actif.

D'autres pigments sont doués également d'une plus ou moins grande valeur en tant que provitamine $A$, on les confond généralement sous le nom de caroténoildes.

Les végétaux verts sont la source principale de provitamines $A$. Cependant, la fonction chlorophyllienne n'est pas indispensable à leur synthèse puisque certaines bactéries peuvent en élaborer.

Le degré de verdure est cependant in excellent indice de la richesse en caroténoïdes. Kramer a constaté que les feuilles vertes des laitues contenaient 30 fois plus de carotène que les feuilles jaunes du coeur de cette plante.

La richesse en caroténoïdes varie au cours de la vie de la plante.

Le maximum est atteint peu de temps avant la floraison. Si les plantes restent sur pied après la floraison, elles perdent rapidement leurs provitamines dont le taux diminue de plus de $50 \%$ en trois semaines.

La fenaison en plein air, au soleil, prive les fourrages d'une grande partie de leur carotène, près de $80 \%$ comme il est indiqué dans le tableau de la page suivante.

Mme Randoin et Simmonet indiquent que sl le foin est séché à l'abri du soleil, il n'y a pas de perte de carotène au cours du séchage; selon eux, le meilleur foin est celui qui, récolté avant la floraison, est séché à' l'abri du soleil dans uno atmosphère non humide qui évite les fermentation. Ces conditions sont remplies dans les séchoirs industriels qui sont utilisés: pour fabriquer les farines de luzerne.

Fairbank a montré que les plantes qui séchaient sur pied ou brunissaient par la sécheresse perdaient leurs provitamines.

Récemment, Ferrando, Jouanneteau et Mme Brenot, examinant par spectrographie des fourrages ensilés, 
se sont aperçus d'une dislocation de la molécule du carotène que ces fourrages contenaient au moment de la mise en silo. Cette dislocation est plus ou moins importante selon les échantillons. Ceci n'implique pas que les produits de cette transformation soient totalement dépourvus d'activité vitaminique $A$, des dosages biologiques permettront ultérieurement de le savoir.

Destruction du carotène

par le séchage lors de la fenaison

(d'après Knut Rottensten)

\begin{tabular}{|c|c|c|c|c|}
\hline $\begin{array}{l}\text { HEURES } \\
\text { après } \\
\text { la coupe }\end{array}$ & $\begin{array}{c}\text { TEMPS } \\
\text { d'exposition } \\
\text { au soleil }\end{array}$ & $\begin{array}{l}\text { EAU } \\
(\%)\end{array}$ & 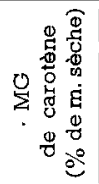 & $\begin{array}{l}\text { CAROTENE } \\
\text { sur la teneur } \\
\text { initiale } \\
(\%)\end{array}$ \\
\hline 0 & $0 \mathrm{ho} \mathrm{m}$ & 65,3 & 25 & 100 \\
\hline 1. & $54 \mathrm{~m}$ & 59,1 & 22 & 88 \\
\hline $3 \ldots$ & $2 \mathrm{~h} 54 \mathrm{~m}$ & 47,8 & 2.1 & 84 \\
\hline $6 \ldots$ & $5 \mathrm{~h} 27 \mathrm{~m}$ & 38,6 & 16,8 & 67,2 \\
\hline 24 & $\theta \mathrm{h} 57 \mathrm{~m}$ & 35,5 & 15,4 & 61,6 \\
\hline $48 \ldots$ & $16 \mathrm{~h} 32 \mathrm{~m}$ & 35,1 & 13,4 & 53,6 \\
\hline $72 \ldots$ & $24 \mathrm{~h} 32 \mathrm{~m}$ & 24,8 & 6,3 & 25,2 \\
\hline $96 \ldots$ & $30 \mathrm{~h} 45 \mathrm{~m}$ & 16,2 & 5,3 & 21,2 \\
\hline
\end{tabular}

La teneur des plantes fourragères en carotène est extrêmement variable. Sont considérées comme bonnes sources : les herbes vertes et surtout les légumineuses, notamment la luzerne, le maïs jaune, les carottes, les feuilles d'olivier, les feuilles de roseaux. Par contre, la plupart des graines de céréales, les betteraves, les pommes de terre, les tourteaux, les drèches en sont très pauvres ou même totalement dépourvus.

Quant à l'axérophtol, on le trouve presque uniquement dans les huiles de foie de poisson, morue, flétan, thon, requin surtout. L'industrie commence à en livrer à l'état pur, qu'il soit obtenu par distillation moléculaire des huiles de poisson ou par synthèse. Il est alors à l'état d'ester, de palmitate notarmment.

\section{Métabolisme de la vitamine $A$.}

Une partie des caroténoïdes ingérés est détruite dans le tube digestif ( 20 à $40 \%$ ), une autre est excrétée intacte dans les fèces. Enfin, une très faible proportion est absorbée au niveau de la muqueuse intestinale et atteint la circulation sanguine. Elle y a deux destinées : elle reste à l'état de provitamine ou bien est transformée par les processus biologiques en vitamine $A$, dans le foie.
Le mécanisme de mise en réserve des caroténoïdes varie avec les espèces : les bovins accumulent de grandes quantités de carotène, à l'exclusion des xanthophylles, dans leur graisse de couverture, ce qui lui donne sa couleur jaune. Les porcs et les petits ruminants transforment les pigments en vitamine A pour les stocker dans le foie et leur graisse, de ce fait, reste blanche.

Les teneurs du sérum et du lait en carotène varient avec l'alimentation. Le taux augmente rapidement dès la mise au pâturage : ainsi le lait de vache qui contient $50 \%$ pour $100 \mathrm{~cm}^{3}$ en hiver en renferme 200 en été. Les valeurs maximales s'observent aux ćpoques de la poussée de l'horbo.

La transformation du carotène en vitamine $A$ dans l'organisme s'accomplit sans doute dans le système réticulo-endothélial, au niveau des cellules de Küppfer du foie, sous l'influence d'une diastase, la caroténase, elle-même activée par la thyroxine qui pernet une scission hydrolytique du carotène.

Chez la poule, Von Euler a constaté la transformation de la provitamine en vitamine dans le sérum sanguin. Le stockage de la vitamine $A$ se fait en grande partie dans le foie. Hart et Guilbert ont trouvé que ce dernier gardait en réserve 67 à $93 \%$ du total de la vitamine $A$ alors que dans les graisses il y a surtout du carotène.

La teneur du tissu hépatique en vitamine $A$ varie avec les espèces, ainsi on trouve par gramme de tissu hépatique :

\begin{tabular}{|c|c|}
\hline Cheval. & $50 \mathrm{UI}$ \\
\hline Bœuf & 40 à 100 UI \\
\hline Mouton & 100 à 300 UI \\
\hline Porc & 3 à 30 UI \\
\hline
\end{tabular}

Les chiffres indiqués sont des extrêmes car la teneur du foie en vitamine varie avec l'âge des animaux et surtout leur régime.

La vitamine A se fixe dans le foie pendant la vie fœtale et constitue une réserve hépatique à la naissance.

La vitamine $A$ est excrétée par le lait comme le carotène selon Cunningham. Un litre de lait de vache peut, en été, en contenir jusqu'à 1.000 U. I. Bien entendu, le lait écrémé en est privé.

Février et ses collaborateurs étudiant des laits moyens de vaches hollandaises ont constaté, que dès que les animaux sont retirés du pâturage, les taux du carotène et de la vitamine $A$, qui sont à cette époque respectivement de 300 et $200 \gamma$ par litre, baissent très rapidement pendant 7 semaines, puis plus lentement jusqu'à atteindre leurs valeurs minimales respectives de 30 et $90 \%$, en avril, à la fin de la stabulation.

Le colostrum est très riche en vitamine A : 9 à 16,8 mg par kilo le premier jour. D'après Dann, 
le veau reçoit par le colostrum, le premier jour de sa vie, uno quantitó do vitamine égale à celle que le ait lui apportera en 30 à 50 jours. Le taux du colostrum en 'vitamine $A$ baisse rapidement dès le $4 \mathrm{e}$ jour.

La richesse du colostrum en vitamine $\bar{A}$ est indépendante de l'alimentation de la mère au moment de l'accouchement; elle est fonction des quantités de provitamines et de vitamine stockées pendant la dernière période de gestation; ces quantités sont d'autant plus importantes que la période du repos de la mamelle a été plus longue.

\section{Pathologie.}

La carence en vitamine $A$ se traduit essentiellement :

a) par l'arrêt de la croissance,

b) par des modifications des épithéliums entraînant des troubles divers selon l'organe considéré,

c) par des lésions nerveuses portant principalement sur la vision,

d) par une prédisposition aux maladies infectieuses et parasitaires.

a) I'arrêt de la croissance est l'un des phénomènes les plus marqués chez les jeunes. Il existe dans toutes les espèces animales. Son importance économique est considérable parce que les carences frustes en vitamine $A$ peuvent ne pas entrainer de manifestations pathologiques nettes mais se traduire par un ralentissement de la croissance qui n'est perceptible que si l'éleveur fait des pesées régulières.

b) Tous les auteurs ont signalé dans l'avitaminose $A$ des modifications de la structure des épithéliums; les plus apparentes parce qu'elles siègent au niveau de la cornée ont valu le qualificatif d'antixérophtalmique à la vitamine $A$. La couche superficielle de l'épithélium conjonctival se kératinise et il se forme des granulations kérato-hyalines dans la couche profonde. A un stade plus avancé, apparaissent des ulcères de la cornée.

Sur la peau, on observe de la "crasse», de l'exanthème, des érosions, de la rudesse du pelage et des alopécies partielles.

L'épithélium cylindrique des muqueuses est séparé de son support originel mésenchymateux et remplacé par un épithélium stratifié, éléidinokérato-hyalin, avec dégénérescence caséeuse ou caséo-fibreuse. Les épithéliums glandulaires sont également kératinisés ou nécrosés; la kératinisation des conduits glandulaires qui entraine souvent leur obstruction précède celle des acini.

Des lésions du type de celles qui ont été décrites ci-dessus sont observées sur les muqueuses digestives et respiratoires : les ulcérations punctiformes de la langue précéderaient celles de la cornée. Dans l'intestin, on observe des lésions de nécrose des villosités è on a trouvé des lésions polypoïdes dans les bronches de rats carcncés.

Les modifications épithéliales des tubes contournés des reins seraient, d'après Van Leersum et De Langerı, la cause de la lithiase urirdaire observée fréquemment dans l'avitaminose $\mathbb{A}$ des veaux.

On attribue également à cette dernière la néphrite appelée "gros rein blanc ».

Ces lésions rénales sont particulièrement importantes chez le poulet et donnent naissance à une affection mortelle, la "goutte viscérale», chez les animaux qui reçoivent trop de protéines. L'acide urique, terme ultime de la dégradation des protéines chez les oiseaux, ne peut plus filtrer à travers le rein et se dépose en cristaux blanchâtres sur les organes internes.

La stérilité et les' troubles génitaux, si fréquents dans l'avitaminose $A$, sont les conséquences des modifications des épithéliums.

Chez le mâle, l'épithélium séminifère dégénère, les éléments de la lignée séminale disparaissent et le tissu interstitiel se charge de graisse. Ces modifications peuvent s'atténuer et l'activité redevenir normale si le régime carencé n'est pas donné pendant trop longtemps.

Chez les femelles, on a trouvé des lésions sur tous les épithéliums de l'appareil génital :

La dégénerescence de l'épithélium de la paroi du follicule de De Graaf entraîne la mort de l'ovocyte et fréquemment la dégénérescence kystique du follicule; l'ovaire devient polykystique et cesse de fonctionner.

Sur l'endomètre, la kératinisation de l'épithélium empêche la nidation et, si la nidation est antérieure à la carence, ou si cette dernière est fruste, les lésions qui intéressent alors l'endomètre et le placenta troublent la nutrition du foetus qui peut mourir, être expulsé ou momifié.

Les lésions au niveau de la liaison endomètreplacenta expliquent les rétentions placentaires ainsi que l'existence de lésions d'avitaminose $A$ chez les veaux de quelques jours : cataractes congénitales, lésions intestinales, ces dernières souvent causes d'entérite.

La kératinisation du vagin (colpokératose) détermine de l'œstrus permanent non suivi d'ovulations.

Ainsi, la stérilité due à l'avitaminose $A$ peut être provoquée par des lésions trc̀s diverscs dont l'origine alimentaire pourrait expliquer les échecs de certaines thérapeutiques symptomatiques, humorales ou chirurgicales.

Expérimentalement, il a été démontré que la vitamine $\mathbb{A}$ intervenait pour hâter les processus de réparation des tissus lésés.

Ishido a été le premier, en 1922, à montrer cette propriété; les animaux carencés ne cicatrisent pas 
leurs plaies si leur réserve de vitamines est épuisée; l'application directe de vitamine A sur les plaies hâte l'épidermisation et la formation de granulations.

Escarras et Paillas, dans une série de recherches portant sur les cultures de tissu et sur les modifications histologiques des plaies au niveau desquelles ils appliquaient les préparations de vitamine $A$, ont montré que le facteur $A$ déterminait une reproduction intense de tissu conjonctif.

c) Les modifications de la vision sont souvent assez marquées, chez le veau surtout, pour attirer l'attention des éleveurs. La cécité congénitale est fréquente. Elle est due à diverses lésions : sténose du canal optique avec névrite optique, œdème de la papille, atrophie, dégénérescence du nerf optique. Chez les veaux plus âgés, la cécité peut être précédée par une conjonctivite purulente ou simplement catarrhale, du nystagmus, de la paralysie pupillaire, de la décoloration de l'iris, un blanchiment du tapis clair; l'héméralopie est l'aboutissement premier de ces lésions qui amènent à la cécité totale au bout d'un temps plus ou moins long. Il va sans dire que tout ce tableau peut être modifié par la xérophtalmie.

d) Prédisposition aux maladies infectieuses et parasitaires. - La vitamine $\mathrm{A}$ a un rôle cytophylactique très important. Joyet-Lavergne la considère comme un facteur de multiplication cellulaire, ce qui expliquerait l'augmentation des besoins en facteur $A$ à certaines périodes de la vie de l'animal : puberté, croissance.

La vitamine A jouiant un rôle dans le métabolisme des lipides (Randoin, Simonnet), l'avitaminose entraînera une diminution de la teneur en lipides des cellules, ce qui déterminera une véritable inanition cellulaire et une rupture de l'équilibre colloïdal du sérum.

Ainsi, dans l'avitaminose $A$, la métaplasie épithéliale supprimant la protection mécanique de l'organisme, et le ralentissement de l'activité cellulaire diminuant la protection physiologique assurée par le système réticulo-endothélial, la carence en facteur A créera dans l'organisme animal des conditions favorables au développement des agents infectieux et parasitaires.

Mouriquand et Nicolau ont constaté que le nombre des germes à la surface de la cornée augmente considérablement dès qu'apparaissent les premiers syptômes d'avitaminose $A$ et qu'ils sont responsables de la suppuration et des ulcères cornéens qui peuvent être évités par des traitements locaux.

Werkmann et ses collaborateurs ont trouvé le lapin carencé en facteur $A$ plus sensible à la bactéridie charbonneuse et au pneumocoque que ceux qui reçoivent une alimentation normale; Green et Mellamby ont confirmé l'observation relative au pneumocoque et trouvé de même une sensibilité plus grande des carencés à la Pasteurella.

Michalka considère l'avitaminose A comme la cause favorisante des épizooties de peste porcine observées en hiver et au printemps.

On doit voir plus qu'une coïncidence dans le fait que les épidémies de pasteurelloses, de colibacilloses, de streptococcies soient observées dans les régions tempérées en hiver et au printemps et que les septicémies hémorragiques s'observent en zone tropicale à la fin de la saison sèche.

Lesbouyriès et Charton pensent qu'il n'est pas douteux que nombre de septicémies de jeunes nés à la fin de la mauvaise saison, ou issus de mères carencées à n'importe quelle période de l'arnnée en facteur $A$, doivent être rapportées à la dégénérescence des épithéliums digestifs et respiratoires (diarrhées colibacillaires ou paratyphiques, bronchopneumonies pasteurelliques ou streptococciques).

Smith et Little. Stewart et Mc Collum, en prouvant l'influence néfaste de la faible teneur en facteur $A$ du colostrum dans l'éclosion des infections colibacillaires du veau, confirment les vues de Tiesboinyries et Charton.

Le rôle de l'avitaminose $A$ dans l'évolution des affections parasitaires a été particulièrement bien étudié.

Les premières observations sont celles d'Ackert ct Hcrrick qui ont trouvé que, chez les poulets carencés en facteur $\mathrm{A}$, le nombre moyen d'Ascaridia lineata était le double de celui des témoins et que les parasites étaient plus longs chez les poulets carencés que chez les sujets normaux.

Wright a observé, chez les chiots infestés expérimentalement par Toxocara canis et Toxascaris leonina, que l'infestation était cinq fois plus forte chez les carencés que chez les sujets non carencés. En uutre, les pneumonies vermineuses évoluent chez les plus jeunes chiots, pneumonies déterminées par les larves migratrices des ascarides, qui ne, sont plus victimes de la phagocytose, comme Callot et ses collaborateurs l'ont montré.

Expérimentalement, Clapham a vérifié qu'un régime carencé en facteur $A$ augmentait la sensibilite des rats à l'infestation par Parascaris equorum. Schwarts, Lucker et Allicata, Splinder ont fait les mèmes constatations en utilisant Nippostrongylus muris.

Witlock et ses collaborateurs attribuent l'apparition de l'haemonchose à la fin de l'été chez les agneaux, à une teneur trop faible des fourrages en facteur $A$, ce dernier étant détruit, comme nous l'avons indiqué plus haut, par la forte insolation et la sécheresse.

Brizard dit que des vétérinaires allemands ont vu apparaitre des enzooties de coccidiose bovine 
sur des animaux carencés en vitamine $A$ dans les régions où cette maladie n'avait pas encore été observée.

Les lésions de l'épithélium cutané favorisent l'apparition de parasitoses externes : teignes à Trichophyton mégaspores chez les veaux, démodécie chez les chiots.

Chez le porc, le rôle de l'avitaminose $A$ dans l'évolution du parasitisme n'a pas été démontré de façon aussi nette que chez les autres animaux domestiques; cependant Hiraishi et Koidzumi ont réussi à infester expérimentalement avec Ascaris lumbricoides des porcs carencés, mais ont échoué avec des porcs recevant une nourriture équilibrée.

\section{Étude clinique.}

Bovidés, - Les manifestations les plus spectaculaires de I'avitaminose $A$ se voient chez les jeunes veaux. Certains, issus de mères carencées, nés sans réserve hépatique suffisante, en présentent des syptômes dès leur naissance. Chez les autres, les troubles n'apparaîtront qu'au bout d'un temps plus ou moins long en fonction de l'intensité de la carence.

En général, le début est insidieux et ce sont les phénomènes oculaires, notamment l'héméralopie, qui attirent l'attention. Tes veaux se heurtent à tous les obstacles, se conduisent comme des aveugles dès qu'ils se trouvent dans un endroit sombre, notamment à l'étable.

L'arrêt de la croissance est constant, mais il n'est pas toujours très perceptible, à son début tout au moins, si l'on ne dispose pas d'animaux de comparaison.

Surviennent alors des troubles digestifs : ulcérations buccalcs. avec ptyalisme, qui peuvent en imposer pour de la fière aphteuse; constipation alternant avec de la diarrhée.

Des ulcères de la caillette et de l'intestin peuvent se développer, mais on ne les trouvera qu'à l'autopsie.

Les troubles respiratoires ne sont pas rares : tantôt simple coryza, ils peuvent gagner l'arbre aérifère et le poumon et se caractérisent comme des bronchiles el broncho-preunnories.

Nous avons vu plus haut que la lithiase urinaire et le "gros rein blanc» pouvaient être considérés comme des manifestations de l'avitaminose $A$.

On a encore signalé la raideur de la démarche, des tremblements musculaires, des contractures, de la tétanie, des crises convulsives.

Les veaux carencés dès la naissance meurent rapidement, Les autres traînent, deviennent la proie du parasitisme et des infections. Non-valeurs économiques, ils succombent en grande partie s'il n'est pas porté remède à la carence dont ils souffrent avant que les lésions ne soient devenues incurables.
Les adultes sont bien plus résistants que les jeunes parce que la vitamine $A$ dont ils ont besoin n'est plus utilisée pour la croissance. L'avitaminose A se manifeste alors surtout sur les phénomènes de la reproduction. Les génisses et taurillons présentent de l'hypoplasie génitale qui, lorsqu'ils seront nubiles, gênera ou empêchera totalement leur reproduction.

Les mâles sont sans désir sexuel ou bien, effectuant normalement des saillies, sont stériles parce que leur sécrétion spermatique est insuffisante ou parce qu'ils ont de l'azoospermie. Chez les femelles, la puberté est retardée, les chaleurs sont discrètes. La nidation des cufs ne se fait pas ou bien l'on assiste à des avortements précoces ou tardifs.

Nous noterons encore que certains auteurs, comme Patton, Mac Kay, Burt, etc., regardent l'acétose des vaches laitières comme une manifestation d'avitaminose $A$ et que des succès thérapeutiques ont, en effet, été obtenus dans cette affection par l'administration d'huiles de foie de poissons.

Porcs. - L'avitaminose $A$ est particulièrement fréquente dans cette espèce partout où les animaux sont élevés à l'intérieur de bâtiments. Le libre parcours sur des espaces herbeux constitue la mesure prophylactique la plus efficace.

L'avitaminose $\AA$ des porcelets débute en général après le sevrage. Les troubles observés sont très divers. La croissance se ralentit et s'arrête. On note des troubles oculaires discrets. La peau se couvre de «crasse »; les soies sont clairsemées, grosses, ternes. Les sujets ont un aspect vieillot. C'est sur ces animaux que l'on constate le syndrome que l'on a appelé « convulsions» ou «tremblements》 des porcelets et qui ressemble étonnamment à des crises épileptiques. On a remarqué que les signes d'avitaminose apparaissent 'd'abord chez les plus beaux sujets des portées, sans doute parce que, en raison de leur rapide développement, ils ont des besoins accrus en vitamine $A$.

Chez les adultes, ce sont les fonctions de reproduction qui sont atteintes de préférence : frigidité, avortements, accouchements de morts-nés ou de petits chétifs, parfois difformes, rétention de placenta, dystocies. On a remarqué aussi des convulsions, des paraplégies, un exanthème cutané, des troubles digestifs avec ulcérations intestinales. Lesbouyriès estime que l'œdème et l'emphysème intestinaux, connus de longue date, sont dus à de l'avitaminose $A$.

Volailles, - Comme pour le porc, l'avitaminose $A_{1}$ si elle ne provoque pas une mortalité importante, est grave économiquement par l'arrêt de la croissance qu'elle produit.

Elle survient surtout à la fin du premier mois de 
la vie et se manifeste avec le maximum d'intensité pendant le $2^{\mathbf{e}}$ mois. Lorsque l'avitaminose a débuté dans l'œuf, les premiers symptômes se voient dès la $3^{\text {e }}$ semaine.

Le signe avertisseur le plus marquant est la diminution du croît qui s'accuse de semaine en semaine : $10 \mathrm{~g}, 20 \mathrm{~g}, 45 \mathrm{~g}, 80 \mathrm{~g}$. On remarque aussi de la torpeur, de la faiblesse, une diminution de l'appétit, la pâleur des pattes, du bec, de la peau. La démarche est chancelante et difficile.

Localement, on pourra noter de l'cedème et des plaques caséeuses sur les paupières, du jetage nasal, du gonflement des sinus, une dermite vésiculaire du dessus des pattes et de la tête.

Cette avitaminose est une cause prédisposante des bronchites et de la coccidiose. Nous avons vu qu'elle entraîne aussi une néphrite qui permet l'éclosion de la «goutte viscérale».

\section{Prophylaxie et traitement.}

Les herbivores qui peuvent pâturer des végétaux verts reçoivent assez de carotène pour que leurs besoins soient couverts. Mais les autres animaux doivent obligatoirement recevoir des rations vitaminisées toutes les fois que l'on n'est pas très sûr d'apporter le carotène nécessaire avec les aliments, soit que leur teneur en soit inconnue, soit que l'on ait des doutes sur sa conservation.

La source de vitamine A la plus courante actuellement est l'huile de foie de poissons. Encore convient-il de savoir que ces huiles perdent leur vitamine $A$ avec le temps et surtout que cette vitamine se détruit très vite, parfois en quelques jours, lorsqu'elle est mélangée à des aliments pulvérulents contenant des substances minérales. Il est donc préférable de faire, lorsque la chose est possible, la distribution d'huile de poissons chaque jour, en même temps que la distribution de nourriture. On peut également, ce qui est infiniment plus commode, avoir recours à des préparations livrées prêtes pour l'emploi par l'industrie, dans lesquelles l'oxydation de la vitamine est empêchée, tantôt par son enrobement dans des substances qui la protegent des contacts avec l'oxygène, tantôt par la présence de corps dits anti-oxydants parce que, réducteurs, ils absorbent l'oxygène disponible dans le milieu.

\section{AVITAMINOSES B.}

Après la découverte initiale de Eijkman en 1890 , mettant en évidence l'action préventive et curative de l'enveloppe du grain de riz vis-à-vis du "éribérib». divers travaux aboutirent à l'isolement du principe actif hydrosoluble qui fut désigné sous le nom de vitamine $B$, facteur antibéribérique ou antinévritique.
Cette notion de viramine $\mathrm{B}$ simple devait bientôt se compliquer du fait de la découverte, en 1926, à côté de la vitamine antibéribérique, thermolabile, d'un autre facteur hydrosoluble, mais thermostable, indispensable à la croissance et que la Biological Society de Londres devait, en 1927, appeler vitamine $B_{2}$, réservant à la vitamine antinévritique le nom de vitamine $B_{1}$.

A ces deux facteurs du complexe $B$ devaient bientôt s'adjoindre d'autres corps, isolés pour la plupart d'extraits de levure ou de foie et doués de propriétés particulières.

On compte actuellement une quinzaine de ces corps; si l'opinion est unanime pour en classer certains dans le groupe $B$, pour a'autres, les auteurs ne sont pas d'accord.

Du point de vue physiologique, on peut dire que les vitamines du groupe B, qui sont toutes hydrosolubles, ont en commun la particularité de participer de façon active à certains métabolismes fondamentaux, indispensables à la vie de toute cellule et, en particulier, au métabolisme des glucides.

Le catabolisme glucidique est caractérisé par l'action de déshydrogénases spécifiques dans la composition desquelles interviennent des vitamines du groupe $B$ : $\left(B_{2}, B_{1}, P\right.$ P).

La pathologie a montré les relations étroites qui existent entre les différents facteurs du groupe B en ce qui concerne l'étiologie et les signes cliniques des avitaminoses correspondantes.

Que les carences soient d'origine exogène ou endogène, elles sont généralement multiples, sinon globales, et nécessitent une thérapeutique polyvitaminique $B$.

Du point de vue clinique, on doit reconnaître certaines similitudes entre les différentes manifestations carentielles des facteurs du groupe B. Ia plupart consistent en troubles du métabolisme glucidique, troubles cutanés, digestifs et, nerveux et, chez les jeunes, arrêt de la croissance.

La classification des différents constituants du groupe vitaminique $B$ est nécessairement artificielle; aussi étudierons-nous tout d'abord les constituants majeurs, les mieux connus, ceux qui semblent avoir la plus grande importance du point de vue de la pathologie; puis les constituants mineurs moins connus, qui semblent moins importants; enfin nous laisserons les facteurs mal connus dont l'existence ou I'appartenance au groupe B sont discutées.
Constituants majeurs :
Vitamine $\mathrm{B}_{1}$,
Vitamine $\mathrm{B}_{2}$
Vitamine $\mathrm{P} P$,
Facteurs antianémiques : Acide folique, Vitarnine $B_{12}$. 


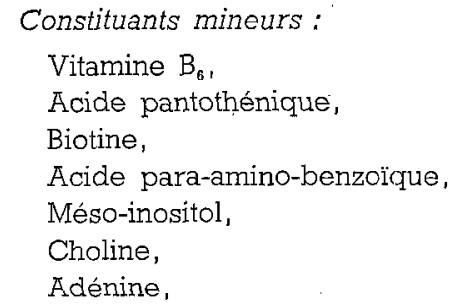

Facteurs hypothétiques:

Vitamine $B_{10}, B_{11}$,

Facteurs R-S.

Facteur G P F 3.

\section{VITAMINE B1}

La vitamine $B_{1}$ est encore appelée aneurine, en raison de son action sur le système nerveux, ou thiamine en raison de sa nature chimique.

Dans le groupe $\mathrm{B}$, la vitamine $\mathrm{B}_{1}$ est la plus fragile, c'est dono celle qui risque le plus de se trouver en quantité insuffisante dans la ration.

La vitamine $B_{1}$ est une substance cristalline, blanche, soluble dans l'eau, dans l'alcool à 700, dans l'acide acétique.

Elle est très peu stable vis-ă-vis de la chaleur. Elle est détruite par une ébullition prolongée ou par chauffage à l'autoclave. Sa destruction en milieu alcalin, qui commence à la température ordinaire. est très rapide à chaud.

On admet que la cuisson diminue de moitié la teneur des aliments en vitamine $B_{1}$ et que les fourrages ensilés n'en contiennent presque plus.

La vitamine $B_{1}$ est stable en présence des oxydants acides.

La formule de la vitamine $B_{1}$ a été précisée par les travaux de Peters, Van Veen, Windaus, Making et Ismai, Williams; ce dernier auteur, ayant réussi à séparer la vitamine $B_{1}$ en deux parties dont l'une est un dérivé de la pyrimidine el l'autre un dérivé du thiazol, a proposé une formule voisine de celle qu'avaient donnée Makino et Ismai.

Formule brute: $\mathrm{C}_{12} \mathrm{H}_{17} \mathrm{ON}_{4} \mathrm{~S} \mathrm{Cl}$.

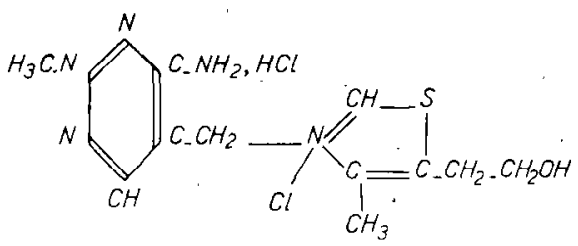

Chiorkydrate d'aneurine

Les principales sources de vitamine $B_{1}$ sont les suivantes (les chiffres indiquent la teneur en milligrammes pour 100 grammes de matière fraîche) :

Levures ............... $5 \mathrm{mg}$
Céréales et farineux :

Pellicules de riz ....., 1,8 à $2,4 \mathrm{mg}$

Graines de céréales .... 0,5 à $1 \mathrm{mg}$

Soja............... I $\mathrm{mg}$

Son de blé $\ldots \ldots \ldots \ldots$. 0,6 mg

Légumes:

Chou-fleur........... 0,1 à $0,2 \mathrm{mg}$

Laituc .............. 0,1 ऐे $0,2 \mathrm{mg}$

Pomme de terre ........ 0,1 mg

Viandes :

Foie.............. 0,45 à $1,3 \mathrm{mg}$

Viande de porc....... 0,5 à $1,4 \mathrm{mg}$

Reins.............. 0,5 à $1 \mathrm{mg}$

Cœur de bovidé....... $0,6 \mathrm{mg}$

Poissons et coquillages :

Huîtres ............. 0,3 mg

Poisson frais .......... $0,15 \mathrm{mg}$

Oeufs et laitages :

Jaune d'œuf .......... 0,3 mg

Lait de vache........, 0,02 à $0,06 \mathrm{mg}$

Fruits :

Pomme, prune, ananas, abricot, banane, grosoille............. $0,15 \mathrm{mg}$

En conclusion, les sources principales exogènes de vitamine $B_{1}$ sont les levures, les céréales pour les herbivores et omnivores, les abats pour les carnivores.

Ces sources seraient assez peu importantes si, chez les herbivores et en particulier les polygastrïques, les micro-organismes des réservoirs digestifs ne synthétisaient de grandes quantités de vitamine $B_{1}$.

Qu'elle soit d'origine alimentaire ou synthétisée dans le rumen, la vitamine $B_{1}$ est absorbee au niveau de l'intestin et mise en réserve dans le foie, le cerveau, les reins, le cœur et les muscles.

Elle existe dans l'organisme soit sous forme libre, soit combinée à l'acide pyrophosphorique; sous cette dernière forme elle joue le-rôle de coenzyme de la carboxylase.

L'excès d'aneurine est éliminé par les reinș dans l'urine sous forme libre et, accessoirement, dans le lait à l'état libre ou d'ester aneurinepyrophosphorique.

L'aneurine intervient dans le métabolisme des glucides, la régulation de l'eau, la résorption des graisses et le maintien du tonus intestinal.

Elle est indispensable au métabolisme du glucose dans les centres nerveux et les muscles. Elle agit en combinaison avec l'acide pyrophosphorique sous forme d'ester pyrophosphorique. Solls cette forme, elle est le groupement prosthétique de la carboxylase ou pyruvo-déshydrogénase qui, en qualité 
de transporteur d'hydrogène, assure la déshydrogénation et la décarboxylation de l'acide pyruvique, terme de passage obligatoire dans le catabolisme des glucides, et sa transformation en acide acétique. $\mathrm{CH}_{3}-\mathrm{CO}-\mathrm{COOH}+\mathrm{H}_{2} \mathrm{O} \rightarrow \mathrm{CH}_{3}-\mathrm{COOH}+\mathrm{CO}_{2}+\mathrm{H}_{2}$

La carence en aneurine aboutit à une accumulation d'acide pyruvique et d'acide lactique, ce dernier se formant du fait que l'hydrogène, n'étant plus capté par la carboxylase, s'unit à l'acide pyruvique.

$$
\mathrm{CH}_{3}-\mathrm{CO}-\mathrm{COOH}+\mathrm{H}_{2} \rightarrow \mathrm{CH}_{3}-\mathrm{CHOH}-\mathrm{COOH}
$$$$
\text { ac. pyruvique ac. lactique }
$$

Les besoins d'aneurine sont, en raison de l'importance de ce rôle, accrus lorsque l'alimentation est riche en glucides.

Le mode d'action sur le métabolisme de l'eau n'est pas précisé. La carence en aneurine produit des lésions très semblables à celles que l'on observe lorsque le centre cérébral de la diurèse est atteint : hydrémie, hypoprotéinémie, œdèmes, épanchements séreux.

L'aneurine accélère la résorption des graisses par stimulation de la lipase pancréatique.

Elle renforce le tonus gastro-intestinal en stimulant l'action de l'acétylcholine.

\section{Carence en vitamine $B_{1}$.}

Les troubles fondamentaux de la carence en vitamine $B_{1}$ sont de nature humorale : accumulation d'acide pyruvique et lactique et des substances intermédiaires du catabolisme des glucides aboutissánt à leur formation et, en particulier, de glucose, d'où hyperglycémie.

L'acidose et l'hyperglycémie sont les conséquences essentielles de la carence en aneurine. On peut supposer qu'elles sont à l'origine des symptômes observés qui sont :

10 Des symptômes digestifs : anorexie, dyspepsie hyposthénique (ou hypochlorhydrie) due à la dégénérescence de la muqueuse stomacale et atonie digestive due à l'altération des éléments du système végétatif.

20 Des symptômes nerveux polynévritiques, surtout périphériques.

L'acidose semble responsable, au moins partiellement, de ces troubles qui, au début, ne sont dus qu'à une modification des mécanismes biochimiques, sans lésions organiques.

A la longue, des lésions se produisent : au niveau du névraxe (engorgement vasculaire, infiltration de cellules basophiles métachromatiques dans les plexus choroides et les ganglions); au niveau des nerfs périphériques (lésions proches de celles de la dégénérescence wallerienne, atteignant le cylindraxe ou la gaine de myéline). $3^{\circ}$ Des symptômes cardiaques, tachycardie, insuffisance et dilatation du cœur, dont l'acidose, par la myocardite toxique qu'elle entraine, semble responsable.

$4^{\circ}$ Enfin, chez les jeunes, l'arrêt de la croissance est lié aux perturbations des métabolismes glucidique et minéral.

Les besoins en aneurine varient avec les espèces et le régime alimentaire.

Mme Randoin et Simonnet ont montré, dès 1923, que les besoins en vitamine $B_{1}$ augmentaient avec la teneur de la ration en glucides digestibles et établi le rôle d'épargne des graisses.

Porc, $4,7 \mathrm{mg}$ par $100 \mathrm{~kg}$ de poids vif.

Bovins, cheval, besoins très difficiles à évaluer.

Oiseaux, 0,12 à 0,25 $\mathrm{mg}$ pour $100 \mathrm{~g}$ de nourriture.

Nous étudierons les symptômes particuliers des carences en aneurine chez le porc, les oiseaux, le cheval; elles sont plus douteuses chez les bovidés.

\section{Carence chez le porc}

Le porc est sensible à la carence en aneurine, que cette carence soit primitive et provienne d'une insuffisance d'apport ou qu'elle soit conditionnée par la richesse du régime en glucides digestibles : cas des régimes exclusivement composés de pommes de terre, de mais, d'orge cuits.

Dans la carence complète, les premiers signes apparaissent environ un mois après le début de la carence; les signes généraux n'ont rien de caractéristique : tristesse, inappétence, poil hérissé, sale, peau fréquemment infiltrée.

La température est normale ou subnormale.

Les signes digestifs sont l'anorexie et la constipation.

Les signes nerveux sont plus nets': l'hyperesthésie est constante; la palpation des masses musculaires entraîne des réactions violentes et des cris; on note ensuite des parésies du train postérieur, sans troubles sphinctériens.

Dans les carences frustes, on note de légers signes de polynévrite et une tendance aux œedèmes:

Les auteurs allemands ont décrit une maladie du porc qu'on semble pouvoir rattacher à une carence conditionnée en aneurine, ils la désignent sous le nom de «Herztod» ou mort cardiaque.

Il est difficile d'en domer une description clinique car elle est caractérisée par une mort presque subite survenant après une très brève période d'excitation.

Il est possible d'observer, dans les élevages où sévit la maladie, des troubles prémonitoires décelables 8 à 15 jours avant le début des accidents mortels : généraux (apathie, hyperthermie passagère), digestifs (anorexie, dysorexie, exceptionnellemẹt diarrhée), respiratoires (polypnée, jetage 
spumeux, quelquefois épistaxis), circulatoires (cyanose, oreilles violacées, cedematiées) et surtout nerveux (mollesse, relever difficile, ataxie, parésie ou paraplégie, mouvements anormaux).

Les lésions touchent essentiellement les muscles et, en particulier, le muscle cardiaque. Le myocarde, mou, est parsemé de taches gris rougeâtre ou gris blanc, parfois de foyers hémorragiques. Les muscles, principalement ceux de l'arrière-train, présentent des zones claires, jaune grisâtre, couleur «chair cuite de poulet ». On trouve quelquefois des lésions catarrhales du tube digestif.

La maladie touche surtout les animaux à l'engrais, de races précoces, nourris de féculents, farineıx, pommes de terre; elle est plus rare sur les sujets maigres et de race tardive.

La maladie survient au printemps et en été. Les crises s'observent après une excitation : au moment de la distribution de la ration, lors de déplacements, débarquements, poursuites, contention, etc.

Si certains auteurs, Köbe en particulier, incriminent un virus ou la gastro-entérite, il est plus vraisemblable que cette maladie soit due à une carence conditionnée en aneurine, le régime riche en glucides augmentant de façon considérable les besoins de cette vitamine et l'animal n'en trouvant pas suffisamment dans une ration généralement cuite.

Les signes prodromiques et la nature des lésions observées n'infirment pas cette hypothèse.

\section{Carence chez les oiseaux}

Le «béribéri 》 des oiseaux est particulièrement bien connu; on l'observe spontanement chez la poule, l'oie, le pigeon; il est assez rare du fait de la variété de l'alimentation des animaux de basse-cour.

Lesbouyriès signale sa fréquence rolative chez les poulets âgés de 4 à 8 semaines dont la base de l'alimentation est le riz cuit ou décortiqué, et dans les élevages ciladirns mral conduits.

Les symptômes sont digestifs, respiratoires et surtout nerveux.

On observe de l'anorexie, de l'amaigrissement avec atonie du jabot et diminution considérable des sécrétions digestives.

Du côté respiratoire, on note de la dyspnée avec cyanose des muqueuses.

Les signes majeurs sont les signes nerveux, caractérisés par des accidents de polynévrite avec astasie, ataxie et phénomènes paralytiques : rétraction de la tête ou torsion de l'encolure, démarche traînante, impossibilité de se percher par suite de la paralysie des fléchisseurs des doigts. On voit parfois des convulsions.

La forme aiguë se termine par la mort en 24 à 36 heures; dans la forme subaiguë, les symptômes décrits précédemment s'extériorisent de façon très nette et le diagnostic est très facile.

\section{Carence chez le cheval}

Il est difficile d'évaluer exactement les besoins du cheval en facteur $B$ et en aneurine en particulier, en raison de la synthèse de ces facteurs par la microflore des réservoirs digestifs.

Malgré cela, on sait que le cheval est sensible à la carence en vitamines B en général et en thiamine en particulier. Naito et coll. ont vu survenir une chute de poids et des accidents cutanés chez des chevaux nourris de riz poli et de paille de riz, avec de I'huilc do foic do morue et un supplément minéral convenable. Carlstrom et Hjarre ont signalé des accidents semblables avec des rations composées de foin et de grains de mauvaise qualité; l'administration de levure de bière sèche a fait disparaître les symptômes de carence. Une ration carencée a déterminé, sur des chevaux examinés par Carrol, Gross et Howell, une perte d'appétit, une chute de poids et de l'incoordination des mouvements. Ces animaux ont guéri par la thiamine, «tout se passe comme si le cheval n'était sensible qu'à la carence en thiamine ou comme si la thiamine favorisait la production et l'utilisation des autres vitamines B (Simonnet et Le Bars) ». Or. Mitchell et Isbell disent que la thiamine est retenue en grande partie par les cellules bactériennes et diffuse peu dans le milieu intestinal, d'où la nécessité d'un apport dans la ration; et d'autre part, on sait (Wegner et coll.) que la présence de la thiamine libre dans l'intestin augmente la synthèse des autres vitamines $B$.

Les recherches effectuées au cours des vingt dernières années sur les troubles humoraux de la myoglobinurie paroxystique du cheval ont suggéré à quclques autcurs l'idée d'une carence conditionnée d'aneurine à son origine.

Carlstrom, Patton, Compton, se sont faits les défenseurs de cette hypothèse.

Le repos avec une alimentation normale, donc excédentaire, entraîne l'absorption d'un excès d'aliments, en particulier de glucides, que l'organisıne doit métaboliser ou mettre en réserve, ce qui entraîne une dépense accrue d'aneurine. Surviennent le travail ou le froid, facteurs qui nécessitent un accroissement brutal du catabolisme glucidique, les besoins en co-carboxylase, donc en aneurine, sont brutalement augmentés et l'organisme.n'est pas à même de les couvrir, d'où blocage des dégradations glucidiques, accumulation des produits intermédiaires, en particulier de l'acide pyruvique, 62 à $70 \%$ pour mille au lieu de 14 (Latteur), et déclenchement des troubles morbides.

Utilisant le test de surcharge qui consiste à administrer des doses massives aux animaux et à 
rechercher les quantités éliminées dans les urines de façon à déterminer, par les quantités retenues, les besoins de l'organisme, Latteur a observé chez les animaux malades une augmentation des besoins en vitamine $B_{1}$.

Les résultats thérapeutiques favorables obtenus grâce à l'emploi précoce d'aneurine viennent à l'appui de cette hypothèse.

Le traitement est d'autant plus efficace qu'il est précoce et que les doses sont élevées, $25 \mathrm{cg}$ à $1 \mathrm{~g}$ d'aneurine par voie veineuse.

Nous noterons encore que Bouckaert et Vandeplassche ont obtenu des succès identiques contre la myoglobinurie insidieuse.

\section{Carence chez les ruminants}

L'aneurine étant synthétisée par les micro-organismes du rumen, il est inutile de parler des besoins en aneurine des ruminants, cependant, chez les jeunes dont la flore intestinale n'a pas encore les qualités de celle de l'adulte, on a observé des carences en facteur Bl.

Certains auteurs ont voulu incriminer une carence relative en aneurine dans l'acétonémie des ruminants. Cette opinion n'est pas admise par tous, en particulier par Lesbouyriès et Charton, qui l'ont sérieusement critiquée.

\section{Vitamine $\mathbf{B}_{2}$}

La vitamine $B_{2}$, appelée d'abord chimiquement lactoflavine est, plus précisément, la riboflavine. Elle fut différenciée de la vitamine $B_{1}$ en 1926 grâce à sa thermostabilité.

En 1933, Kuhn, Györgyi et Wagner-Jaurcgg l'identifièrent aux pigments jaunes à fluorescence verte, ou flavines, que Warburg et ses collaborateurs avaient isolés de la levure en 1932.

Kuhn et ses collaborateurs préparèrent, à partir du pigment jaune du petit lait, un corps cristallisé, actif à la dose de l'ordre du millième de milligramme, qu'ils nommèrent lactoflavine.

Karrer, Von Euler, Alder et Malmberg confirmèrent les résultats de Kuhn; ils établirent la constitution des flavines qu'ils avaient isolées de l'œuf, du foie, du lait; toutes avaient la même formule.

En 1934, Kuhn et ses collaborateurs pouvaient réaliser la synthèse de la vitamine $\mathrm{B}_{\mathbf{8}}$ et en tracer définitivement la formule développée qui comprend une molécule d'un pentose, le ribose, et une flavine, la benziso-alloxanine, d'où le nom de riboflavine.

La vitamine $\mathrm{B}_{2}$ est soluble dans l'eau grâce à son groupement glucidique; elle est insoluble dans les solvants dépourvus d'oxhydrile. Elle est thermostable (jusqu'à $120^{\circ}$ ). La cuisson ne modifie pas la teneur des aliments en vitamine $B_{2}$.
Les réducteurs transforment la riboflavine en un leucodérivé, la leucoflavine.

Les principales sources de riboflavine sont les suivantes (teneur en milligrammes pour $100 \mathrm{gr}$ de matière fraîche) :

Levure de boulangerie..... 2,5 à $3 \mathrm{mg}$

Graines entières de céréales. 0,5 à $1,5 \mathrm{mg}$

Viande de bceuf, de veau.... 0,25 à $0,30 \mathrm{mg}$

Abats, lait de vache ....... 0,25 à $1 \mathrm{mg}$

Oeuf $\ldots \ldots \ldots \ldots \ldots \ldots \ldots . \ldots, 23$ à $0,28 \mathrm{mg}$

Dans l'organisme, la riboflavine se rencontre sous trois formes différentes:

- sous forme de ribollavine libre;

- sous forme d'un dinucléotide où elle est unie par l'acide phosphorique à l'adénosine;

- sous forme de flavo-protéines où elle est unie à une protéine par l'intermédiaire de l'acide phosphorique; trois de ces flavo-protéines sont douées de propriétés diastasiques : la d-amino-acidedéhydrase, la xanthine-déhydrase, le ferment jaune de Warburg et Christian.

Dans ces distases, l'ester riboflavine-phosphorique joue le rôle de coenzyme et la protéine spécifique, variable avec les diastases, le rôle d'apo-enzyme.

Les formes combinées de la riboflavine apportées par les aliments sont dissociées par le suc gastrique; la riboflavine est absorbée au niveau de l'intestin puis subit une phosphorylation sous l'influence des phosphates organiques.

La copulation de l'ester phosphorique de la riboflavine avec la protéine spécifique se fait au niveau du foie et le ferment jaune est ainsi reconstitué.

L'excrétion se fait par les fèces, accessoirement par la sueur, le lait, l'urine.

Le ferment jaune de Warburg se combine non à l'oxygène, commo le ferment respiratoire typique, mais à l'hydrogène, d'une manière réversible, en formant un leucodérivé. Il agit en liaison avec un autre transporteur d'hydrogèno dans' lequel intervient la vitamine P P : le ccenzyme de Warburg.

On peut résumer schématiouement la chaîne des réactions :

La dégradation oxydative progressive des glucides libère de l'hydrogène qui est 'd'abord fixé sur le coferment (où intervient la vitamine $P P$ ), puis ce coferment réduit cède à son tour l'hydrogène au ferment jaune, lequel fixe l'oxygène de l'oxyhemoglobine pour former de l'eau.

La riboflavine semble intervenir au niveau de la rétine dans l'adaptation visuelle; par sa fluorescence elle transformerait les rayons de courte longueur d'onde en radiations d'onde plus grande correspondant aux lumières verte et jaune auxquelles l'œil est plus sensible. 


\section{Carence en vitamine $B_{2}$}

La connaissance des activités du ferment de Warburg et Christian laisse prévoir que les troubles dus à une carence en riboflavine seront graves et retentiront sur l'état général du malade.

Les besoins en riboflavine varient avec les espèces :

Porc, 65-70 $\gamma$ par kilo do poids vif.

Poussin, 3,5 mg par kilo d'aliment.

Poulet d'élevage, $3 \mathrm{mg}$.

Poule pondeuse, $4,8 \mathrm{mg}$.

Chez les jeunes la croissance est arrêtée puis, comme chez les adultes, on observe des répercussions cutanées, digestives (défaut d'absorption, diarrhée, amaigrissement, sans lésions anatomiques), nerveuses (paralysies, dégénérescence des fibres à myéline).

\section{Carence chez le porc.}

La carence en riboflavine se traduit, chez le porc, par de l'hypothermie, des troubles circulatoires avec cyanose, des troubles nerveux paralytiques, de l'anémie, des symptômes cutanés (érythème, éruptions, ulcérations) et souvent de la cataracte; chez les porcelets, l'arrêt de la croissance est le symptôme dominant.

\section{Carence chez les oiseaux.}

On regarde comme son expression clinique la plus pure l'affection appelée « paralysie de nutrition».

Les symptomes surviennent en général vers la $3^{\text {e }}$ semaine. Les malades se déplacent avec difficulté, tremblent en cherchant à se soulever. Les jarrets sont fléchis et appuient sur le sol pendant la marche, Les doigts sont crispés, enroulés de dehors en dedans; l'appui se fait par la face dorsale. Malgré un appétit intact, les malades finissent par ne plus pouvoir se déplacer pour manger.

Ce qui provoque surtout cette paralysie de nutrition, c'est le déséquilibre entre l'excès de protéines et la carence en riboflavine de la ration. On la voit par exemple sur des poussins à qui l'on donne une ration de pondeuses à $20 \%$ et plus de protéines, sans supplément de riboflavine.

Hors ce cas particulier, on peut trouver, chez les oiseaux, des manifestations pathologiques complexes dans lesquelles intervient la carence en plusieurs vitamines $\mathrm{R}$, dont la riboflavine.

\section{Vitamine PP}

La vitamine PP (préventive de la pellagre) porte encore les noms d'amide nicotinique, nicotinamide, niacine.
Elle a été identifiée à l'amide de l'acide nicotlnique par Elvehjem en 1937. On la prépare couramment par synthèse.

L'acide nicotinique en est la provitamine. Physiologiquement, elle se montre aussi active que l'amide qui est la forme de stockage et d'utilisation dans l'organisme.

L'amide nicotinique est une substance blanche cristalline très soluble dans l'eau, résistant à la chaleur et aux oxydants.

Les sources les plus riches en vitamine PP sont les suivantes (teneur en milligrammes pour $100 \mathrm{~g}$ de matière) :

Foie de bøuf .............. 10 à $25 \mathrm{mg}$

Foie de porc .............. $19 \mathrm{mg}$

Rein de bouf ................ 12 à $20 \mathrm{mg}$

Foie de cheval................ $16 \mathrm{mg}$

Levure de bière fraîche........ $12 \mathrm{mg}$

Levure de bière sèche ......... 50 à $100 \mathrm{mg}$

Germe de blé ............... $12 \mathrm{mg}$

Viande de cheval, de boeuf...... $5 \mathrm{mg}$

Soja $\ldots . . . \ldots \ldots \ldots \ldots \ldots \ldots, 5$ mg

Les légumes verts, les fruits, les farines de céréales, sauf l'orge, n'en renferment pratiquement pas; comme, de plus, il semble qu'une partie de la vitamine $\mathrm{PP}$ d'origine végétale ne soit pas assimilable, on s'explique la fréquence de la pellagre dans les populations végétariennes et pauvres. principalement chez les gros consommateurs de maïs, de riz, de mil, de seigle. De même, la synthèse de l'acide nicotinique par la flore intestinale des ruminants est probable, mais les preuves de son utilisation par l'animal ne sont pas données avec: certitude.

La nicotinamide se rencontre dans l'organisme, soit sous forme libre, soit sous forme combinée avec des protéines spćcifiques ces dernic̀ros combinaisons jouant un rôle enzymatique important de transporteur d'hydrogène, rôle dévolu au co-enzyme qui renferme la nicotinamide.

On connaît deux de ces coferments :

Le coferment 1 , cozymase 1 ou codéshydrogénase 1, isolé en 1935 par Von Luler de la levure de bière, constitué par la combinaison de l'amide nicotinique avec deux molécules de ribose, une molécule d'adénine, deux molécules d'acide phosphorique (c'est donc un diphosphopyridyl-adényldinucléotide), qui joue un rôle important dans la fermentation alcoolique des sucres.

Le cciferment. 2, codéshydrogénase 2, ou coenzyme de Warburg, isolé par Warburg et Christian des hématies du cheval, puis du foie, puis du muscle, a une structure analogue à celle de la cozymase 1, mais renferme une molécule supplémentaire d'acide phosphorique. Il semble être la 
fraction active de la nicotinamide dans l'organisme des mammiferes.

Certains êtres vivants ont absolument besoin d'un apport extérieur de vitamine PP : homme, singe, chien, chat, porc, cobaye, oiseaux, alors que d'autres en font la synthèse : végétaux, bactéries, levures, ou bénéficient des synthèses bactériennes réalisées dans les réservoirs digestifs : polygastriques, cheval.

La vitamine PP, absorbée au niveau de l'intestin sous forme d'amide ou d'acide nicotinique, se répartit dans l'organisme mais principalemont, ct en quantités plus considérables, dans le foie et les reins sous forme libre ou coenzymatique. Dans le sang, on la trouve exclusivement dans les hématies (5 à $7 \mathrm{mg}$ par litre).

L'élimination se fait sous forme d'amide dans les urines et le lait; celui de vache en contient de 2 a $3 \mathrm{mg}$ par litre. Cette présence dans le lait serait, d'après Lwoff et Morel, le fait plutôt d'une sécrétion que d'une excrétion.

Les besoins sont variables avec les espèces et augmentent au cours des infections, des intoxications, du travail au soleil, de la gestation, de la croissance et dans certains cas où le régime alimentaire contient des antivitamines : alimentation exclusive au maiss qui contient un dérivé de la pyridine laquelle est une antivitamine PP.

Par contre, la vitamine' PP peut être suppléée par un apport de tryptophane. Cette découverte, faite d'abord chez le rat, a été contrôlée pour le porc. Cette interchangcabilitó s'explique, à la suite des travaux de Raoul, par la possibilité de synthèse de l'acide nicotinique à partir du tryptophane.

Mais la réaction inverse est impossible et une carence en cet acide aminé ne peut être corrigée par un apport de niacine.

Le besoins considérés comme normaux sont les suivants :

Porcelet, $600 \gamma$ à $1,8 \mathrm{mg}$ par kilo de poids vif.

Porc, $200 \%$ par kilo de poids vif.

Chien, 0,5 à 1,5 mg par kilo et par jour.

Poulets et poules $17 \mathrm{mg}$ par $\mathrm{kg}$ de nourriture.

\section{Carence en vitamine PP}

La pellagre est connue depuis longtemps puisque Casal en a donné la description chez l'homme en 1735.

Les carences pures en vitamine PP sont rares; on note plus souvent des polycarences avec dominance des symptômes dus à l'avitaminose PP.

Chez le chien, l'avitaminose PP détermine une maladie connue sous le nom de "black tongue" caractérisée essentiellement par une stomatite nécrotique avec coloration bleu noirâtre de la langue.

Ses caractères épidémiologiques, cliniques, étiologiques, l'ayant fait considérer depuis les travaux de Goldberger comme une maladie analogue à la pellagre, elle a fait l'objet de nombreuses recherches de la part des physiologistes et des cliniciens.

Limitant notre exposé aux affections intéressant les animaux domestiques à caractère économique. nous n'insisterons pas sur la description de cette carence chez le chien.

\section{Carence chez le porc}

L'avitaminose PP s'obtient facilement chez le porc soumis à un régime carencé : Chick et coll. ont signalé, au bout de 6 semaines de ce régime, de l'inappétence, de la diarrhée profuse et une dermite croûteuse au niveau des oreilles. Chez les porcelets, on note surtout une sévère anémie hypochrome, de l'anorexie et une diarrhée hémorragique.

L'entérite nécrotique semble être due à une carence en vitamine PP qui préparerait le terrain à l'infection par Salmonella cholerae suis. A la dose de $10 \mathrm{cg}$ par jour, l'amide nicotinique prévient l'apparition de l'entérite nécrotique et, à la dose de $3 \mathrm{cg}$, elle guérit les lésions quand l'infection secondaire ne s'est pas encore installée.

Les lésions d'avitaminose PP s'observent spontanément lorsque les animaux sont soumis à un régime composé exclusivement de mais jaune, les symptômes sont moins graves si le régime contient du blé, de l'avoine ou surtout de l'orge.

\section{Carence chez les oiseaux}

L'avitaminosc PP so traduit par des troubles digestifs, stomatite et glossite.

\section{FACTEURS ANTLANÉMIQUES}

\section{Acide folique, Vitamine $B_{12}$}

Parmi les constituants majeurs du complexe B, nous classons les facteurs antianémiques en raison de l'importance considérable de ceux-ci en pathologie humaine et en physiopathologie.

La découverte récente de ces facteurs apporte la solution d'un problème posé depuis le début du siècle, à savoir l'explication du rôle des extraits du foie et d'estomac dans le traitement des anémies pernicieuses du type de celle de Biermer.

En 1920, Whipple montre que, dans l'anémie expérimentale, le foie et le rognon de bceuf avaient une action régénératrice de première importance. En 1926, Minot et Murphy utilisent le foie total dans le traitement de l'anémie de Biermer et des recherches ultérieures confirment l'efficacité du foie dans le traitement de toutes les anémies. Castle, frappé de l'absence de sécrétion gastrique du biermérien, traite l'anémio pernicicuse par un apport do viando et de suc gastrique; les résultats sont heureux et l'influence sur l'hématopoïèse, favorable. 
Castle en déduit que le biermérien, vu sa déficience gastrique, ne peut utiliser certains matériaux, et il en déduit que le facteur antianémique comprend un élément intrinsèque stomacal qui agirait sur un facteur extrinsèque alimentaire pour donner un facteur gastrique qui serait peut-être à l'origine du facteur hépatique.

En 1942, Mitchell, Snell et Williams isolent des extraits hépatiques un facteur antianémique : l'acide folique. Mais s'il existe en grande quantité dans les feuilles vertes des plantes, il n'est contenu qu'à l'état de traces dans les extraits hépatiques et ne peut être considéré comme le principe actif.

En 1948, les découvertes de Lester Smith en Angleterre et de Rickes aux Etats-Unis aboutissent a la mise en évidence de la vitamine $B_{12}$ qui semble être le facteur contenu dans le foie et que certaines recherches récentes identifient au facteur extrinsèque de Castle.

L'acide folique n'a que peu d'intérêt chez les animaux. Il n'en est pas de même de la vitamine $B_{12}$; l'intérêt qu'on lui porte actuellement tient au fait que certains auteurs expliquent les symptômes observés dans les carences spontanées ou expérimentales en cobalt par une carence conditionnée en vitamine $B_{12}$.

La constitution chimique de la vitamine $B_{12}$ n'est pas encore complètement élucidée mais on a déjà quelques indications précises.

Sa molécule contient $4 \%$ de cobalt et une, deux, ou trois molécules d'acide phosphorique.

La vitamine. $B_{12}$ cristallisée est soluble dans l'eau, elle résiste au chauffage à l'autoclave, en solution de $\mathrm{pH}$ compris entre 4 et 7 . La destruction est plus rapide en solution alcaline qu'en solution acide.

Pendant de nombreuses annécs, les essais do reproduction expérimentale de carence en facteur antianémique furent infructueux; cela tenait au fait que la vitamine $B_{12}$ est relativement plus abondante dans les aliments qu'on ne le supposait au début des recherches et à celui que les expérimenteurs s'intéressaient plus à son action hémalopoiétique qu'à son action sur la croissance. On essayait de reproduire chez l'animal des conditions voisines de I'anémie pernicieuse : saignees répétées, injection ou ingestion de substances hémolytiques : phényl-hydrazine, composés plombiques.

Les essais faits aux Etats-Unis en vue de remplacer dans la ration les protéines animales par des protéines végétales de moindre prix déterminèrent chez les animaux domestiques des signes de carence: le rythme de la croissance était ralenti chez les porcelets et les poulets et les pondeuses produisaient des cufs de faible fécondité. On a pensé que les protéines animales contenaient un facteur indispensable à la croissance, qui fut nommé A.P.F. (Animal Protein Factor).
Les signes de carence étaient aggravés s] on augmentait le taux de certaines protéines: celles de soja en particulier; ils étaient diminués si on ajoutait à la ration de la farine de poisson ou du fumier de vache (Hammond et Titus, 1944, Bird, 1946).

Rubin et coll., Bird et coll. montrèrent que le facteur présent dans le fumier de vache et dans le «fish soluble » avaient des propriétés très voisines. On isola du foie du rat un facteur antianémique actif dans l'anémie infectieuse (Cary et coll., 1946), puis un facteur de croissance pour le rat fut décelé dans les protéines animales (Zucker, 1948).

Il devenait probable que ces facteurs étaient identiques et que l'activité du fumier de vache provenait d'un corps synthétisé par les microorganismes des réservoirs digestifs. Stokstad en donna la preuve quand il isola du tube digestif des volailles un micro-organisme qui opérait la synthèse d'un facteur favorisant la croissance des volailles et qui était actif contre l'anémie pernicieuse.

Ott, Lillie et leurs collaborateurs montrèrent en 1948 que la vitamine $B_{12}$, donnée oralement ou par injection, avait la même action sur les poulets que l'A.P.F.

Cependant, on admet que si la vitamine $B_{12}$ est un composant de l'A.P.F. elle ne lui est pas identique.

On a trouvé que la vitamine $B_{12}$ avait une activité antianémique considérable si elle était administrée par voie parentérale et qu'elle était peu ou pas active par voie digestive.

Par voie digestive, elle retrouve ses propriétés si elle est administrée en même temps que du suc gastrique normal. Ce qui rapproche son activité de celle du facteur extrinsèque de Castle.

Comme dans les fèces des biermériens on trouve de grandes quantités de vitamine $B_{12}$ ( 65 y par jour). il semble que son absorption soit conditionnée par la présence du facteur intrinsèque qui est absent chez les malades (Berk et Castle, 1948).

Les travaux de Norris et Majnarich conduisent à penser que le facleur intrinsèque de Castle serait une diastase, xanthine-oxydase, qui, agissant sur un facteur extrinsèque (acide folique, xanthoptérine, vitamine $B_{12}$ ), le transformerait en une substance active qu'ils appellent vitamine $B_{14}$ et qu'ils isolent de l'urine humaine.

On ne possède encore que peu de précisions sur le rôle biologique de la vitamine $\mathrm{B}_{\mathbf{1 2}}$. Cependant, on a établi qu'avec l'acide folique elle joue un rôle certain dans la synthèse et le métabolisme des chaînes contenant des groupes méthyle labiles.

Salmon et Schaefer ont trouvé que, chez le rat et le poulet, la vitamine $B_{12}$ et l'acide folique sont impliqués dans des réactions de transméthylation.

Oginski en 1950 a montré que la méthionine pouvait être synthétisée à partir d'homocystine par des 
tranches de foie de rat recevant de la vitamine $B_{12}$, alors que des tranches de foie de rat carencé ne produisent que des quantités infimes de cet acide aminé.

Ce rôle a été confirmé par Dinnin; si des régimes pauvres en méthionine et en bétaine ne fournissent pas assez de groupements méthyle pour une leucocytose normale, des régimes contenant de la méthionine seule ou de la bétaine et de la vitamine $B_{1}$ permettent une production normale de leucocytes.

La vitamine $B_{12}$ semble avoir des actions lipotropes (Drill et Mc Cormick, Schaefer).

Elle intervient enfin dans la synthèse des acides nucléiques par les bactéries et, vraisemblablement, par les animaux supérieurs (Stern et coll.).

\section{Carence chez les poulets}

Les poulets ayant servi d'animaux d'expérience dans les études sur les carences en vitamine $B_{12}$ on a un certain nombre de précisions sur les besoins et sur les symptômes de carence chez ces animaux.

Les embryons provenant d'œufs de poules carencées en vitamine $B_{12}$ présentent souvent des déformations et meurent en coquille. Lillie et coll. ont montré que l'injection de vitamine $B_{12}$ dans des cufs provenant de poules carencées augmente le taux des éclosions, permet d'obtenir des poussins dont la croissance est plus rapide, le plumage plus beau et le taux de mortalité plus faible que ceux des poussins provenant d'œufs non traités.

Mushett et Ott estiment que la vitamine $B_{12}$ évite les érosions de la muqueuse du gésier.

Nombre d'expériences prouvent que les besoins en vitamine $B_{12}$ augmentent avec la teneur de la ration en protéines végétales. Mais nous n'avons pas à envisager ici l'action conjointe de cette vitamine et des antibiotiques dans l'accélération de la croissance, tant des volailles que du porcelet, sujet qui est traité dans le rapport de M. Ferrando.

\section{Carence chez le porc}

On n'a que peu de renseignements sur les symptômes observés dans les carences spontanées.

La plupart des recherches ont été faites avec des régimes synthétiques auxquels les expérimentateurs ajoutaient des antivitamines ou des sulfamides. Elles ont montré l'interdépendance de l'acide folique et de la vitamine $B_{12}$.

Les troubles observés portent sur la croissance et l'hématopoïese chez les jeunes. Les truies carencées sont incapables d'élever leurs porcelets, elles peuvent les conserver jusqu'au sevrage si elles reçoivent des injections de vitamine $B_{1 s}$.

\section{Carence en cobalt et avitaminose $B_{12}$}

Nous renvoyons au chapitre des oligo-éléments pour l'étude des troubles observés chez les rumi- nants entretenus sur des pâturages déficients en cobalt.

Récemment, Monroe, Sauberlich, Comar et Hood (1952), en utilisant du cobalt radioactif, ont montré qu'après absorption de cobalt il y avait une nette augmentation de la biosynthèse de vitamine $B_{12}$, qu'après injection intraveineuse de cobalt 60 il n'y avait qu'une très faible syrithèse, si même il y en avait une, dans le tractus digestif, mais formation de quantités considérables de vitamine $B_{12}$ dans les tissus. Il y a 10 fois plus de cobalt transformé en vitamine $B_{12}$ après ingestion qu'après injection.

A la lumière des résultats obtenus; chez des agneaux carencés en cobalt, après injection parentérale de vitamine $B_{12}$, les auteurs pensent que les orps synthétisés par les tissus après injection de cobalt inorganique sont voisins de la vitamine $B_{12}$, mais que ces corps sont incapables d'atténuer les symptômes de carence en cobalt.

S'il est prouvé de façon indubitable que les symptômes observés dans les carences en cobalt sont ceux de la carence en vitamine $B_{12}$, il ne fait aucun doute que son étude occupera une place importante dans la pathologie tropicale.

\section{CONSTTITUANTS MINEURS}

\section{Vitamine $B_{0}$}

La vitamine $B_{6}$ ou adermine (elle prévient des troubles cutanés) est encore appelée par son nom chimique de pyridoxine, sa synthèse a été réalisée par Kuhn et Harris (1939).

C'est une substance cristalline, incolore, inodore, soluble dans l'eau. Elle est résistante à la chaleur mais se trouve rapidement altérée à la lumière.

Les principales sources sont (teneur en milligrammes pour $100 \mathrm{~g}$ de matière) :

\begin{tabular}{|c|c|}
\hline Jaune d'œuf. & $18,7 \mathrm{mg}$ \\
\hline Levure sèche . . . . . . . . . . & 4 à $10 \mathrm{mg}$ \\
\hline Soja & 0,8 à $9,5 \mathrm{mg}$ \\
\hline Foie de bceuf. . & 1,7 à $2,5 \mathrm{mg}$ \\
\hline Viande de bceuf. & 0,4 à $0,8 \mathrm{mg}$ \\
\hline Pomme de terre ..... & 0,2 à $0,3 \mathrm{mg}$ \\
\hline
\end{tabular}

Dans l'organisme, la vitamine $\mathrm{B}_{0}$ est liée à une protéine et agit comme transporteur d'hydrogène au cours des réactions d'oxydo-réduction dans le métabolisme des protides et des lipides : décarboxylation de certains acides aminés, en particulier de la tyrosine et du tryptophane, amination des acides cétoniques.

Les besoins varient avec l'espèce :

porc, $112 \because$ par kilo de poids vif, oiseaux, $0,36 \mathrm{mg}$ pour $100 \mathrm{~g}$ de nourriture.

On ne connaît pas, en clinique vétérinaire, de 
carences caractérisées. Expérimentalement, on a déterminé chez le chien des anémies hypochromes s'accompagnant d'arrêt de la croissance et de convulsions.

Chez le porcelet, on observe un arrêt de la croissance, de l'anémie microcytaire, des convulsions s'accompagnant d'infiltration graisseuse du foie.

La pyridoxine à la dose de $1 \mathrm{mg}$ pour $10 \mathrm{~kg}$ de poids vif amène rapidement la guérison.

Chez les oiseaux, la carence en pyridoxine se traduit par de l'excitabilité, de l'ataxie, des mouvements convulsifs et de l'anémie; chez la poule on note une baisse de la production des œufs et du taux d'éclosion.

\section{Acide pantothénique}

L'acide pantothénique a été identifié au facteur filtrable des extraits hépatiques de Lepkovsky, au facteur antidermatite du poulet d'Elvehjem et Koehn, au facteur antigris ou vitamine $\mathrm{Bx}$ qui empêche la décoloration des poils du rat noir, du chien et du renard.

L'acide pantothénique fut isolé en 1938 par Williams; c'est un derivé de la $\beta$-alanine de formule brute $\mathrm{C}_{8} \mathrm{H}_{17} \mathrm{O}_{5} \mathrm{~N}$.

Il se présente sous forme d'une huile jaune clair. Ses sels de șodium et de calcium sont cristallisés. Soluble dans l'eau et l'alcool, il résiste à la lumière et à l'oxygène, mais est sensible à la chaleur, aux alcalis et aux acides.

Les principales sources sont : la levure (20 mg pour $100 \mathrm{~g}$ de matière fraîche), l'œuf en poudre (10 $\mathrm{mg}$ ), le foie (4 à $5 \mathrm{mg}$ ).

L'acide pantothénique interviendrait en tant que codéshydrogènase dans le métabolisme des glucides et des lipides (Spies). II interviendrait également dans la synthèse du tryptophane.

L'acide pantothénique agit comme facteur de croissance aussi bien chez les microor ganismes que chez les animaux supérieurs.

Ses fonctions essentielles portent :

1 o Sur les tissus épithéliaux : muqueuses digestives ef respiratoires (stimulation, protection, résistance à l'infection), peau et phanères. Son action trophique s'étend aussi aux divers éléments d'origine ectodermique, au système nerveux en particulier; ce rôle est particulièrement net chez le poulet (Phillips et Engel, 1939).

$2^{\circ}$ Sur la cellule hépatique (fonction trophique et stimulante).

$3^{\circ}$ L'acide pantothénique neutralise le pouvoir antibactérien de l'acide salicylique.

Besoins. - Les besoins du porc sont évalués à 10 ou 12 \% par kilo de poids vif, ceux des poulets à
1,1 mg. pjour $100 \mathrm{~g}$ d'aliments et ceux des poules pondeuses à 1,5 ma.

\section{Carences expérimentales}

Chez les animaux de laboratoire, la carence en acide pantothénique est caractérisée par une rhinoalvéolite descendante, une hépatite centro-Iobulaire aveo dégénérescence graisscuse du foic, uno cortico-surrénalite hémorragique.

La carence chez le porc amène : un arrêt de la croissance, de la sécheresse et de la rougeur de la peau, des vomissements, de la diarrhée, des troubles locomoteurs et nerveux (Wintrobe et coll, Hugues et Ittner).

La carence chez le poulet se traduit par un arrêt de la croissance, de l'achromotrichie, de l'ébouriffement des plumes, de la dermite périoculaire, péribuccale, péricloacale, podale et de la dégénérescence de la moelle épinière. Ia guérison des signes nerveux par l'acide pantothénique prouve leur origine carentielle spécifique (Phillips et Engel 1939).

\section{Carence et parasitisme}

Taylor et Becker ont montré que, si Trypanosoma lewisi n'est pas pathogène pour le rat, les animaux carencés en acide pantothénique et biotine ne peuvent supporter l'infection et meurent. Ray et Harbans confirment l'action de l'acide pantothénique dans l'infection du rat par $T$. evansi. Ces auteurs incriminent une carence en acide pantothénique dans l'éclosion d'épizooties meurtrières de "surra observées aux Indes sur les chevaux et les bovins.

L'acide pantothénique étant un facteur de croissance pour les êtres unicellulaires, une carence pourra déterminer une baisse du taux d'infection. C'est ce qui a été observé dans le cas de l'infection des poulets par Plasmodium gallinarum.

Certains auteurs (Brackett et coll.) ont même préconisé un traitement de cette affection qui consiste à déterminer une carence conditionnée par l'administration de substances antivitaminiques de l'acide pantothénique; ainsi le pantoyl-tauryl-amide s'est révélé plus actif que la quinine pour lutter contre l'infection à $P$. gallinarum.

Des résultats comparables ont été obtenus par Deschiens et Pick dans le traitement dı paludisme expérimental de la poule par un autre antagoniste de l'acide pantothénique, le P.A.S.

\section{Biotine}

La biotine a été successivement étudiée sous les noms de bios $I I$, coenzyme $R$, vitamine $H$.

Szent-Györgyi, en 1940, identifia à la biotine : le 
facteur bios 2 de Fulmer, le coenzyme $\mathrm{R}$ de Allison et la vitamine $\mathrm{H}$ active contre la «maladie du blanc d'cuf » du rat, qu'il avait extraite du foie.

La biotine est largement répandue dans la nature, mais à de faibles concentrations. Les meilleures sources sont le rein, les levures, le jaune d'œuf, les céréales.

Les mammifères synthétisent cette vitamine dans leur tube digestif et les carences spontanées ne s'observent que chez les oiseaux.

Les besoins en biotine sont de $15 \gamma$ pour $100 \mathrm{~g}$ d'aliments chez le poussin et le poulet.

La carence par défaut d'apport ou conditionnée par la présence dans la ration de l'antivitamine correspondant à la biotine, l'avidine, se traduit par les signes suivants : peau craquante et saignante aux pattes, gonflement et rougeur des paupières, croûtes sanglantes près de la bouche, perte des plumes; en autre, en ce qui concerne la poule pondeuse, on note une fortc mortalité embryonnairc et la fréquence des malformations chez les poussins : chondrodystrophie, syndactylie, tibias crochus et tordus (Craven).

La carence en biotine favorise l'infection du poulet par Plasmodium lophurae et le pigeon normalement réfractaire à Trypanosoma brucei peut être infecté quand il est carencé en biotine.

\section{Acide para-amino-benzoïque}

L'acide para-amino-benzoïque, P.A.B., est encore appelé vitamine $\mathrm{H}^{\prime}$ ou vitamine $\mathrm{H}_{2}$.

Connu depuis 1863, le P.A.B. a été rattaché au groupe B lorsqu'on étudia son rôle dans le métabolisme des bactéries.

Chez les vertébrés supérieurs, il intervient dans la pigmentation des poils.

Il est interessant du point de vue de la pathologie tropicale par son action rickettsio-statique et par son emploi dans le traitement du typhus (Snyder).

\section{Choline et inositol}

Ces deux substances rattachées au groupe $B$ ont un rôle lipotrope. En leur absence, le foie se surcharge en acides gras et peut présenter des lésions de cirrhose.

En absence de choline, la synthèse des phospholipides est entravée; elle pourrait être remplacée par la méthionine qui interviendrait en cédant son groupement méthylé.

La fonction "anti-foie gras " du pancréas serait due à un enzyme permettant la libération de la méthionine des aliments à partir de laquelle la choline serait synthétisée (Chaikoff et coll.).
Le méso-inositol a un rôle très voisin de celui de la choline.

Leurs carences ne sont pas connues en clinique.

\section{Conclusion}

De l'ensemble des recherches faites depuis vingt ans sur les vitamines du complexe $B$, on peut retenir que, très généralement, les expériences ont été faites sur des animaux soumis à des régimes synthétiques dont la composition était très éloignée de celle des régimes auxquels sont soumis les animaux d'élevage.

Aussi n'est-il pas étonnant que les carences spontanées soient relativement rares. De plus, l'étude des symptômes de carence en un seul des éléments du groupe B montre qu'il est difficile de diagnostiquer par le seul examen clinique l'étiologie exacte de la carence.

Très généralement, dans la pratique, plusieurs facteurs du groupe $B$ sont absents de la ration et cette absence provient du fait que le régime n'est composé que d'un petit nombre d'aliments d'origine végétale.

Comme l'indique Ferrando : «On peut admettre que les porcs, les animaux à fourrure, les oiseaux de basse-cour ont des besoins élevés en vitamine du complexe B. Mais il apparaît que la ration habituelle de ces animaux, composée de céréales, de produits d'origine animale, de tourteaux, est suffisamment riche en ces facteurs ».

«Pourtant, chez les animaux de basse-cour en particulier, certains d'entre eux peuvent être déficients; la riboflavine par exemple, et de petits suppléments ne sont pas à dédaigner. Cela mis à part, dans l'ensemble, sauf cas exceptionnels, on peut admettre qu'avec une ration composée bien équilibrée, les monogastriques ne risquent pas de carences en vitamines du complexe B. Quant aux polygastriques les synthèses réalisées dans leurs vastes réservoirs digestifs suffisent amplement à couvrir leurs besoins. »

\section{AVITAMINOSE C.}

Nous serons très brefs sur ce chapitre car la vitamine $\mathrm{C}$, acide ascorbique, est aisément synthétisée par les animaux domestiques. Dans leurs organes, même lorsque la carence alimentaire a été totale et prolongée, on décèle de l'acide ascorbique.

La carence n'est donc concevable que si, d'une part, la ration est déficiente en vitamine $\mathrm{C}$ et si, d'autre part, le processus de synthèse est entravé. Ceci explique sans doute les faits de maladie de Barlow, ou scorbut des jeunes chiens, qui sont rapportés par plusieurs auteurs (Collet, Morell, 
Grégoire, Jordan, Fooy, Arnous, Merillat); il s'agit essentiellement d'une ostéopathie douloureuse qui guérit par l'administration de jus de citron ou d'acide ascorbique.

Nous rappelcrons que Phillips a accusé une carence en vitamine $C$ d'être la cause de certains cas de stérilité chez la vache. Nous avons examiné cette question précédemment à propos du manganèse.

Enfin, la vitamine $\mathrm{C}$ jouerait un rôle dans le métabolisme du muscle et son administration permet d'éviter la fatigue musculaire. Cette particularité, qui est intéressante chez l'homme, et peut-être chez les animaux de trait ou de selle, ne saurait nous retenir ici.

\section{AVITAMINOSE D.}

L'avitaminose $D$ est indissolublement liée au rachitisme dont elle est I'un des facteurs étiologiques, à côté du déséquilibre phospho-calcique de la ration. Nous ne reviendrons pas sur les caractères de la maladie, que nous avons étudiés par ailleurs.

On sait depuis le début du XIX e siècle qu'elle peut être prévenue et guérie par l'administration d'huile de foie de morue. D'autre part, on connaissait l'heureuse influence de la lumière solaire sur cet etat.

Un pas décisif est franchi quand, en 1919, Huldschinsky découvre que ce sont les rayons ultraviolets de la lumiere solaire qui agissent. Pappenheimer et Hess élèvent de jeunes rats blancs avec une ration qui contient un excès de calcium mais très pauvre en phosphore, les rendant ainsi, à l'abri de la lumière, rachitiques, et les guérissent en les irradiant avec des rayons ultra-violets. Hess' Steenbock, Daniel, Kramer, vérifient les propriétés antirachitiques de certaines substances, contenant toutes des graisses, lorsqu'elles ont été irradiées. Ainsi naît l'idée d'une vitamine antirachitique qui proviendrait, dans la nature, de l'irradiation par les rayons ultra-violets solaires d'une substance mère, la provitamine. Mais quelle est cette provitamine? Il est d'abord démontré qu'elle ne se trouve pas dans la graisse proprement dite mais dans la fraction des graisses naturelles qui n'est pas saponifiée par la soude ou la potasse : c'est cette fraction que l'on appelle l'insaponifiable. Dans l'insaponifiable se trouvent, entre autres corps, des stérols. Ces stérols sont nombreux; deux sont particulièrement répandus dans la nature, le cholestérol dans les graisses animales, l'ergostérol dans les végétaux. Le cholestérol pur n'est pas transformable en vitamine antirachitique lorsqu'il est irradié. Par contre, l'ergostérol se montre être une provitamine antirachitique, selon les travaux de Windaus, de Rosenheim et
Webster, de Hess et Steenbock (1926). Cet ergostérol est particulièrement abondant dans la levure de bière. En irradiant cette substance; Windaus obtient un produit antirachitique qu'il pense être la vitamine elle-même. Mais, en réalité, dans les conditions où, il opère, il a un mélange de vitamine et de corps; inactifs naissant de l'irradiation. La vitamine pure est bientôt isolée, en même temps, par Windaus et Linsert, et par Bourdillon, à l'état cristallisé. Au premier produit, impur, on donne le nom de vitamine $\mathrm{D}_{1}$; le second est la vitamine $\mathrm{D}_{2}$ ou calciférol que l'on a proposé récemment d'appeler ergocalciférol.

L'irradiation de l'ergostérol donne successivement naissance à des corps plus ou moins désirables. On peut schématiser ainsi la série de ces corps :

Ergostérol, inactif.

Lumistérol, inactif.

Tachysterol, inactif, toxique.

Calciférol ou vitamine $D_{2}$, actif, non toxique aux doses thérapeutiques.

Suprastérol ou toxistérol, inactifs, toxiques.

Tous se trouvent dans les produits irradiés. Mais, seul parmi eux, le calciférol est intéressant pour la thérapeutique en raison de son activité et de son infime toxicité.

La découverte du calciférol, outre qu'elle permettait de disposer d'un médicament hautement antirachitique, eut pour autre conséquence de fournir un étalon univoque pour apprécier les effets physiologiques des produits renfermant de la vitamine D. Jusque là, en effet, l'accord était loin d'être fait sur une unité à adopter; on connaissait l'unité Lesné et Clément, l'unité Sed, l'unité Steenbock, l'unité Oslo, etc.

Une conférence internationale de 1931, puis une seconde en 1934, adoptent comme étalon une solution huileuse de calciférol dont un milligramme renferme 0,025 de ce corps. L'Unité Internationale représente l'activité physiologique de un milligramme de cette solution, soit de $0 \gamma 025$ (25 millionièmes de milligramme) de calciférol : c'est la dose qui, administrée quotidiennement 10 jours de suite au rat rachitique, rétablit la calcification du cartilage d'accroissement.

Cependant, on remarquera que tous ces travaux procèdent de l'expérience primitive ayant montré la haute valeur antirachitique de l'ergostérol irradié pour le rat blanc. Mais rien ne démontrait que, chimiquement, la vitamine $\mathrm{D}$, fut bien celle que contenait l'huile de foie de morue, celle que fabriquent les animaux soumis à l'insolation. En somme, la vitamine antirachitique naturelle n'était pas encore découverte. On se bornait à assimiler physiologiquement la vitamine $D_{2}$ au produit auquel 
les animaux devaient la calcification correcte de leur squelette.

Les recherches s'orientent alors différemment. Les unes ont pour but d'isoler la vitamine antirachitique de l'huile de foie de morue : elles n'ont qu'un intérêt purement scientifique; les autres visent à obtenir synthétiquement de la vitamine antirachitique, en partant non plus de l'ergostérol mais du cholestérol et à produire éventuellement cette vitamine sur le plan industriel.

Le cholestérol étant inactivable, Windaus, Lettre et Schenck, en 1935, partent de son dérivé, le 7-déhydro-cholestérol que, par irradiation, ils transforment en vitamine antirachitique.

Or, Brockmann montre, à la même époque, que cette dernière est identique à la vitamine extraite de l'huile de foie de morue. On est donc bien en présence de la vitamine $\mathrm{D}$ naturelle.

On a donné à cette dernière le nom de vitamine $D_{3}$ ou cholécalciférol.

La vitamine $\mathrm{D}$ que l'on trouve dans les foies de poissons proviendrait de l'irradiation des stérols du plancton que consomment les crustacés pélagiques, base de l'alimentation des poissons qui sont la proie des morues (Knut Wejdling).

La vitamine $\mathrm{D}$ existe en quantité moindre dans le lait d'été, le beurre d'été, le beurre de noix de coco, le jaune d'œuf, les champignons développés à la lúmière.

En Afrique, «l'huile de tinini» fabriquée par les pêcheurs du Niger serait très riche en vitamines $D$ et $A$.

Pratiquement la vitamine $D$ n'est fournie qu'en très faible quantité par l'alimentation.

Sa synthèse se fait par irradiation des stérols au niveau de la peau.

Les animaux qui sont soumis à l'action des radiations ultra-violettes solaires peuvent, par conséquent, fabriquer la vitamine $D$ dont ils ont besoin. Mais cette synthèse n'est pas toujours possible. Elle est nulle pour les sujets qui sont élevés à l'abri du soleil: porcheries industrielles, volailles en batteries, herbivores en stabulation permanente ou de longue curée. Elle est souvent insuffisante lorsque les animaux ne reçoivent qu'une lumière solaire filtrée par des nuages, des brouillards, des poussières; les rayons ultra-violets sont alors arrêtés en grande partie.

On peut mème se demander si, dans les pays fortement insolés, une transformation des stérols ne se produit pas, identique à celle que l'on réalise au laboratoire lorsqu'on soumet la provitamine à 1'irradiation; une trop forte insolation pourrait alors aboutir à des suprastérols inactifs.

Les animaux ne trouvant jamais dans leur alimentation suffisamment d'ergocalciférol, il est nécessaire, dans tous les cas où l'on n'est pas certain que la synthèse effectuée par la peau est suffisante, d'apporter la vitamine $D$ dans la nourriture.

L'huile de foie de morue a de sérieux inconvénients : son odeur, qui peut se transmettre à la chair et surtout à la graisse des sujets qui la consomment; sa teneur inconstante, et difficilement vérifiable, en vitamine $D$, qui n'est pratiquement titrable que par des essais biologiques longs et coûteux; sa fonction antivitaminique $E$ enfin, que nous étudierons plus loin et qui semble se situer dans les acide gras qui la composent.

La vitamine $D_{2}$ convient pour les mammifères. Mais son activité chez les oiseaux est de 30 à 100 fois inférieure à celle de la vitamine $D_{3}$. Même chez le porc, cette dernière semble avoir une meilleure action antirachitique' (Bonfante, Brion), tandis qu'elle a la même valeur que la $D_{2}$ pour les autres mammifères.

Il est à noter également que, comme la vitamine $A$, la vitamine $D$ se détruit plus ou moins rapidement par oxydation, d'où l'intérêt des préparations qui permettent d'empêcher, ou, tout au moins, de retarder cette destruction.

Les carences en vitamine $D$ sont évitées par les distributions journalières suivantes :

$\begin{array}{cc}\text { Bovidés ... } & 5.500, \text { U. I. } \\ \text { Veaux..... } & 4.000 \\ \text { Poulains ... } & 3.500-5.000 \\ \text { Chevreaux. } & 1.500 \\ \text { Agneaux .. } & 750 \\ \text { Porcelets .. } & 4.000 \\ \text { Poulets .... } & 400 \text { à } 900 \text { Unités A.O.A.C. (Vita- } \\ \text { mine } \mathrm{D}_{3} \text { ) } & \text { par kilo de nourriture. } \\ \text { Poules pondeuses. . } 1.000 \text { unités A.O.C.A. }\end{array}$

Les Unités A.O.A.C. sont établies par titrage sur poulets tandis que les Unités Internationales le sont sur rats.

\section{AVITAMINOSE E.}

La vitamine $\mathrm{E}$ est encore appelée improprement vitamine de reproduction, de fécondité ou de fertilité : ces noms lui ont été donnés en considération de l'une de ses actions sur les animaux de laboratoire.

La vitamine $E$ se trouve surtout dans l'huile de germes de blé.

Les recherches de Evans et Burr et de Evans et Emerson permirent de déterminer sa nature chimique qui a été confirmée par la synthèse (Karrer). Il s'agit d'un corps polycyclique à fonction phénol, le tocophérol, dont on connait 3 isomères, $\alpha, \beta$ et $\gamma$. L'estérification de la fonction phénol est utilisée industriellement pour le blocage de cette fonction : on se sert surtout, en thérapeutique, de l'acétate de (d. 1.) a-tocophérol. 
La vitamine $\mathrm{E}$ se rencontre dans nombre d'aliments d'origine végétale :

\begin{tabular}{|c|c|}
\hline & par $\mathrm{kg}$ \\
\hline do & 60 à $100 \mathrm{mg}$ \\
\hline ches & 71 à $355 \mathrm{mg}$ \\
\hline Farine et feuilles de luzerne.... & $383 \mathrm{mg}$ \\
\hline Foin de graminée.... & 7 à $14 \mathrm{mg}$ \\
\hline Foin de légumineuse & 60 à $90 \mathrm{mg}$ \\
\hline Mais en grains. & 15 à $36 \mathrm{mg}$ \\
\hline & 23 à $54 \mathrm{mg}$ \\
\hline
\end{tabular}

Les quantités ingérées varient avec la saison. Ainsi une vache qui consomme $45 \mathrm{~kg}$ d'herbe par jour prend de 2,7 ă $4,5 \mathrm{~g}$ de tocophérol, alors qu'en hiver, avec un régime sec, elle n'en aura que de faibles quantités à sa disposition.

$\mathrm{La}$ vitamine $\mathrm{E}$ a été trouvée dans tous les tissus mais en très faibles quantités (Evans et Burr, 1927). Cependant, les muscles, la graisse musculaire, le foie contiennent relativement plus de vitamine $E$ que les autres tissus et organes.

Underbjerg, en 1910, a montré que la vitamine $\mathrm{E}$ était présente dans les muscles et le tissu adipeux des chèvres recevant un régime normal, mais ne pouvait être décelée dans les mêmes tissus chez les chèvres soumises à un régime carencé.

Tous les auteurs sont d'accord pour admettre que la vitamine $\mathrm{E}$ traverse le placenta et que la teneur du serum du foetus est fonction du régime de la mère et du type de placentation; la transmission transplacentaire serait plus faible chez le porc que chez les ruminants.

Le lait et le colostrum contiennent d'autant plus de tocophérol que la ration en est plus riche. (Harris et coll.; Parrish; Whiting et coll.).

L'un des caractères chimiques essentiels du tocophérol est son rôle dans les oxydo-réductions. On sait, par exemple, que le rancissement des graisses alimentaires de la ration s'accompagne d'une destruction de la vitamine $E$ qu'elle contient: C'est pourquoi les graisses riches en acides gras polyéthyléniques et qui rancissent facilement peuvent être regardées, fonctionnellement tout au moins, comme des antivitamines $E$.

Par contre, le tocophérol s'oppose à l'oxydation de la vitamine $A$ : Ces deux vitamines ont donc une action synergique (Moore, Martin, Rajogopal).

La vitamine $E$ favorise la mise en réser ve dans le foie de l'axérophtol (Moore) tandis que l'avitaminose $A$ accélère l'epuisement du stock de vitamine $E$ (Mason). Ceci est extrêmement important pour l'explication de certains faits pathologiques que nous aurons à étudier plus loin.

Il est probable que la vitamine $\mathrm{E}$, comme d'autres, entre dans la composition d'un ou plusieurs enzymes. L'effet de sa carence sur le muscle et sur le cerveau pourrait en être une preuve. Son intervention est supposée dans les processus d'oxydation dont le muscle est le siège (Houchin), dans le métabolisme de la créatine (Verzar).

\section{Carence en vitamine $\mathrm{E}$}

Les carences peuvent être directes ou conditionnées. Nous les classerons selon leurs aspects cliniques.

\section{Troubles de la reproduction.}

10 Mâles. - La carence en vitamine E entraîne chez le rat, d'abord une perte de mobilité des spermatozoïdes, puis l'azoospermie, la perte de l'instinct sexuel avec, comme substratum anatomique, une dégénérescence irréversible de l'épithélium germinatif et l'atrophie testiculaire (Matill et Conklin، Evans et Bishop).

Des faits semblables ont été observés chez le cobaye et le lapin. Mais le taureau, le bélier, le bouc, le verrat ne paraissent pas sensibles à la carence en vitamine $E$ (Hanson et Hathaway). Adamstone n'a trouvé aucune lésion testiculaire chez le coq carencé, et Titus et Burrows observent que l'huile de germes de blé n'a pas d'action positive sur la production du sperme.

Seul Lagerlöf prétend avoir constąté des lésions testiculaires chez le taureau, ce qui va à l'encontre des observations de Gullickson faites dans des conditions identiques.

En somme, on peut conclure que les mâles des espèces domestiques ne sont pas sensibles à l'absence de vitamine $E$ dans leur ration en ce qui concerne leur vie génitale.

$2^{\circ}$ Femelles, - Chez la rate gravide, la carence en vitamine $E$ empêche le développement de l'embryon et des annexes. L'œstrus, la fécondation, la nidation ne sont pas influencés.

Une importante expérimentation de Krider et James faite sur la truie montre que sa fécondité est diminuée par une forte mortalité embryonnaire: que les porcelets qui viennent à terme meurent rapidement ou grandissent mal; que les survivants sont fréquemment atteints a'incoordination des mouvements et de paraplégie.

Des constatations identiques sont faites chez les brebis et leurs agneaux par Loosli.

Gullickson s'est livré à une expérience semblable sur 3 générations successives de vaches, toutes précautions étant prises pour s'assurer que les rations ne contiennent pas de vitamine $E$ et qu'il n'y en a pas de formée dans l'appareil digestif par les micro-organismes. Aucune modification de la reproduction ne s'ensuit. cestrus, gestation, délivrance, lactation sont normaux. Mais sur les 28 sujets, 
13 sont morts entre 21 mois et 5 ans avec des myocardites et, sur certains, des hémorragies du cerveau, de l'intestin, du cœur, du pancréas.

Underbjerg et coll. trouvent les mêmes résultats chez la chèvre.

Ceci est à rapprocher des constatations faites par de nombreux auteurs (Kaay et coll., Sherrer, Ferrando) et selon lesquelles le taux de tocophérol sanguin, qui varie avec l'alimentation, est indépendant du cycle génital et demeure normal chez des vaches stériles par hypercestrus ou ancestrus. Toutefois, il faut reconnaître qu'il est des observations où l'administration de vitamine $\mathrm{E}$ a amélioré l'état de vaches stériles (Tuut, Andersen, Schweitzer, etc.).

Chez la brebis, la carence en vitamine $E$ ne modifie pas la reproduction.

Chez les volailles, si la ponte n'est pas affectée, le taux d'éclosion des œufs est diminué (Barnum, Card, Mitchell et Hamilton, Adamsone, etc.).

En résumé, à quelques exceptions près, il semble qu'il n'y ait pas d'influence marquée de l'avitaminose $E$ sur les femelles reproductrices mais que la carence soit susceptible de déterminer une mortalité importante des embryons et des nouveau-nés.

\section{Dystrophie musculaire nutritionnelle.}

Depuis la fin du XIXe siècle, on avait remarqué, dans les abattoirs, des carcasses dont les muscles étaient d'une coloration blanchâtre et on désignait cette lésion des noms de : muscle blanc, viande de poisson, viande de poulet, viande blanche. Histologiquement il s'agit de dégénérescence cireuse et des lésions semblables se voient également sur e myocarde.

Or, on connait depuis longtemps la « maladie du raide » des agneaux, dont Moussu avait fait la " paraplégie enzootique ». Cependant, elle n'est nullement contagieuse (Barrat); elle survient, en certaines années, lorsque la récolte du foin s'est faite dans de mauvaises conditions. Ce qui importe surtout, dans son étiologie, c'est l'hygiène des brebis gestantes, entretenues en stabulation durant l'hiver et mettant bas à cette période, tandis qu'elles ne sont nourries que de mauvais fourrages et qu'elles donnent peu de lait (Barret, Metzger et Hagan). La maladie est très rare entre mai et novembre.

L'agneau ne présente pas de fièvre : il se lève et marche de plus en plus difficilement. Les membres postérieurs deviennent le siège d'une paralysie spastique qui gagne ensuite les antérieurs. Incapable de se déplacer, le malade ne peut plus téter et il meurt.

Lorsqu'on sacrifie précocement des sujets du même troupeau, on voit que des lésions musculaires s'établissent avant qu'il y ait des signes cliniques : tuméfaction éosinophile des fibres, qui sont rompues. Plus tard se préciseront les lésions de dégénérescence tandis qu'évolue une néoformation fibroblastique dans le tissu interstitiel.

Les recherches faites, aux U.S.A. surtout, ont démontré que cette maladie était en étroite relation avec l'alimentation des brebis. La ressemblance avec les lésions obtenues chez les espèces de laboratoire en avitaminose $\mathrm{E}$ ont permis d'orienter en ce sens les idées sur l'étiologie, après que l'on eût supposé des carences en vitamines $B$ et $\dot{C}$. Willman et coll. ont apporté les premieres précisions en obtenant des résultats, prophylactiques ou curatifs, par l'emploi de l'acétate de (d.l.) $\alpha$-tocophérol; Marsh a utilisé l'huile de germes de blé avec le même succès. Depuis, de tels résultats ont été régulièrement confirmés.

Chez le veau, la maladie identique existe aussi. On l'appelait autrefois rhumatisme. Elle a donné lieu à de nombreuses relations. On l'observe surtout dans les élevages où l'hygiène de l'habitation et de l'alimentation est défectueuse. En France, elle est fréquente dans les régions de montagno où la stabulation hivernale est longue et où l'alimentation est à base de foin et de paille. On l'a vue sur des veaux à la mamelle âgés de 10 jours à 2 mois et sur des sujets plus âgés sevrés. Les lésions musculaires entraînent la difficulté de la marche et du relever. Mais ce sont les lésions de myocardite qui sont les plus graves. Elles ressemblent absolument à celles que Gullickson avait obtenues par l'avitaminose E experimentale et dont il pouvait suivre les effets par l'électrocardiographie.

Dans cette maladie, nous avons, en France, obtenu d'heureux effets prophylactiques par l'emploi de l'huile de germes de blé et de tocophérol.

Une maladie des muscles blancs est connue également chez le porcelet. Karsten en a donné la description sous le nom de "syncope mortelle" et, au début, l'attention fut, en effet, attirée par les lésions du myocarde. Mais Hupka, puis Cohrs ont montré qu'il y avait également des lésions musculaires et suggérèrent que la syncope mortelle était une forme de la dystrophie musculaire enzootique.

Symptômes et lésions sont très semblables à ceux de la maladie observée dans les carences en vitamine $B_{1}$ et certains auteurs pensent que cette dernière maladie serait en réalité une carence conditionnée en vitamine $\mathrm{E}$. Dans les expériences qui ont servi à prouver qu'une carence en aneurine était la cause de la maladie, la source de graisse était du saindoux (Etten et coll.) ou de l'huile de foie de morue (Wintrobe), produits riches en acides gras non saturés.

Chez le poulain, enfin. Jones et Reed attribuent à une avitaminose $\mathrm{E}$ une dystrophie musculaire ayant 
frappé un jeune foal pur-sang dont la mère recevait une diète très carencée.

Le chevreau ne paraît pas sensible.

\section{Encéphalomalacie de nutrition des poussins.}

Cette très grave maladie apparaît chez les poussins âgés de 3-4 semaines. Ils sont ataxiques, ont une démarche chancelante; la tôto cst rćtractée vers le corps. On observe des contractions cloniques de divers muscles et surtout des tremblements de la tête et des membres.

La maladie se termine souvent par la mort.

Histologiquement, on remarque des lésions nerveuses telles que de l'cedèrne el de la dégénérescence des cellules de Purkinje, de fines hémorragies cérébrales ef cérébelleuses, des thromboses capillaires et de la nécrose.

L'étiologie de cette maladie ne parait pas univoque.

Les expériences de Pappenheimer et Goetsch, celles de Dam montrent que l'avitaminose E est capable d'en reproduire exactement les symptômes. Mais il est fort possible qu'il s'agisse non d'une carence d'apport mais d'une carence conditionnée par l'existence dans la ration de graisses qui rancissent. Les rations dangereuses, en effet, contiennent souvent des tourteaux insuffisamment déshuilés, des farines de viande et de poissons.

Les bons réșultats, préventifs et thérapeutiques, apportés par l'administration de verdure et de tocophérol sont en faveur de l'avitaminose E.

\section{Diathèse exsudative.}

La diathèse exsudative nutritionnelle de Dam et Glavind (1938) a été imputée à une avitaminose E. Cette maladie, qui atteint les poussins, est caractérisée par l'existence d'un œdème sous-cutané abondant qui s'accumule dans les parties déclives et oblige, dans certains cas, les animaux à rester les pattes écartées. L'œedème s'accompagne d'hémorragies dans le tissu adipeux. Il est exceptionnel d'observer des exsudats péritonéaux. Dam et Glavind ont trouvé que l'apparition de l'œdème coïncidait avec celle de peroxydes dans les tissus. L'administration d'a-tocophérol fait régresser les symptômes.

L'étiologie et la pathogénie de cette affection ne sont pas encore complètement élucidées.

\section{Relations entre avitaminoses $\mathrm{A}$ et $\mathrm{E}$.}

Ferrando a très bien fait remarquer que les expériences et observations faites sur l'avitaminose $\mathrm{E}$ n'ont peut-être pas toujours tenu compte des étroites relations entre les effets des vitamines $A$ et $E$, non plus que de leur présence concomitante dans les huiles utilisées en thérapeutique.
Nous avons exposé plus haut comment le tocophérol agissait comme protecteur de la vitamine $\mathbb{A}$ contre l'oxydation. On sait, d'autre part, et nous l'avons rappelé, que la vitamine $A$, en protégeant les épithéliums, joue un rôle important dans les phénomènes de reproduction. On sait, en particulier, que sa carence entraîne des lésions qui, chez le mâle, aboutissent à l'atrophie testiculaire et à la stérilité.

Au cours de l'inanition, les lésions des testicules sont insensibles à l'action de la vitamine $E_{\text {; }}$ par contre, elles sont améliorées par l'administration de vitamine $A$ et, plus encore, par celle des deux vitamines à la fois. De telles constatations doivent inciter à reprendre, chez les animaux domestiques, l'expérimentation, toujours dans le même sens, mais sur des bases nouvelles. Elle lèverait peut-être l'incertitude qui continue à peser sur tous les faits que l'on attribue à l'avitaminose $\mathrm{E}$.

\section{AVITAMINOSE $\mathrm{K}$.}

La vitamine $K$, vitamine de coagulation du sang, existe naturellement sous deux formes, $K_{1}$ et $K_{\mathrm{z}}$, qui, toutes deux, sont des dérivés de la 2-méthyl1,4-naphtoquinone. La première se trouve principalement dans les feuilles vertes; la seconde est synthétisée par diverses bactéries que l'on rencontre dans le tube digestif des animaux. L'industrie prépare une vitamine de synthèse, ou vitamine $K_{3}$, encore appelée ménadione, qui, légèrement différente des précédentes (un groupe méthyle remplace un groupe phytyle), a les memes propriétés.

La vitamine $K_{1}$ se trouve abondamment dans les feuilles de luzerne, dans celles d'épinard, d'ortie, de chou, dans les tomates, dans l'orge et l'avoine germées, etc. Elle est rare dans l'cuuf. Mais il semble que l'apport le plus important est fourni, en vitamine $K_{2}$, par les bactéries gastro-intestinales.

On sait que la coagulation du sang se passe en deux phases :

$1^{\circ}$ formation de la thrombine à partir de la prothrombine par action de la thromboplastine libérée des tissus endommagés et des plaquettes sanguines désintégrées, en présence d'ions $\mathrm{Ca}++$;

$2^{\circ}$ transformation du fibrinogène en fibrine par action de la thrombine.

La carence en vitamine $K$ empêche la fabrication de la prothrombine; par conséquent, elle est génératrice d'hémorragies: Celles-ci s'observent surtout lors de lésions hépatiques, le foie étant l'organe où s'opère la synthèse de la prothrombine.

Parmi les animaux domestiques, ce sont, de loin, les volailles qui sont les plus sensibles à l'avitaminose $\mathrm{K}$. Mais, dans les conditions ordinaires de l'élevage, celle-ci ne se constate pas parce que la synthèse bactérienne est toujours suffisante. 
Par contre, elle devient déficiente dans deux cas :

10 lorsque la flore intestinale est modifiée, soit par des affections microbiennes, soit par des traitements à base de sulfamides et de substances antibiotiques :

$2^{\circ}$ par action d'antivitamine $\mathrm{K}$.

Les affections qui en résultent seront envisagées plus loin, à propos des antivitamines.

\section{ROLE PATHOGÈNE DES ANTIVTTAMINES}

La notion d'antivitamine est encore toute récente puisqu'elle apparait pour la première fois dans les travaux de Fildes et Woods en 1940, et cependant, elle est déjà extrêmement féconde puisqu'elle explique le mode d'action des agents bactériostatiques, a doté la thérapeutique de médicaments nouveaux et expliqué certains faits pathologiques. C'est ce dernier point qui nous intéresse seul ici.

Une antivitamine est une substance normalement présente dans l'alimentation ou se formant dans l'organisme, qui neutralise l'action de la vitamine corrcspondante. Il s'ensuit une carence vitaminique susceptible de s'extérioriser cliniquement. Ainsi ont pu être rapportés à leur véritable cause quelques maladies ou syndromes observés chez les animaux.

\section{Maladie du mélilot gâté et antivitamine $\mathrm{K}$}

Roderick, puis Roderick et Schalk ont décrit, entre 1926 et 1930, une maladie hémorragique des bovidés. $\mathrm{Ce}$ sont les jeunes surtout qui sont atteints; ils présentent des hémorragies spontanées ou bien saignent abondamment à la moindre plaie ou excoriation. Il s'agit en somme d'un syndrome clinique d'hémophilie. Ces auteurs avaient remarqué que les malades avaient été alimentés avec du mélilot (Melilotus alba ou officinalis) mal conservé et gâté, et que les premiers symptômes apparaissent une quinzaine de jours après le début de l'alimentation avec ces fourrages. La guérison pouvait être obtenue par l'administration de luzerne fraîche.

Le sang des malades est pauvre en prothrombine. $\mathrm{Ce}$ fait devait suggérer l'hypothèse d'une avitaminose K. Campbel, Link et leurs collaborateurs isolèrent d'abord du mélilot gâté une substance qui, chez le lapin, reproduit les mêmes effets que le végétal, à une dose 35.000 fois moindre. Stahman, Huebner en déterminent la nature chimique : il s'agit d'un dérivé de la coumarine, le dicoumarol, qui se forme dans le végétal à partir de la coumarine sous l'influence des altérations microbiennes ou mycosiques. $2 \mathrm{mg}$ de dicoumarol, administrés per os au lapin, provoquent en 48 heures une hypothrombinémie de l'ordre de $50 \%$; celle-ci s'accentue encore les jours suivants, demeure stationnaire au bout du $6^{e}$ ou $7^{e}$ jour, puis le taux de la thrombine remonte à la normale. On évite cet accident si, en même temps que le dicoumarol, on donne de très fortes doses de vitamine $\mathrm{K}$. La luzerne qui guérissait les animaux malades dans les observations cliniques agissait par la vitamine $\mathrm{K}$ qu'elle contient. Le mécanisme d'action du dicoumarol a été étudié par Quick : ce corps inhibe le processus enzymatique qui produit la prothrombine. On peut remarquer que la formule du dicoumarol est voisine de celle de la vitamine $\mathrm{K}$ : elle en constitue approximativement le double. Mentzer a pu écrire que, pour passer de la vitamine à l'antivitamine, il suffit de doubler la formule, ou de remplacer un méthyle par un chlore.

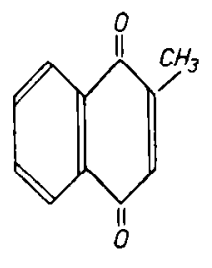

Vitamine $K$

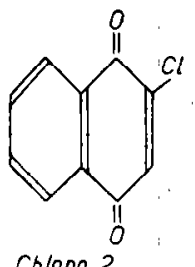

Chloro 2

Naphtoquinone 1,4<smiles>O=C1CC(CC2CC3CCC2(O)c2ccccc23)c2ccccc21</smiles>

$$
\begin{gathered}
\text { Dicoumaral } \\
\text { Antivitamine } k
\end{gathered}
$$

\section{Maladie hémorragique du poussin}

Cette maladie provoque actuellement des ravages en Amérique : elle est caractérisée par des hémorragies multiples au sein des muscles de la poitrine, des cuisses et aux pattes. Les volailles deviennent anémiques et, quand les hémorragies sont massives, les sujets meurent subitement. Cette affection prend volontiers l'allure d'une épizootie; cependant on remarque que ce sont les plus beaux animaux qui succombent le plus volontiers ou qui sont frappés d'anémie. Comme l'alimentation contient suffisamment de vitamine $K$, comme, d'autre part, l'administration de ménadione ou vitamine $K$ de synthèse donne des résultats thérapeutiques certains, on suspecte l'action d'une antivitamine K. Celle-ci se formerait dans l'intestin, aux lieu et place de la vitamine $\mathrm{K}$, sous l'influence de la désorganisation de la synthèse microbienne de la vitamine $K$.

On peut suspecter un même processus pour divers états hémophiliques ou hémorragiques, 
comme les sueurs de sang des bovidés, les hématuries, les diarrhées sanglantes purpuriques. Mais ici, rien n'est encore démontré!

\section{Antivitamines B. - Paralysie de Chastek}

Dans les élevages de renard d'Amérique, on connaît, depuis une vingtaine d'années, une paralysie dite "paralysie de Chastek ». Les animaux sont anorexiques, puis ataxiques; une paraplégie s'installe, avec des épisodes de crises nerveuses. La mort survient en 3 jours, dans sa forme aiguë, ou dans un délai plus long; les femelles pleines avortent. A l'autopsie, on voit de la dégénérescence du foie et des lésions vasculaires des centres gris nerveux. Ces dernières ressemblent à celles de la päralysie de Wernicke de l'homme.

Dans tous les élevages atteints, les animaux reçoivent dans leur ration plus de $10 \%$ de poisson cru. Ceux qui sont coprophages échappent à la maladie, même en consommant la ration nocive aux autres.

Green, Carlson et Evans ont vu que ce sont les viscères et non les muscles des poissons qui sont responsables de la maladie; de nombreuses espèces de poissons, tant d'eau douce que de mer, possèdent cette propriélé : carpe, bruchet, merlan, hareng, maquereau... Certains mollusques et même le caviar peuvent aussi être incriminés.

L'administration de chlorhydrate d'aneurine inhibant la nocivité du poisson, on en vint aussitôt à penser à l'existence, d'une antivitamine $B_{1}$ ou thiaminase.

Il s'agit d'un enzyme, découvert et préparé par Woolley d'une part, par Spitzer et ses collaborateurs d'autre part. La thiaminase scinde la molécule de thiamine en ses deux portions; elle se compose de deux parties, l'une thermolabile et non dialysable, I'autre thermostable et dialysable. Elle est détruite par une chaleur de $100^{\circ} \mathrm{C}$ pendant 15 minutes. Cette thiaminase ne se retrouve pas dans les farines de poissons bien préparées.<smiles></smiles>

Scission de la molecule de thramine par la thiaminase.

\section{Intoxication par les fougères et prêles}

Le rôle d'une antivitaminc $B_{1}$ semble aussi démontré dans une affection décrite chez les bovidés et les chevaux ayant consommé de la fougère aigle (Pteris aquilina) ou des prêles (Equisetum arvense et palustre). On lui a donné le nom de «brackenfernpoisoning ». Il s'agit d'un syndrome dans lequel on retrouve des symptônes d'avitaminose $B_{1}$ expérimentale : hypersensibilité, hyperexcitabilité, hyperréflectivité, anxiété, ataxie, convulsions, paralysies. On a décrit aussi de la constipation, de l'insuffisance hépatique, des lésions du fond de l'cil. Les examens histologiques montrent des lésions de polynévrite. Forenbacher dit que les premiers symptômes apparaissent au bout de 20 à 30 jours après le début de l'alimentation nocive; en Croatie et Slovénie, on a remarqué que la maladie survient quand le foin que l'on distribue aux chevaux contient 5 à $10 \%$ de prêles. Les plantes vertes ne semblent pas avoir une telle nocivité, et les accidents ne se voient qu'en hiver et au printemps, dans les années de disette où les animaux n'ont qu'un mauvais foin à leur disposition. Ce syndrome guérit avec l'administration de 250-500 mg d'aneurine pendant 3 ou 4 jours.

Weswing, Freed et Haag ont montré que le principe actif est une thiaminase différente de celle de la paralysie de Chastek, car elle est thermostable; elle résiste au chauffage à $105^{\circ} \mathrm{C}$, elle est légèrement soluble dans l'alcool à $92^{\circ}$, insoluble dans l'éther et l'acétone. Elle n'existe pas dans les fourrages qui ont été séchés au soleil.

\section{Huiles de foie de poisson et antivitamines $\mathrm{E}$}

Les faits rapportés ici ne sont pas encore expliqués de façon certaine. Ils peuvent cependant avoir une importance économique appréciable. Dans certaines espèces animales, il y a des corps gras, et notamment les huiles de foie de poisson, qui semblent se comporter comme des antivitamines $\mathrm{E}$ et provoquent des troubles physiologiques et parfois des lésions.

Déjà Simonnet, en 1925, signalait que des rats ayant un régime riche en graisse, pauvre en vitamine $\mathrm{E}$ et recevant de l'huile de foie de morue avaient une croissance retardée.

Meunier, Mlle Vinet et Jouanneteau observent l'arrêt de la croissance de lapins qui reçoivent $5 \%$ de leur ration d'huile de foie de merlu; cette croissance reprend si l'on administre un excès de tocophérol. Des faits semblables sont rapportés sur le bélier par Meunier, Ferrando et Mlle Chenavier, sur le lapin par Chevrel et Cormier, avec des huiles de poissons divers.

Sous l'influence de ces mêmes huiles, à la condition de les donner pendant un temps suffisamment prolongé, on arrive à provoquer des lésions des 
organes génitaux chez le rat (Evans) et le lapin (Chevrel et Cormier). Les lapins mâles, à 7 mois, ont des testicules impubères et, si l'administration de l'huile est continuée, des lésions de dégénérescence apparaissent sur les divers éléments des tubes séminifères.

Goettsch et Pappenheimer observent une dystrophie musculaire sur des animaux de laboratoire ayant un régime insuffisant en vitamine $E$ et recevant de l'huile de foie de morue comme source de vitamine A. L'administration de tocophérol supprime ou retarde l'apparition de ces lésions qui sont, d'ailleurs, d'autant plus marquées que le régime renferme plus de graisses à acides gras insaturés.

Madsen confirme ces faits et montre qu'en l'absence de vitamine $E$, le saindoux et les huiles de foie de poisson sont les plus nocives parmi les graisses alimentaires. Ils se retrouvent chez le lapin, le cobaye, la chère et le mouton.

Golding et ses collaborateurs s'aperçoivent que des vaches recevant $50 \mathrm{~g}$ d'huile de foie de morue par jour donnent un lait dont le taux butyreux est diminué de $30 \%$. Ceci est confirmé par Meunier, Ferrando et Mlle Chenavier.

Dans les expériences de Cormier sur le lapin. l'administration d'un excès d'huile de foje de morue provoque une diminution de la réserve hépatique de vitamine $A$, laquelle est moins élevée que chez les sujets recevant une dose suffisante de vitamine $A$ et, comme graisse, de l'huile d'arachide.

Meunier et ses collaborateurs ont montré que les divers phénomènes observés, ralentissement de croissance, diminution du taux butyreux du lait, dystrophies musculaires, s'accompagnaient d'une chute du taux du tocophérol sanguin.

D'autre part, l'administration d'un excès de tocophérol empêche les accidents de survenir ou bien rétablit une situation normale.

Depuis Madsen, tous les auteurs ont eu l'attention attirée par le fait que les graisses qui provoquent le plus facilement ces chutes de tocophérol et les phénomènes concomitants sont celles qui renferment des acides gras non saturés en grande quantité. C'est le cas pour les huiles d'animaux marins, dont les acides gras comportent souvent quatre à cinq doubles liaisons éthyléniques, et pour le saindoux. Il est possible également que la vitamine $A$ soit antagoniste de la vitamine $E$, comme le montrent des expériences de Chevrel et Cormier effectuées avec de l'axérophtol de distillation moléculaire. Jacquot ct Hirsch ont provoqué, chez lc rat, des dystrophies musculaires paralysantes et des lésions testiculaires avec du linoléate de méthyle et de l'huile de tournesol.

Il existe donc des aliments, et également certains corps chimiques, comme le phosphate de tri-o- crésyle, qui se comportent comme des antagonistes de la vitamine $E$. Mais toutes les espèces n'y sont pas également sensibles. Nous avons vu, par exemple, avec Ferrando, que, chez le porc, un excès d'huile de foie de morue ne diminue pas le tocophérol sanguin.

Faut-il parler d'action antivitaminique? On ne peut répondre à la question tant que l'on n'aura pas véritablement isolé la substance ou les substances présentes dans certaines graisses et inactivant la vitamine $\mathrm{E}$.

Bien que le problème ne soit pas encore résolu, il faut cependant conclure que, chez les ruminants au moins, les huiles de poisson ne doivent être utilisées que sous le plus faible volume possible, ce qui conduit à éliminer celles qui sont peu riches en vitamines $A$ et $D$.

\section{CONCLUSIONS}

Si on dresse un tableau des symptômes observés dans les différentes carences, on est frappé d'abord par leur diversité, puis par le fait que certaines fonctions sont troublées quel que soit l'élément absent de la ration: ainsi la croissance est arrêtée. la fécondité et la productivité sont diminuées dans presque toutes les carences.

Tout se passe comme si l'organisme qui ne reçoit pas tous les éléments qui lui sont nécessaires, en quantité et qualité, réduisait progressivement son activité aux fonctions indispensables au maintien de son existence et mettait en sommeil les activités de luxe, reproduction, alimentation des jeunes.

Dans ces états, l'interssité des symplônes dépend en premier lieu de la condition de l'animal au début de la carence. En effet, dans tous les cas où le métabolisme est augmenté, les besoins en éléments indispensables et, par là, la rapidité d'apparition et l'intensité des troubles organiques sont accrus.

Nous avons dû, pour la clarté et la commodité de notre exposé, employer la méthode analytique. Or dans les conditions naturelles d'alimentation, surtout en élevage extensif, on a rarement affaire à des carences totales uniques mais plus généralement à des subcarences polyvalentes; l'interaction des modifications du métabolisme sous l'effet de chacune des carences en jeu détermine l'apparition de tableaux cliniques à partir desquels le diagnostic étiologique est très malaisé.

Ces types de carences n'amènent pas directement la mort, mais une baisse de l'état général, un ralentissement de la croissance, une diminution de la productivité. Comme généralement on ne possède pas de termes de comparaison, l'évaluation des troubles est délicate. Les conséquences immédiates sont plus un manque à gagner qu'une perte sèche. 
Cependant, les animaux subcarencés se trouvent dans un état métastable et sont à la merci de la moindre infection, car leurs réserves sont faibles, sinon inexistantes, et leurs défenses naturelles amoindries.

Les facteurs climatiques des zones tropicales, qui imposent un supplément de travail aux organismes obligés de lutter contre la chaleur et l'humidité, augmentent les besoins des animaux en éléments essentiels, et comme, par leur action sur le sol et la végétation, ils diminuent le disponible en ces éléments, il ne sera pas surprenant d'observer des polycarences.

La faible teneur en protéines des fourrages, leur faible digestibilité, associées à des subcarences minérales sont à l'origine des déséquilibres observés à la fin de la saison sèche, auxquels on peut imputer la gravité des épizooties d'origine microbienne et parasitaire et d'affections banales qui seraient sans conséquences graves si elles agissaient sur des animaux non carencés : entérite, pneumonies.

La constatation des çarences ne serait qu'une satisfaction scientifique sans intérêt si elle ne s'accompagnait de recommandations pratiques propres à les éviter.

Le vieil adage «primum non nocere » est encore plus valable dans la prophylaxie des carences que dans toutes les autres maladies. Il faut éviter de vouloir tout changer aux conditions locales d'élevage qui, depuis un millénaire, ont déterminé un équilibre, qui vaut ce qu'il vaut mais qui existe, entre le sol, le milieu et l'animal élevé par l'homme. On risqueraiț, par rupture de cet équilibre, de déterminer des accidents plus graves que les carences elles-mêmes.

Ainsi la transhumance a été regardée par certains comme nuisible, par d'autres comme peu recommandable. Or, elle permet d'utiliser suivant l'époque de l'année des pâturages sahéliens, des pâturages de décrue, très variés, autant dans leur composition botanique que chimique. Cette 'variété a le mérite de pallier, dans une certaine mesure, les carences qui se manifesteraient certainement si les troupeaux étaient maintenus en permanence sur les mêmes pâturages.

Dans de nombreuses régions, les carences minérales sont évitées par une cure sur des terres salées riches en chlorures et sulfates alcalins et alcalinoterreux.

La transhumance, laissant les pâturages inoccupés pendant de grandes périodes de l'année, s'oppose aux réinfestations parasitaires. De plus, la variété du régime peut, par les modifications du milieu intestinal qu'elle détermine, inhiber la pullulation d'une faune parasitaire qui s'accomode plus volontiers d'une constance de ce milieu.

L'expérience a malheureusement confirmé ces constatations : chaque fois qu'on a voulu maintenir en permanence des moutons ou des chèvres toute l'annéé sur les mêmes pâturages, on a observé une baisse générale de l'état des troupeaux s'accompagnant d'affections parasitaires ou infectieuses graves : strongylose, œsophagostomose, pleuropneumonie.

Dans l'état actuel de nos possibilités, c'est dans l'organisation de la transhumance qu'il faut chercher la solution du probleme des carences en elevage extensif.

Cette organisation peut se faire assez facilement par l'intermédiaire de l'hydraulique pastorale qui, permettant d'ouvrir à l'élevage des zones inutilisées faute de points d'eau, assurera une plus grande abondance et une variété des régimes. Le contrôle des points d'eau permettra d'éviter la surcharge des pâturages et, par là, l'érosion des sols, cause première des carences en éléments solubles chez les plantes, en protéines et éléments solubles chez les animaux. 